\title{
Informational Contagion in the Laboratory
}

\author{
Marco Cipriani, Antonio Guarino, Giovanni Guazzarotti, Federico \\ Tagliati and Sven Fischer ${ }^{1}$
}

October 2016

\begin{abstract}
We study the informational channel of financial contagion in the laboratory. In our experiment, two markets with privately informed subjects open sequentially. Subjects in the second market observe the history of trades and prices in the first market. Although in both markets private information is imperfectly aggregated, subjects in the second market make correct inferences from the information coming from the first market. As theory predicts, when fundamentals are correlated, contagion occurs in the laboratory; in contrast, with independent fundamentals, there is no contagion effect. In both cases, the correlation between asset prices is very close to the theoretical one.

\footnotetext{
${ }^{1}$ Cipriani: Federal Reserve Bank of New York (e-mail: marco.cipriani@ny.frb.org); Guarino: Department of Economics, University College London (e-mail: a.guarino@ucl.ac.uk); Guazzarotti: Bank of Italy (email: giovanni.guazzarotti@bancaditalia.it); Tagliati: Department of Economics, University College London (e-mail: federico.tagliati.10@ucl.ac.uk); Fischer: Max Planck Institute for Research on Collective Goods (e-mail: fischer@coll.mpg.de). We are grateful to participants in seminars in several institutions and to a co-editor and a referee for invaluable comments and suggestions. We thank Teresa Steininger for outstanding research assistance. Guarino gratefully acknowledges the financial support of the ERC, the ESRC and the INET. We are responsible for any error. The views expressed in this paper are solely those of the authors and do not necessarily represent those of the Federal Reserve Bank of New York or of the Federal Reserve System, or of the Bank of Italy.
} 


\section{Introduction}

Comovements among asset prices, whether across countries or across asset classes, are often higher than what can be explained by comovements among asset fundamentals. This empirical regularity, usually referred to as financial contagion, has been widely documented in the empirical finance and international finance literatures. ${ }^{1}$ Indeed, almost all the recent episodes of financial turmoil, from the Asian financial crisis of 1997 to the events of 2007-2008, suggest that financial asset prices are very highly correlated, in excess of what can be expected by looking at fundamentals, and that financial instability can quickly spread from one country to another, or from one asset class to another.

The theoretical asset pricing literature has highlighted several mechanisms that generate contagion in financial markets. In Calvo (2004), contagion arises from correlation in liquidity shocks: agents, hit by a liquidity shock in one market, liquidate their position across markets in order to meet a margin call (see also Yuan, 2005). In Kyle and Xiong (2001), financial contagion is due to wealth effects. In Fostel and Geanakoplos (2008), financial contagion arises as a result of the interplay between market incompleteness, agents' heterogeneity, and margin requirements. In Kodres and Pritsker (2002), contagion happens through cross-market rebalancing, when traders hit by a shock in one market rebalance their portfolios. In Pavlova and Rigobon (2007), contagion arises from wealth transfers and portfolio constraints. ${ }^{2}$

\footnotetext{
${ }^{1}$ See, among the many papers on the topic, Eichengreen et al. (1996), Edwards and Rigobon (2002), and Ehrmann et al. (2011).

${ }^{2}$ While the studies just mentioned explain contagion across markets, others have focused on contagion across financial institutions (see, e.g., the seminal contribution of Allen and Gale, 2000). Cipriani et al. (2013) present an experimental test of the cross-market rebalancing channel; Trevino
} 
In their seminal paper, King and Wadhwani (1990) argued that financial contagion can be explained by informational spillovers across markets. Price changes in a market may be due to news about an idiosyncratic shock or about a systematic shock affecting many markets at the same time. Traders in other markets attach some probability to the event that the price movement is due to a systematic shock, and, therefore, adjust their position in their own market even when, in fact, the shock is idiosyncratic. Because of this informational spillover, the correlation among asset prices is higher than that among fundamentals. The role of information spillovers in generating financial contagion is also illustrated by Cipriani and Guarino (2008) in a sequential trading model: they show that because of informational spillovers, herd behavior and informational cascades transmit from one market to another.

The information channel is one of the most prominent channels of financial contagion identified by the theoretical literature (see, e.g., the surveys by Pericoli and Sbracia, 2003; Allen and Gale, 2008; Knyazeva et al., 2012). It has an intuitive appeal because it relies on a simple informational structure; namely, that asset prices are affected by both idiosyncratic and systematic shocks.

Nevertheless, the empirical evidence in support of this mechanism is only circumstantial. King and Wadhwani (1990) showed that volatility increases in the London Stock Exchange when Wall Street opens; moreover, they showed that cross-sectional asset price correlation increases during a crisis. Other papers have looked at correlation coefficients in crises versus tranquil times with similar results. ${ }^{3}$ As the authors (2016) presents a coordination game of contagion among creditors solved through global games tecniques and tests the model in the laboratory.

${ }^{3}$ The interpretation of an increase in correlation coefficient as contagion has been criticized by Boyer et al. (1999) and Forbes and Rigobon (2001, 2002). Their criticism, however, has been 
themselves acknowledge, however, this evidence is indirect, and contagion could stem from different mechanisms. The reason for the lack of strong empirical support is that a direct test of the theory would require data on traders' information, which is of course difficult to obtain. More broadly, it is hard to understand whether there is excess correlation with respect to the fundamentals since it is hard to control for fundamentals.

The empirical relevance of the information channel can be questioned for two opposite reasons. On the one hand, the theoretical mechanism proposed by King and Wadhwani (1990) assumes that agents learn in a Bayesian fashion; whether human beings are actually Bayesian, however, is at the centre of a large debate both in experimental economics and psychology. To cite but one finding of this vast literature, a number of experimental papers suggest that people put more weight on their private information than on the public one (see, e.g., Ziegelmeier et al., 2013). If traders do not make inference from the other market in a Bayesian way, they could simply not react (or at least underreact) to the information coming from the order flow and the price changes in other markets, making the channel less relevant.

On the other hand, the empirical predictions of the informational channel are based on the assumption that market participants do not engage in "panic selling" or "irrational exuberance," which is questioned by the behavioral finance literature. This is the concern of, among others, Knyazeva et al. (2012, p. 18): "The idea that investors can infer an economy's prospects from crises in other economies is central overcome by the use of asset pricing models in the estimation of cross-asset linkages (Bekaert et al., 2005). De Bandt and Hartman (2000) provide an overview of the different empirical approaches to contagion. 
to the information contagion view [...]. [...] The caveat about investor rationality applies here as well. The explanations above focused on rational investors. Often at least some degree of irrationality is involved in investor panics. If investors overreact to news or make other mistakes when drawing inference from other crises, contagion can spread faster as a result of investor irrationality."

In a nutshell, although informational contagion is one of the most oft-cited contagion mechanisms, the (real-market) evidence about it is only circumstantial. Moreover, there are various reasons that the theoretical channel of contagion may either not be present in real markets or, on the contrary, underestimate the importance of cross-market spillovers.

Our work fills the gap between the theoretical and the empirical literature by offering a direct test of the informational channel of King and Wadhwani (1990) using experimental data. In a laboratory financial market, the experimenter directly controls the information set available to subjects acting as traders, and can study the effect of a piece of news regarding one market on other markets. In our experiment, we extend the traditional experimental asset market design to a two-asset economy with informational spillover across markets.

Whereas our aim is to test the informational channel of financial contagion, there is an important aspect in which we depart from King and Wadhwani (1990). In their work, King and Wadhwani (1990) assume that the price fully reflects an asset's fundamental value, thereby disregarding how the market aggregates private information. Whereas theoretically full revelation of information can be assumed, in an empirical study it is important to test the extent to which it occurs. A large literature 
on experimental asset markets with asymmetrically informed traders (see, e.g., Plott and Sunder, 1988; Forsythe and Lundholm, 1990) has already studied the empirical validity of the Rational Expectations Equilibrium. The literature has found support for the conclusion that experimental financial markets are able to aggregate private information, albeit to different degrees. ${ }^{4}$ In our paper we study how informational spillovers across markets interact with information aggregation within each market.

As a theoretical counterpart to the experimental data, we first extend the original setup of King and Wadhwani (1990) to an economy where agents have private information. ${ }^{5}$ In the model, two markets open in sequence, and traders in the second market observe the history of trades and prices in the first. In both markets, traders receive private information about their own asset's fundamental value, which is efficiently aggregated by the price. We contrast two parameterizations. In the first parameterization, asset values are correlated, whereas in the second they are independent. With correlated asset fundamentals, information coming from the first market is relevant for the second and informational spillovers lead to informational contagion. In contrast, with independent asset fundamentals, there is no contagion.

Based on these two parameterizations, we ran two experimental treatments, one with correlated (Treatment $I$ ) and one with independent fundamentals (Treatment $I I)$. In contrast to the existing literature on experimental asset markets with asym-

\footnotetext{
${ }^{4}$ Information aggregation has also been studied in sequential trade models (see, e.g., Cipriani and Guarino, 2005, 2009; Drehmann et al., 2005, who test in the laboratory a Glosten and Milgrom, 1985 type of model). In those studies, however, the focus is on whether individual traders herd on the decisions of others and not on informational spillovers across markets.

${ }^{5}$ Grossman (1976) is the first contribution to the study of Rational Expectations Equilibrium with privately informed agents; Grossman (1978) extended the analysis to a multi-asset economy, without explicitly studying financial contagion caused by informational spillovers across markets.
} 
metrically informed traders, in our experiment subjects have two sources of information: i) a noisy private signal on the idiosyncratic shock to their own asset; ii) the ability to observe what occurs in the market opening first, in which other subjects are trading on the basis of their own private information. Notice that this is different from the case in which subjects observe a private and a public signal: in our experiment, every subject makes his own judgement on how well other subjects use their own private information and, as a result, how well the price in the market opening first reflects the true asset value. ${ }^{6}$

The experimental data show that, in line with the previous literature, private information is aggregated, but not completely in either market. Because the aggregation of private information is not complete, Bayesian agents in the market opening second would attach a lower weight to the (noisy) information coming from the market opening first. If fundamentals are correlated, financial contagion, however, would still occur as agents respond to the noisy signal coming from the first market.

Our results for Treatment $I$ are in line with this theoretical argument. Subjects correctly infer the value of the information contained by the trading activity in the first market and use it to trade in the second market. As a result, there is financial contagion across markets, with the correlation between asset prices higher than that between their fundamentals. In fact, in the laboratory, the correlation between asset prices is very close to that of the theoretical model (where full aggregation of

\footnotetext{
${ }^{6}$ Most experiments in the literature only study information aggregation in a one-asset economy. There are a few experimental papers in which trading in a multiple asset financial economy is studied (e.g., in Plott and Sunder, 1988, some of the treatments have three securities traded contemporaneously in an economy with three states of the world - so that markets are complete), but the focus remains on information aggregation, and the issue of informational spillovers across markets is not studied.
} 
private information is assumed). Although surprising at a first glance, we will show that this result comes from two facts: i) in the two markets, private information is approximately aggregated to the same degree; ii) subjects attach (approximately) the theoretically correct weight to the information coming from the first market (this weight turns out to be the same in the Rational Expectations Equilibrium and taking into account that information in the laboratory is noisy). Finally, in Treatment $I I$, with independent fundamentals, theory predicts that contagion does not occur. The experimental data are consistent with the theory's prediction.

Taken together, the results of the two treatments suggest that i) information contagion is robust to the departures from equilibrium that human subjects inevitably exhibit; ii) information contagion is not characterized by an excess (irrational) reaction to news; instead, it is the outcome of correct inference from the information received from the market opening first. These results complement the indirect evidence collected from real-markets data that information contagion is an important transmission mechanism of shocks.

The rest of the paper is organized as follows. Section 2 presents the theoretical framework. Section 3 illustrates the experiment. Section 4 explains the results. Section 5 concludes. The Appendix (available online) contains the instructions of the experiment and additional results. 


\section{Theoretical framework}

\subsection{PRELIMINARIES: KING AND WADHWANI (1990)'S MODEL}

The purpose of our paper is to test the informational contagion channel first proposed by King and Wadhwani (1990) in a controlled laboratory environment. It is therefore useful for us to explain how informational contagion arises in their model.

Let us consider a two-asset financial economy. In both markets, denoted by $A$ and $B$, the asset price change during a given time interval is a function of newly released information. King and Wadhwani (1990) consider two types of information: i) systematic news - affecting the fundamental values of both assets; and ii) idiosyncratic news, specific to each asset.

For simplicity's sake, consider the case in which the two markets open in sequence, with market $A$ opening first. Traders in market $A$ receive news about their own asset, and the price of asset $A$ changes accordingly. When market $B$ opens, traders in market $B$ observe the price change occurred in market $A$, but do not know whether it is due to idiosyncratic or systematic news. As a result, the equilibrium price in market $B$ will change even when the price change in market $A$ was due to purely idiosyncratic reasons. The reason is that traders attach some probability to the event that the price change in market $A$ was due to news about the systematic component, common to both assets.

In this economy, the correlation between asset prices in the two markets is higher than what we would observe if traders knew whether a shock is idiosyncratic or 
systematic (fundamental correlation). King and Wadhwani label this phenomenon "informational contagion". ${ }^{7}$

\subsection{THE MODEL}

To test informational contagion in the laboratory, we develop a model that embeds the main insights of King and Wadhwani (1990) in a two asset-economy with privately informed traders.

Specifically, we consider a two-market economy, in which the two markets, labeled by $A$ and $B$, open sequentially. In each market, a continuum of risk-neutral traders trade one asset. The fundamental value of asset $A\left(V^{A}\right.$, which can be thought of as the present discounted value of the asset's future stream of dividends) takes two values, 0 or 100 , with the same probability:

$$
V^{A}=\left\{\begin{array}{l}
0 \quad \text { with probability } \frac{1}{2} \\
100 \text { with probability } \frac{1}{2}
\end{array}\right.
$$

Although the realization of $V^{A}$ is unknown to market participants, they have private information about it; in particular, they receive a symmetric binary signal with precision $0.75 .^{8}$ In other words, each participant in market $A$ receives a signal $s^{A}$ distributed as follows: $\operatorname{Pr}\left(s^{A}=0 \mid V^{A}=0\right)=\operatorname{Pr}\left(s^{A}=100 \mid V^{A}=100\right)=0.75$.

Market $B$ opens after trading in market $A$ ends. Traders in market $B$ only trade

\footnotetext{
${ }^{7}$ King and Wadhwani (1990) contrast this contagion equilibrium, which they label "partiallyrevealing Rational Expectations Equilibrium," with a "fully-revealing Rational Expectations Equilibrium" (in which traders observe whether a shock is idiosyncratic or systemic, and although information flows across markets, there is no contagion), and with a "no-communication Rational Expectations Equilibrium" (in which traders do not observe the price in the other market, and no informational spillover occurs across markets).

${ }^{8}$ Obviously, any precision greater than 0.5 would deliver the same qualitative results.
} 
asset $B$. The fundamental value of asset $B, V^{B}$, equals $V^{A}$ with probability $p$ and $C$ with probability $1-p$, where $C$ is a random variable distributed as follows:

$$
C=\left\{\begin{array}{l}
0 \quad \text { with probability } \frac{1}{2}, \\
100 \text { with probability } \frac{1}{2} .
\end{array}\right.
$$

In other words, when $V^{A}=0$, then $V^{B}=0$ with probability $p+(1-p) \frac{1}{2}$ and $V^{B}=100$ with probability $(1-p) \frac{1}{2}$; when $V^{A}=100$, then $V^{B}=100$ with probability $p+(1-p) \frac{1}{2}$ and $V^{B}=0$ with probability $(1-p) \frac{1}{2} \cdot{ }^{9}$

Traders in market $B$ receive a symmetric binary signal $s^{C}$ on the realization of $C$ with precision 0.75 , that is, $\operatorname{Pr}\left(s^{C}=0 \mid C=0\right)=\operatorname{Pr}\left(s^{C}=100 \mid C=100\right)=0.75$. Furthermore, traders in market $B$ not only observe their own private information, but also the price in market $A .{ }^{10}$

The perfectly competitive Rational Expectations Equilibrium (REE) price of asset $A$ is 0 when $V^{A}=0$ and 100 when $V^{A}=100$; that of asset $B$ depends both on $V^{A}$ and on $C$. If both $V^{A}$ and $C$ are 0 (or 100), then the price of asset $B$ is 0 (or 100, respectively); if instead $V^{A}$ and $C$ are different, then the equilibrium price of $B$

\footnotetext{
${ }^{9}$ In King and Wadhwani (1990), the distribution of asset values is

$V^{A}=u_{A}+\alpha u_{B}+v_{A}$,

$V^{B}=\beta u_{A}+u_{B}+v_{B}$,

where $u_{A}, u_{B}, v_{A}$ and $v_{B}$ are normal random variables and $\alpha$ and $\beta$ are parameters; $u_{A}$ and $u_{B}$ reflect systematic news and $v_{A}$ and $v_{B}$ idiosyncratic ones.

In our model, the distribution of asset values is different. Nevertheless, we can interpret the realization of $V^{A}$ as an idiosyncratic shock to market $A$ with probability $(1-p)$, and as a common shock affecting both markets with probability $p$; and the realization of $C$ as an idiosyncratic shock to market $B$ that may occur when the market is not hit by a common shock. Since our assumptions imply that both asset values have the same support $\{0,100\}$, their distribution is simple to explain to subjects, which makes the model implementation in the laboratory easier.

${ }^{10}$ Note that, from a theoretical standpoint, in order for information contagion to occur, one would not need to assume that market $B$ has its own idiosyncratic shock (i.e., $C$ would not need to be a random variable), nor do traders in market $B$ need to be privately informed. Our setup, however, assures that trading activity in market $B$ is not driven by the information coming from market $A$ only. This is in line with the situation in many actual markets, in which, presumably, traders use information about their own market too.
} 
is $V^{A} p+C(1-p) \cdot{ }^{11}$

In the literature, a standard definition of contagion is correlation between prices higher than correlation between fundamentals. This is natural, since contagion is thought of as excess co-movement (that is, we observe higher co-movement among prices than what can be explained by fundamentals, such as trade or financial linkages).

In King and Wadhwani (1990), contagion occurs because agents do not know whether a change in the price of one market stems from an idiosyncratic or systematic shock. In our set up, with probability $p$ the realization of $V^{A}$ affects $V^{B}$, whereas with probability $(1-p)$ it does not; ${ }^{12}$ in the first case, the shock to $V^{A}$ is systematic (as it affects the fundamental values in both markets), whereas in the second case it is idiosyncratic (and $V^{B}$ is determined by its own idiosyncratic component). Since agents do not know whether the shock is systematic or idiosyncratic, learning is incomplete.

Specifically, incomplete learning in Market $B$ causes the variance of $P^{B}$ to be lower than the variance of $V^{B} \cdot{ }^{13}$ However, because of informational spillovers, the co-variance between prices does not decrease below that between fundamentals. As

\footnotetext{
${ }^{11}$ See Appendix $A .1$ for the derivation of the equilibrium in the case $p=0.5$ (the parameter value used in the laboratory). The REE equilibrium for different levels of $p$ can be found in a similar way. The derivation of the REE with privately informed traders is conceptually similar to that of Grossman (1976) for a single asset economy and Grossman (1978) for a multi-asset economy.

${ }^{12}$ To compare our set up with King and Wadhani (1990) we can think of the unconditional value in both markets as being equal to 50 and interpret the realizations of $V^{A}$ and $C$ as the shock (or the arrival of news) in the market.

${ }^{13}$ In contrast, $\operatorname{Var}\left(V^{A}\right)=\operatorname{Var}\left(P^{A}\right)$ since, to keep our setup simple, we assumed that there is no uncertainty on whether the shock in market $A$ affects market $A$ 's fundamental. Our results on excess correlation and contagion, however, are robust to allowing for incomplete learning also in market $A$.
} 
a result, correlation between prices is higher than correlation between fundamentals. In Appendix A.2, we show that, in the REE, the correlation between prices is $\frac{p}{\sqrt{\left(1-2 p+2 p^{2}\right)}}$, whereas the correlation between fundamentals is $p$; since $\frac{p}{\sqrt{\left(1-2 p+2 p^{2}\right)}}$ is greater than $p$, there is contagion from market $A$ to market $B$. It is important to note that this result does not stem from incomplete learning (i.e., the fact that price variances are lower than fundamental variances). One can easily write a model of incomplete learning with no uncertainty on the idiosyncratic or systematic nature of the shock, in which both covariance and variances of prices are lower than their fundamental counterparties, and the correlation between prices is equal to the correlation between fundamentals.

\section{The Experiment}

REE models are silent on the mechanism through which agents trade in the economy and equilibrium prices and allocations are reached. The standard practice in experimental economics, which we follow in our experiment, is to test this class of models in the laboratory through a continuous-time double auction. Because double auctions mirror the trading mechanism of many exchanges, they allow the experimenter to test a theoretical model in a setup that resembles a real financial market. ${ }^{14}$

We ran the experiment in the ELSE Experimental Laboratory at the Department

\footnotetext{
${ }^{14}$ Several trading mechanisms are used in real financial markets; some of them (such as a batch auction) have also been implemented in the laboratory. However, double auctions have proven to have good properties in terms of information and allocative efficiency (see, e.g., Smith et al., 1982; Friedman, 1993; Cason and Friedman, 1999). They are used not only to test theoretical models of asymmetric information (e.g., Plott and Sunder, 1982), but also standard asset pricing models (e.g., Bossaerts et al., 2007).
} 
of Economics at UCL. Overall, we recruited 192 subjects (undergraduate students in all disciplines) to conduct twelve sessions, six for each of two experimental treatments. Subjects had no previous experience with this experiment and participated in one session only.

\subsection{EXPERIMENTAL DESIGN}

In each session, 16 subjects traded in a two-market, computerized double auction. ${ }^{15}$ We ran two treatments. In the baseline treatment (Treatment $I$ ), the value of asset $B$ was equal to the value of asset $A$ with probability 0.5 (i.e., $p=0.5$ ); in this case, $\operatorname{Pr}\left(V^{B}=i \mid V^{A}=i\right)=0.75>\operatorname{Pr}\left(V^{B}=i\right)$ for $i=0,100$, that is, asset fundamentals were not independent. In the control treatment (Treatment $I I$ ), the value of asset $B$ was set equal to the value of $C$ (i.e., $p=0$ ), and $\operatorname{Pr}\left(V^{B}=i \mid V^{A}=i\right)=0.5=$ $\operatorname{Pr}\left(V^{B}=i\right)$, that is, asset fundamentals were independent. Table 1 shows the REE prices, $P^{A}$ and $P^{B}$, in the two treatments.

Because in Treatment $I$ asset fundamentals are not independent, informational contagion arises in equilibrium: in the REE, the correlation between prices is 0.71 , higher than that between fundamentals (0.5). In contrast, in Treatment $I I$, since the two asset values are independent, informational contagion does not arise in equilibrium - in the REE, the correlation between prices is 0 , the same as that between fundamentals.

\footnotetext{
${ }^{15}$ A large number of experiments have shown that double auctions produce competitive allocations and prices even with a small number of subjects (e.g., Smith 1962, 1964; Plott and Sunder, 1982 , 1988).
} 
Table 1. The REE equilibria in the two treatments

\begin{tabular}{lcccc}
\hline & Treatment $I$ & \multicolumn{2}{c}{ Treatment $I I$} \\
\hline$V^{A}=0, C=0$ & $P^{A}$ & $P^{B}$ & $P^{A}$ & $P^{B}$ \\
$V^{A}=0, C=100$ & 0 & 0 & 0 & 0 \\
$V^{A}=100, C=0$ & 0 & 50 & 0 & 100 \\
$V^{A}=100, C=100$ & 100 & 50 & 100 & 0 \\
$\operatorname{Corr}\left(P^{A}, P^{B}\right)$ & \multicolumn{2}{c}{0.71} & & 0 \\
$\operatorname{Corr}\left(V^{A}, V^{B}\right)$ & \multicolumn{2}{c}{0.5} & & 0 \\
\hline
\end{tabular}

\subsection{PROCEDURES}

In each of the 12 sessions of the experiment, we had 10 rounds of trading activity. Each session was organized in the following way:

- Subjects were given written instructions (see Appendix $H$ ). Subjects could ask clarifying questions, which we answered in private. After reading the instructions, subjects answered a short questionnaire to check their understanding of the experiment. A subject giving the wrong answer was notified that the answer was wrong and was asked to answer again until he gave the correct answer.

- We randomly assigned the 16 participants of each session to two groups of 8 subjects, group $I$ and group $I I$. A subject remained in the same group for the entire experiment.

- In each round, market $A$ and market $B$ opened in sequence. In even rounds, group $I$ traded asset $A$; after trading in market $A$ ended, group $I I$ traded asset 
$B$. In odd rounds, group $I I$ traded asset $A$ and group $I$ asset $B$.

- In each market, subjects traded the asset by exchanging it among themselves for 200 seconds. They used the trading platform shown in Figure H1, Appendix $H$.

- While one group of subjects was trading, the other observed the history of quotes and trades. Moreover, while one of the two groups traded in market $A$, we asked the subjects in the other group to indicate their belief on the value of asset $A$ being 100 after 80, 140 and 190 seconds of trading activity. This helped subjects to pay attention to the trading flow in the other market; additionally, it provided us with information about how subjects interpreted the history of trading in market $A$.

Let us now discuss the procedures for each round in detail. In each round, before the start of trading activity in market $A$, the computer program drew the asset value $V^{A}$, which, with equal probability, was equal to 0 or 100 units of a fictitious experimental currency called lira.

At the beginning of the round, each participant received an endowment of 4 units of asset $A$ and 500 liras. Subjects also received information about the asset value in the form of a symmetric binary signal with precision 0.75 . Specifically, when the asset value was 100, six participants observed a "green ball" and two participants a "red ball;" if the value was equal to 0 , six participants observed a "red ball" and two participants a "green ball." This signal structure guarantees that in each round the private signals collectively reveal the fundamental $V^{A}$ even if the number of subjects 
is finite. ${ }^{16}$

During the 200 seconds of trading activity in market $A$, subjects could post offers to sell or buy units of asset $A$. To post a sell offer, a subject would click on a sell button and enter the minimum price he was willing to accept. The offer appeared immediately on everyone's screen, in a column labeled Current Sell Offers (the identity of the subject making the offer was not revealed). Similarly, to post a buy offer, a subject would click on a buy button and enter the maximum price he was willing to pay. A trade would automatically be executed by the computer whenever the lowest sell price (ask) was lower than the highest buy price (bid). As a result, if a subject wanted, for instance, to buy at the prevailing (i.e., the lowest) ask, he could simply enter a price equal to or greater than that price, and the trade would be immediately executed (at the outstanding price). If, instead, a subject input, for example, an ask price higher than the outstanding ones, his ask would simply appear among the Current Sell Offers (where all asks were shown in increasing order).

Subjects could choose any buy or sell price greater than or equal to zero. ${ }^{17}$ For each subject, the maximum number of outstanding sell offers allowed was equal to the units of the asset held in his portfolio; and the sum of all the buy offer prices could not exceed the cash held in his portfolio. At any time, a subject could withdraw outstanding buy or sell offers that had not already been executed.

A subject's screen also displayed his current portfolio of cash and of units of the asset, the list of past trades in the round (with his own executed trades highlighted),

\footnotetext{
${ }^{16}$ Other signal structures, even if informative, may not deliver the same result (for instance, i.i.d. signals with precision 0.75 ).

${ }^{17}$ Also, a subject was not allowed to place a buy offer higher than one of his outstanding sell offers (in other words, a subject could not trade with himself).
} 
all the outstanding bid and ask prices, and the time left before the end of the round (see Figure $H 1$ ).

After trading in market $A$ ended, trading in the other market occurred according to the same protocol. In particular, each participant in market $B$ received an endowment of 4 units of asset $B$ and 500 liras. Subjects also received information about the realization of the random variable $C$ (which we labeled the " $B$-coin," in the experiment) in the form of a symmetric binary signal with precision 0.75 , exactly as explained above for asset $A$. In the instructions for Treatment $I$, we explained to subjects that the value of asset $B$ was equal either to asset $A$ or to the $B$-coin with equal probability; and for Treatment $I I$, we explained that the value of asset $B$ was equal to the $B$-coin. At the end of the round, the values of the two assets, $V^{A}$ and $V^{B}$, were revealed, and each subject saw a detailed summary of his per-round payoff on the screen. Each subject's per-round payoff was equal to the sum of the cash and of the value of the assets in his portfolio. Additionally, we paid subjects a transaction bonus of 5 liras for the first 5 trades. The bonus gave subjects an incentive to exchange the asset in an environment in which payoffs and endowments are the same. ${ }^{18}$ We limited the bonus to the first five trades to avoid the possibility that subjects would keep exchanging the asset among themselves just to earn the bonus. ${ }^{19}$

\footnotetext{
${ }^{18}$ Note that, in the economy we described in Section 2, there are no gains from trade and as a result, agents do not have any incentive to trade at the REE price (no-trade theorem). Note also that because of the bonus, the REE prices in either treatment are not unique, rather they are intervals of 5 liras around the equilibrium predictions described in Section 3.1.

${ }^{19}$ As we will show in Section 4, the transaction bonus of 5 liras is large enough to give subjects an incentive to trade in the laboratory.
} 
In each session, before we ran the actual experiment, we had a training phase to familiarize subjects with the trading platform. ${ }^{20}$ The training phase consisted of 10 rounds of trading in only one market. Since the session was for training purposes only, we do not report its results in the main text of the paper. ${ }^{21}$ It is important to remark that, in the training sessions, subjects familiarized themselves with the trading platform in a one-market economy; in contrast, the focus of our empirical analysis is how, in the laboratory, subjects interpreted the history of prices and trades in market $A$ while trading in market $B$, something that they did not experience during the training phase.

At the end of the experiment, we randomly selected three rounds and summed up the per-round payoffs. We converted experimental liras into British Pounds at the exchange rate of $£ 1=100$ liras; additionally, subjects earned $£ 5$ as a show-up fee. We paid subjects in private immediately after the end of the experiment. On average, subjects earned $£ 28$ (approximately equal to $\$ 47.5$ ). Sessions lasted approximately 3 hours.

Before we discuss the experimental results, we would like to emphasize that our experiment is a particularly challenging test for the informational channel of financial contagion. One could have brought King and Wadhwani (1990)'s model to the lab-

\footnotetext{
${ }^{20}$ The use of experienced subjects is typical in trading experiments with double auctions, since convergence to competitive equilibrium requires repetitions, even in simple environments (Smith, 1962). For example, Copeland and Friedman (1991) use subjects who had previously participated in an asset market trading experiment; Forsythe and Lundholm (1990) make subjects participate in double auctions experiments in two consecutive nights. In our experiment, we are interested in the informational spillover from market $A$ to market $B$. It is, therefore, important to make sure that subjects have learned how to trade; otherwise the trading activity in market $A$ could be pure noise and reveal no information about the asset value.

${ }^{21}$ In Appendix $B$, we show that the training session was indeed useful for subjects to learn how to trade.
} 
oratory by simply studying the behavior of subjects in market $B$ who had observed a price in market $A$ set by the experimenters (which is tantamount to observing a public signal). With respect to this set up, our experiment is richer in two dimensions. First, subjects trading in market $B$ had two sources of information: trading activity in market $A$ and their own private information. This by itself could have impaired information aggregation in market $B$, while at the same time making the inference problem from market $A$ more complicated. Second, the information coming from market $A$ was not a public signal: every subject made his own judgement on how well the price in market $A$ reflected the true asset value in that market. In the next section we will show that although subjects faced a complicated task, the experimental results provide support for the theory of information contagion.

\section{Results}

We now turn to the discussion of the experimental results. We will first discuss the results of Treatment $I$, where $p=0.5$, and, therefore, theory predicts that informational contagion occurs. Later, we will compare these results with those of Treatment $I I$, where $p=0$ and, according to theory, there is no informational contagion.

In our model, contagion is caused by an informational spillover from market $A$ to market $B$. Of course, the information that subjects in market $B$ obtain from the trading activity in market $A$ depends on how well the price in that market aggregates private information. For this reason, as a first step, in the next section we investigate 
the aggregation of private information in market $A$.

\subsection{TRADING AND PRICE CONVERGENCE IN MAR- KET $A$}

As we explained above, given the signal structure implemented in the laboratory, the signals that subjects receive reveal $V^{A}$ : that is, there is enough information in the market to learn $V^{A}$ through trading activity. Therefore, the price aggregates private information if, at least by the end of the round, it equals $V^{A}$ (or, given our transaction bonus, it differs from it by at most 5 liras).

The amount of trading activity we observed in the laboratory is consistent with the volume of trade that the bonus we gave to subjects is expected to generate. Recall that we paid subjects a bonus for the first five trades they executed in order to give them an incentive to trade in an economy in which otherwise there would be no gains from trade. Indeed, in the laboratory, we observed an average of 5 trades per subject per round (without meaningful differences in subjects' behavior depending on whether they received a green (i.e., good) or a red (i.e., bad) signal, or a correct or incorrect signal). Given that in each market there are 8 subjects and that a trade involves two parties, overall we observed on average 20 trades per round (with a median of 18.5 and a standard deviation of 6.3$).{ }^{22}$

To study the aggregation of information in market $A$, we consider the average of the last five trade prices in each round, which we label the "final price" and denote by

\footnotetext{
${ }^{22}$ These statistics refer to market $A$. The statistics for market $B$ are similar (an average of 20.68 trades per round with a standard deviation of 7.13). For additional statistics on subjects' trading behavior, see Appendix C.6.
} 
$\bar{p}_{A}^{\text {Last5 }}$. Figure 1 shows a histogram of the per-round distance (defined as the absolute value of the difference) between the final price and $V^{A}$. As the figure shows, in almost 70 percent of the cases, the distance is less than 20 liras. The distribution is heavily skewed to the right: the average distance is 23 liras, higher than the median, which is less than 10 liras (see Table 2); in $20 \%$ of the rounds, the distance is higher than 50 liras. In other words, the price does aggregate private information well, but there are some rounds in which aggregation fails. ${ }^{23,24}$

\section{Table 2. Distance of the final price of asset A from $V^{A}$}

The table shows the mean, median, and standard deviation of the distance of the final price of asset A from $V^{A}$. The final price is the average of the last five trade prices in a round (column 1), or of the last three trade prices (column 2), or of the trades that occurred in the last 30 seconds of a round (column 3).

\begin{tabular}{lccc}
\hline & Last 5 trades & Last 3 trades & Last 30 seconds of trade \\
\hline Mean & 22.64 & 22.67 & 21.67 \\
Median & 9.29 & 8.67 & 8.60 \\
Std. Dev. & 27.86 & 28.51 & 28.37 \\
$N$ & 60 & 60 & 52 \\
\hline
\end{tabular}

These findings are confirmed by regression analysis. In particular, we ran the following regression:

\footnotetext{
${ }^{23}$ We tried to understand whether the lack of price convergence in some rounds is the result of different trading strategies by subjects. Unfortunately, we did not find meaningful differences. For instance, the proportion of trades and orders executed and posted by subjects with the correct signal was similar in rounds where there was convergence and in those where there was not. The only relevant finding of the analysis was that in rounds in which the price converged to the wrong value, at the beginning of the round subjects posted many orders far from their private expected values (which, therefore, did not reveal their signals); this did not happen in rounds where there was convergence. These abnormal quotes imply that the price was far from the fundamental since the beginning of the rounds and the misalignment was never fully corrected. See Appendix C.6.

${ }^{24}$ These results are not different when $V^{A}=100$ and when $V^{A}=0$; that is, we do not observe asymmetry in information aggregation when the fundamental is high or low. See Appendix C.4.
} 


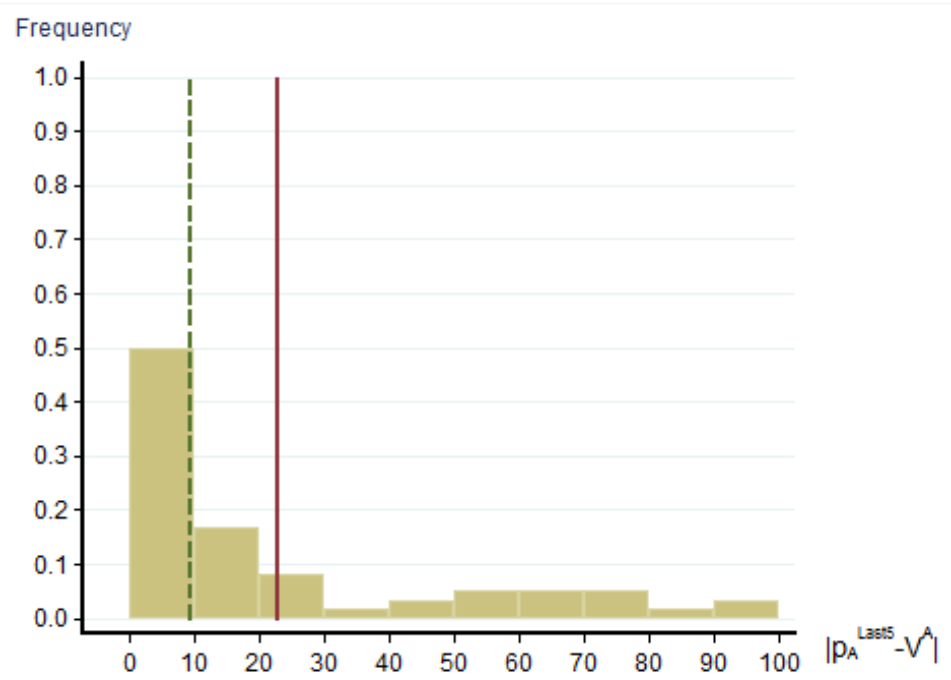

Figure 1. Per-round distance between the final price and $V^{A}$. The final price is defined as the average of the last five trade prices in a round. The mean is indicated by the solid line; the median by the dashed line.

$$
\bar{p}_{A, i}^{L a s t 5}=\alpha+\beta V_{i}^{A}+\varepsilon_{i},
$$

where $i$ is the round. As the first column of Table 3 shows, the slope coefficient is positive and significant, but only equal to 0.5 : only half the information that the subjects receive is aggregated by the final price. ${ }^{25}$ According to the regression, when the fundamental is 0 , the expected final price is 23 ; and when the fundamental is 100 , it is 78 . In both instances, the final price moves from its unconditional expected value of 50 toward the realization of the fundamental, but it is further away from it than the 5 liras bonus justifies.

\footnotetext{
${ }^{25}$ We reject the hypothesis that the coefficient is equal to the theoretical value of 1 (p-value equal to 0.01 , using a cluster-robust t-test at the session level).
} 


\section{Table 3. Regression results for market A}

The table shows the regression results of the final price of asset $\mathrm{A}$ on $V^{A}$. The final price is the average of the last five trade prices in a round (column 1), or of the last three trade prices (column 2 ), or of the trades that occurred in the last 30 seconds of a round (column 3). Standard errors in parentheses are clustered at the session level. ${ }^{*},{ }^{* *},{ }^{* * *}$ denote significance at the 10, 5, 1 percent level, respectively.

\begin{tabular}{lccc}
\hline & Last 5 trades & Last 3 trades & Last 30 seconds of trading \\
\hline \multirow{2}{*}{$V^{A}$} & $0.545^{* *}$ & $0.546^{* *}$ & $0.564^{* *}$ \\
& $(0.124)$ & $(0.126)$ & $(0.114)$ \\
Constant & $23.10^{* *}$ & $22.70^{* *}$ & $22.56^{* *}$ \\
R-squared & $(8.380)$ & $(8.302)$ & $(8.210)$ \\
$N$ & 0.475 & 0.464 & 0.496 \\
\hline
\end{tabular}

Note that our results do not depend on how we define the per-round final price, as the second and third columns of Tables 2 and 3 show. The regression coefficients do not meaningfully change if we define the final price as the average price of the last 3 trades, or the average price of the trades that occurred over the last 30 seconds of trading activity. ${ }^{26}$

In summary, our results show that final prices in market $A$ are a noisy signal of the asset value. Therefore, they could be used by subjects in market $B$ to infer $V^{A}$ and, in turn, to construct their beliefs on $V^{B}$. To understand how rational agents form their beliefs on $V^{A}$ by observing the prices in market $A$, we regressed $V^{A}$ on the final price in a probit regression and estimated the conditional expected value of $V^{A}$ (i.e., the conditional probability that $V^{A}=100$ ). Figure 2 shows the conditional expected

\footnotetext{
${ }^{26}$ See also Appendix C.2. Note that in eight trading rounds, no transactions occurred in the last 30 seconds of trade. This explains why in column 3 of Tables 2 and 3 the average final price is computed over 52 rather than 60 rounds. Finally, in Appendix C.5, we show that the regression results do not change if we add session and/or round fixed effects.
} 


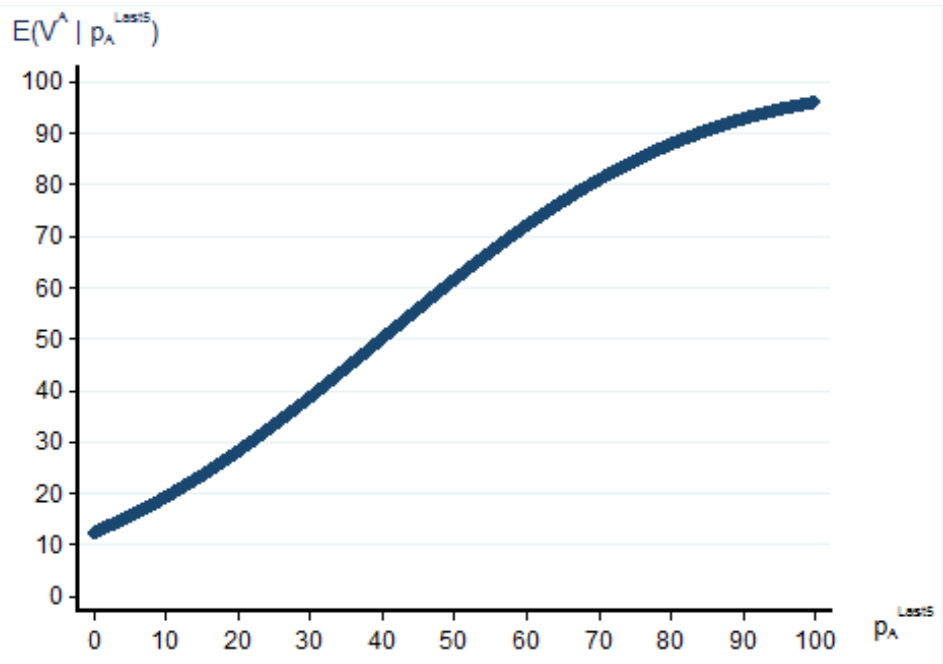

Figure 2. Expected value of $V^{A}$ as a function of the final price in market $A$.

value of $V^{A}$ as a function of market $A$ 's final price. For instance, the conditional expected value of $V^{A}$ is around 28 for a final price of 20 and climbs to over 80 for a final price of $80 .^{27}$

Note that the expectations we obtain through the probit regression are very similar to those that a Bayesian agent would compute after observing the empirical frequencies of $V^{A}$ being equal to 0 or 100 for different ranges of the final price (see the first three columns of Table 4). Interestingly, there expectations are also very close to the (average) beliefs we elicited from subjects trading in market $B$ while they were observing the trading activity in market $A$ (last column of Table 4$).{ }^{28}$

\footnotetext{
${ }^{27}$ We report the coefficients of the probit regression in Table $C 1$ in Appendix C.1.

${ }^{28}$ Recall that while one group was trading asset $A$, subjects in the other group had to state their belief about the value of asset $A$ (i.e., their expected value of the asset) when there was a remaining trading time of 120, 60 and 10 seconds in market $A$. Here, and in the rest of the paper, we focus on subjects' elicited expectation when there were only 10 seconds of trading activity left in market $A$. In Appendix $F$ we carry out some additional analysis of subjects' elicited beliefs.
} 


\section{Table 4. Empirical Bayesian Updates}

The table shows: 1) the frequencies with which the final price (defined as the average of the last five trade prices in a round) belonged to a particular range, conditional on $V^{A}$ (columns 1 and 2); 2) the Bayesian updates about $V^{A}$ computed using these frequencies (column 3); 3) average subjects' beliefs elicited 10 seconds before the end of the trading activity in market A (column 4).

\begin{tabular}{lcccc}
\hline & \multicolumn{2}{c}{ Frequencies } & Bayesian updates & Beliefs \\
\hline & $V^{A}=0$ & $V^{A}=100$ & $\operatorname{Pr}\left(V^{A}=100 \mid \bar{p}_{A}^{\text {Last } 5}\right)$ & \\
$\bar{p}_{A}^{\text {Last } 5}>75$ & 0.09 & 0.71 & 0.89 & 85.8 \\
$50<\bar{p}_{A}^{\text {Last } 5} \leq 75$ & 0.09 & 0.08 & 0.46 & 59.7 \\
$25 \leq \bar{p}_{A}^{\text {Last } 5} \leq 50$ & 0.09 & 0.10 & 0.54 & 43.0 \\
$\bar{p}_{A}^{\text {Last }}<25$ & 0.73 & 0.10 & 0.13 & 10.7 \\
\hline
\end{tabular}

Until now, we have focused on the price towards the end of the 200 seconds of trading. Aggregation of information took some time to occur. In Figure 3, we show the evolution of the distance between the price and $V^{A}$ over time. We divided the trading round into 10 intervals and computed the average distance in each of these intervals. As the figure shows, the price becomes closer and closer to the fundamental, as private information is aggregated through the trading activity. ${ }^{29}$

\footnotetext{
${ }^{29}$ We computed the evolution of the distance between the price and $V^{A}$ also in trade- and quotetime. Interestingly, most of the learning occurs in the first 20 trades (which is also the average number of trades in the experiment). See Appendix C.3.
} 


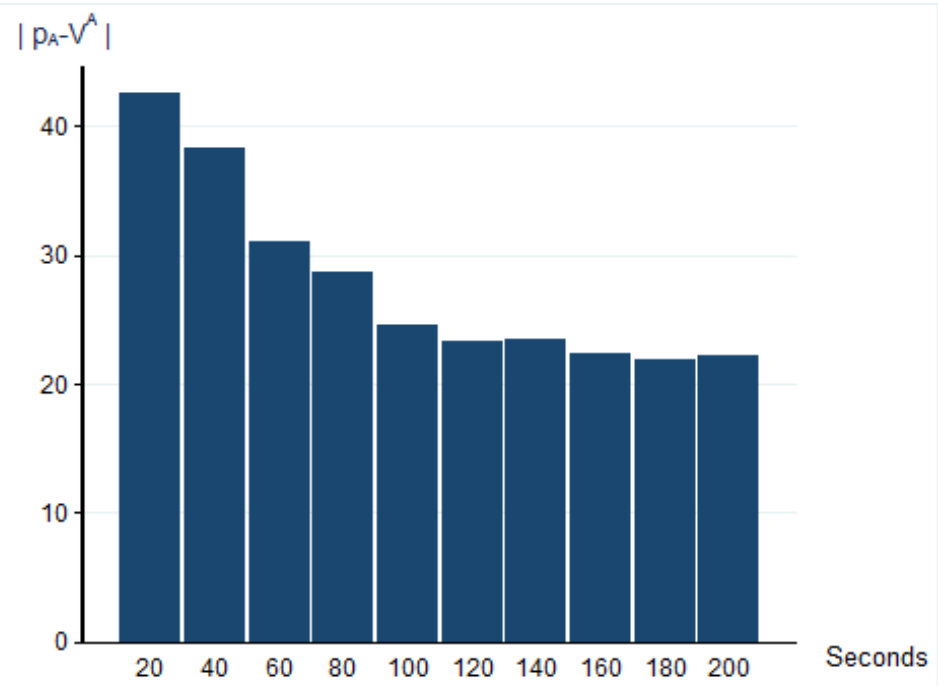

Figure 3. Distance of the price of asset $A$ from $V^{A}$ over time. The figure shows the distance between the average price and $V^{A}$ for each interval of 20 seconds.

\subsection{TRADING AND PRICE CONVERGENCE IN MAR- KET $B$}

We now turn our attention to market $B$. We conduct a similar analysis to that of market $A$ and study the behavior of the final price, defined, as in the previous section, as the average of the last five trade prices. Figure 4 shows the histogram of the per-round distance between the final price in market $B$ and $V^{B}$; Table 5 shows the mean, the median, and the standard deviation across rounds. As one can observe, the distance between price and fundamental is higher than in market $A$ (the difference is significant at the $5 \%$ level using a Wilcoxon signed-rank test at session 


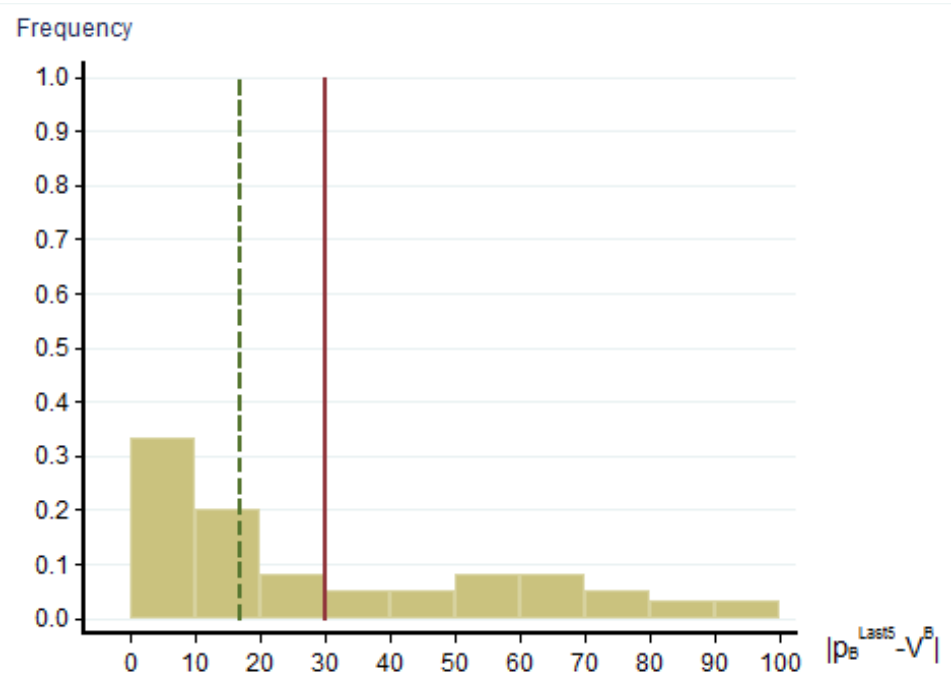

Figure 4. Per-round distance between the final price and $V^{B}$. The final price is defined as the average of the last five trade prices in a round. The mean is indicated by the solid line; the median by the dashed line.

level).

This is not surprising. In contrast to market $A$, the information that subjects receive (i.e., the signals about $C$ and the history of trading activity in market $A$ ) does not reveal $V^{B}$ : there is not enough information in the market to learn the fundamental through trading activity. ${ }^{30}$

The higher distance between final price and fundamental may be due to two reasons: i) the fact that in market $B$ there is less information about the fundamental than in market $A$; and ii) the fact that the aggregation of private information in market $B$ is less efficient (e.g., because subjects, when interpreting their private

\footnotetext{
${ }^{30}$ The degree of convergence of the price to $V^{B}$ depended on the realisations of $V^{A}$ and $C$. The price settled at a level further away from the fundamentals in those rounds in which $V^{A} \neq C$. Indeed, even theoretically, in such a case price convergence to $V^{B}$ should not occur (given that subjects do not know whether $V^{B}$ is equal to $V^{A}$ or to $C$ ). See Appendix D.3.
} 
Table 5. Distance of the final price of asset B from $V^{B}$

The table shows the mean, median, and standard deviation of the distance of the final price of asset B from $V^{B}$. The final price is the average of the last five trade prices in a round (column 1), or of the last three trade prices in a round (column 2), or of the trades that occurred in the last 30 seconds of a round (column 3).

\begin{tabular}{lccc}
\hline & Last 5 trades & Last 3 trades & Last 30 seconds of trading \\
\hline Mean & 29.93 & 29.54 & 29.01 \\
Median & 16.7 & 13.5 & 15.75 \\
Std. Dev. & 29.18 & 29.68 & 30.26 \\
$N$ & 60 & 60 & 58 \\
\hline
\end{tabular}

signal, have an additional source of information, the public information from market $A$, that may confuse them). To gauge the ability of subjects in market $B$ to aggregate information, we compare the final price to the REE price. In the REE, trading activity in markets $A$ and $B$ reveal both $V^{A}$ and $C$, but does not reveal whether $V^{B}$ equals $V^{A}$ or $C$. For this reason, as discussed above, the REE price in $B$ is 100 when $V^{A}=C=100 ; 0$ when $V^{A}=C=0 ;$ and 50 when $V^{A} \neq C$. If the (final) price in market $B$ aggregates the information contained in the patterns of trading activity in market $A$ and in the signals, it should equal the REE price.

As Figure 5 and Table 6 show, the average distance between the final price and the REE price is 25.9. This is not statistically different from the distance in market $A$ (Wilcoxon signed-rank test at session level-p-value $=0.20)$. In other words, there is no evidence that the aggregation of information in market $B$ is reduced by the fact that the task that subjects are facing is harder.

In order to understand the aggregation of information in market $B$, we also regress the initial and the final price in market $B$ over the realization of $C$ and over the value 


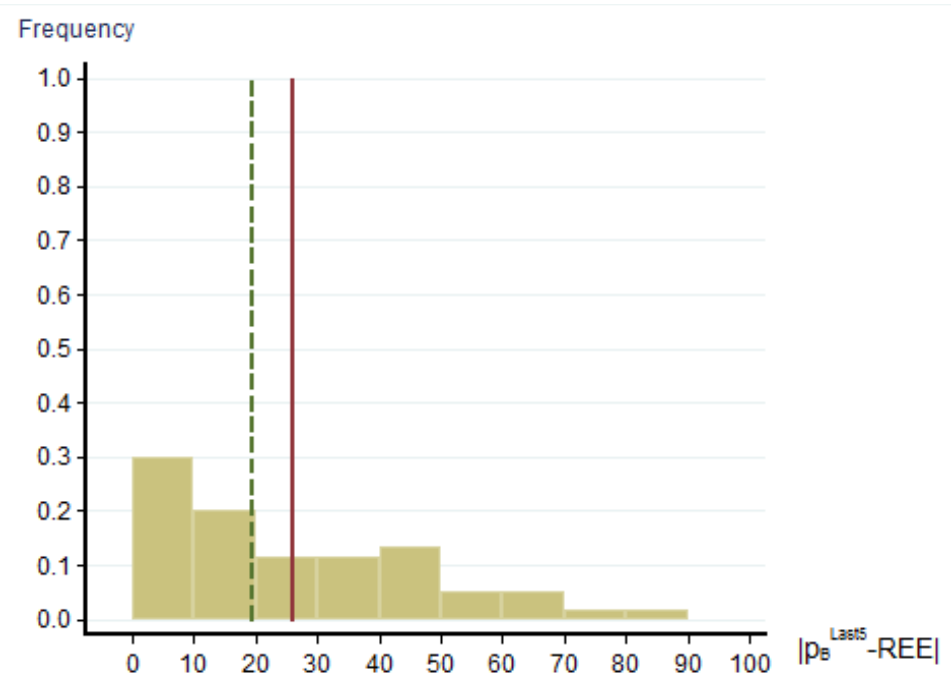

Figure 5. Per-round distance between the final price and the REE. The final price is defined as the average of the last five trade prices in a round. The mean is indicated by the solid line; the median by the dashed line.

of the fundamental in market $A$ :

$$
p_{B, i}=\alpha+\beta_{1} C_{i}+\beta_{2} V_{i}^{A}+\varepsilon_{i}
$$

The initial price is defined as the average price of the first 5 trades in each round, whereas the final price is defined, as before, as the average of the last 5 .

The results of the initial-price regressions are reported in the first three columns of Table 7. As the first column shows, the effect of $C$ on the initial price is positive and significant; it is also smaller than it would be if signals were immediately reflected in the price at the beginning of the round (0.16 versus 0.5$)$. This is not surprising, as the aggregation of private information happens over time. Additionally, the effect of the fundamental in $A\left(V^{A}\right)$, although positive, is both lower than what theory predicts 
Table 6. Distance of the final price of asset B from the REE price

The table shows the mean, median, and standard deviation of the distance of the final price of asset $\mathrm{B}$ from the REE price. The final price is the average of the last five trade prices in a round (column 1 ), or of the last three trade prices in a round (column 2), or of the trades that occurred in the last 30 seconds of a round (column 3).

\begin{tabular}{lccc}
\hline & Last 5 trades & Last 3 trades & Last 30 seconds of trading \\
\hline Mean & 25.90 & 25.92 & 25.32 \\
Median & 19.50 & 19.0 & 22.33 \\
Std. Dev. & 22.30 & 23.21 & 23.63 \\
$N$ & 60 & 60 & 58 \\
\hline
\end{tabular}

(0.15 versus 0.5$)$ and non-significant. To understand this result, let us look at the second column of Table 7 , where we replaced $V^{A}$ with its conditional expectation given by the probit regression $E^{\text {probit }}\left(V^{A} \mid \bar{p}_{A}^{\text {Last5 }}\right)$ (as illustrated in Section 4.1), that is,

$$
p_{B, i}=\alpha+\beta_{1} C_{i}+\beta_{3} E^{p r o b i t}\left(V_{i}^{A} \mid \bar{p}_{A, i}^{\text {Last5 }}\right)+\varepsilon_{i} .
$$

The coefficient on $E^{\text {probit }}\left(V^{A} \mid \bar{p}_{A}^{\text {Last5 }}\right)$ is significant and close to the theoretical value of 0.5 . That is, subjects trading in market $B$ correctly incorporate the information coming from market $A$. It is only because market $A$ 's price is a noisy signal of $V^{A}$ that the spillover from market $A$ to market $B$ is lower than the theoretical prediction. ${ }^{31}$

\footnotetext{
${ }^{31}$ In a recent paper, Longstaff $(2010)$ presents evidence against the information channel in the case of the 2007-8 financial crisis (this evidence is "of course limited to the specific episode studied" as the author observes). The author finds that the cross market spillover happened with a lag, which he interprets as evidence against the information channel. His conclusions are based on the assumption that markets are informationally efficient; if, instead, it took time for the price to aggregate information he could not have concluded much from the lag in the spillover effect. Our result shows that indeed this assumption is supported by the data: in our experiment the information spillover from the other market occurs as soon as the second market opens.
} 
Table 7. Regression results for market B

The table shows the regression results of the initial (final) price of asset $\mathrm{B}$ on $\mathrm{C}$ and on $V^{A}$ in column 1 (4). Columns 2 and 5 show the regression results using the conditional expectation of $V^{A}$ (computed by the probit regression). Columns 3 and 6 show the regression results using the average elicited belief at the end of the round. Standard errors in parentheses are clustered at the session level. ${ }^{*},{ }^{* *},{ }^{* * *}$ denote significance at the $10,5,1$ percent level, respectively.

\begin{tabular}{|c|c|c|c|c|c|c|}
\hline \multirow[b]{2}{*}{$C$} & \multicolumn{3}{|c|}{ Initial Price (first 5 trades) } & \multicolumn{3}{|c|}{ Final Price (last 5 trades) } \\
\hline & $\begin{array}{l}0.165^{* *} \\
(0.043)\end{array}$ & $\begin{array}{l}0.128^{* *} \\
(0.038)\end{array}$ & $\begin{array}{l}0.132^{* *} \\
(0.035)\end{array}$ & $\begin{array}{l}0.278^{* *} \\
(0.058)\end{array}$ & $\begin{array}{l}0.235^{* *} \\
(0.047)\end{array}$ & $\begin{array}{l}0.235^{* *} \\
(0.047)\end{array}$ \\
\hline$V^{A}$ & $\begin{array}{l}0.151 \\
(0.083)\end{array}$ & & & $\begin{array}{l}0.305^{*} \\
(0.133)\end{array}$ & & \\
\hline$E^{\text {probit }}\left(V^{A} \mid \bar{p}_{A}^{\text {Last } 5}\right)$ & & $\begin{array}{l}0.418^{* *} \\
(0.065)\end{array}$ & & & $\begin{array}{l}0.632^{* *} \\
(0.137)\end{array}$ & \\
\hline Belief & & & $\begin{array}{l}0.410^{* *} \\
(0.065)\end{array}$ & & & $\begin{array}{l}0.659^{* *} \\
(0.097)\end{array}$ \\
\hline Constant & $\begin{array}{l}33.49^{* *} \\
(6.679)\end{array}$ & $\begin{array}{l}18.78^{* *} \\
(6.202)\end{array}$ & $\begin{array}{l}22.53^{* *} \\
(6.435)\end{array}$ & $\begin{array}{l}12.52 \\
(7.825)\end{array}$ & $\begin{array}{l}-5.616 \\
(4.391)\end{array}$ & $\begin{array}{l}-1.781 \\
(2.765)\end{array}$ \\
\hline R-squared & 0.235 & 0.463 & 0.475 & 0.385 & 0.563 & 0.624 \\
\hline
\end{tabular}

Note also that, as shown in the third column of Table 7, the coefficient on subjects' expectations is virtually unchanged if, instead of using the Probit regression, we use the average belief we elicited from subjects at the end of the round in market $A$ (see footnote 27):

$$
p_{B, i}=\alpha+\beta_{1} C_{i}+\beta_{4} \text { Belief }_{i}+\varepsilon_{i}
$$

Let us now consider how the final price aggregates subjects' information. In the last three columns of the table, we regress the final price on the realizations of $C$ and on $V^{A}$ (column 4), on its conditional expected value computed through a Probit regression (column 5), and on subjects' average beliefs on $V^{A}$ elicited at 
the end of trading activity in market A (column 6). If the final price aggregated subjects' signals correctly, the coefficient on $C$ should be 0.5 (since $V^{B}=C$ only with probability 0.5 ). In the last three columns of Table 7 , the coefficient is positive and significant, but approximately only half the theoretical value. This is a similar result to what was observed in market $A$, where the coefficient of 0.5 was half its theoretical counterpart. ${ }^{32}$ In both markets, the price aggregates subjects' private signals only partially.

Moreover, according to the theory, the coefficients on $V^{A}$ should be 0.5 (since $V^{B}=V^{A}$ with probability 0.5$)$; in the regression, the coefficient is positive and significant, but smaller than the theoretical one. Similarly to what happened for the initial price, however, when we use as a regressor the conditional expectation of $V^{A}$ the coefficient increases to approach its theoretical value. ${ }^{33}$ In other words, also when we look at the final price, it is apparent that subjects incorporate the information coming from the other market correctly.

In analyzing the price in market $B$, we computed subjects' expectations about $V^{A}$ as if subjects could only observe prices in market $A$. Of course, subjects could also observe trades and quotes. One could wonder whether our results change when we take this into account. To answer this question, we study subjects' expectations as a function of the trade imbalance ("TI," i.e. the difference between buy and sell orders) and of the quote imbalance ("QI," i.e., the difference between the number of posted bid and ask orders). In Table 8 we repeat the analysis of Table 7 , assuming that

\footnotetext{
${ }^{32}$ In market $A$, full aggregation of private information would have implied that the coefficient on $V^{A}$ was equal to 1.

${ }^{33}$ We cannot reject the hypothesis that the coefficient is equal to the theoretical one- $\mathrm{p}$-value $=$ 0.38 - using a cluster-robust t-test at the session level.
} 
subjects use the trade imbalance (columns 1 and 5), the quote imbalance (columns 2 and 6 ), and the trade and quote imbalance along with the final price (columns 3 and 7 ; and 4 and 8) to form their expectations on Market $A$. As one can see, neither the estimated coefficient on $C$ nor that on subjects' expectation on $V^{A}$ changes with respect to what presented in Table $7 .^{34}$ In other words, our analysis is robust to different specifications on how subjects learn from the other market. Although the quote and trade imbalances do contain information, this information is also aggregated by the market price.

As a further robustness check, we studied whether results change across rounds, either because of learning effects or because subjects' attention is lower at the end of the experiment. In Appendix $G$, we replicated our empirical analysis dividing our dataset into three subsamples: the first three rounds, the middle four rounds, and the last three rounds. We do not find economically or statistically significant differences across subsamples. Moreover, our regression results are robust to the inclusion of session and round fixed effects (see Appendix D.4).

Overall, the regression results suggest that the information inference from the trading activity in market $A$ is close to what theory predicts. In contrast, both in market $A$ and in market $B$, subjects have more difficulties aggregating private information. Although private signals are aggregated by the price, the aggregation is not complete.

\footnotetext{
${ }^{34}$ As for Table 7 , the expectations are computed through a Probit regression. The coefficients of the regression are reported in Appendix C.1. Note that the fit performance of the trade imbalance and quote imbalance Probit regressions are similar (although slightly worse) to those of the price regression.
} 


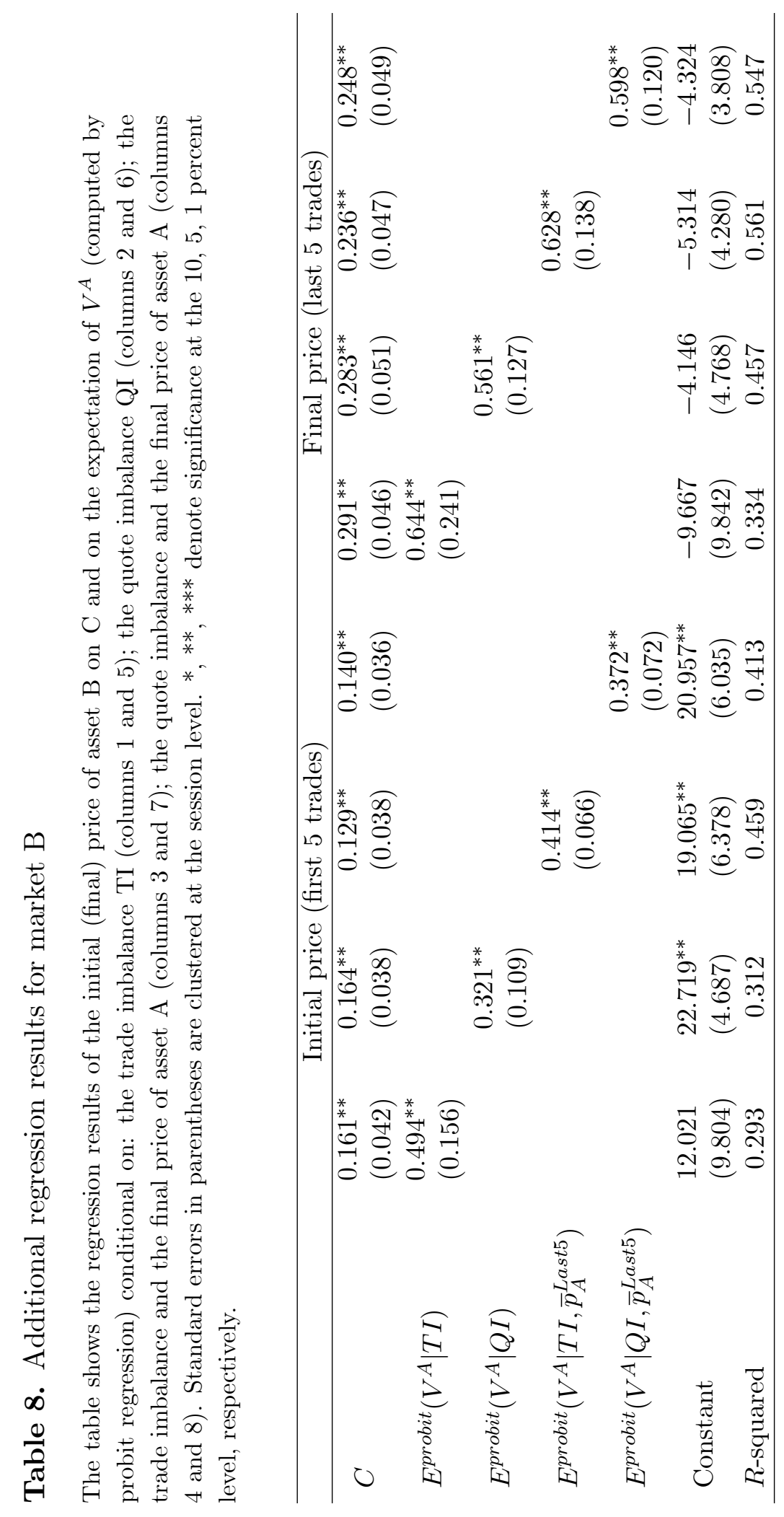




\subsection{PRICE CONVERGENCE WITH HIGH AND LOW FUN- DAMENTAL VALUES}

One may wonder whether information aggregation and spillover effects in market $B$ are different according to whether the asset's fundamentals, $V^{A}$ and $C$, have high or low values. For instance, such asymmetry may be the result of subjects exhibiting panic behavior in the face of bad news or irrational exuberance in the face of good news.

In footnote 23 , we remarked that the level of information aggregation in market $A$ is very similar when $V^{A}=0$ and when $V^{A}=100$. In Table 9, we show the distance between the price in market $B$ and $V^{B}$ conditional on the realizations of $V^{A}$ and $C{ }^{35}$ Two observations are in order. First, as in market $A$, the distances between the price and $V^{B}$ are very similar when $V^{A}=C=0$ and when $V^{A}=C=100$. This indicates that good and bad information about the fundamentals are aggregated to a similar extent.

Second, the distances between the price and $V^{B}$ are also very close in the two cases when $V^{A}$ and $C$ are different, that is, when $V^{A}=0$ and $C=100$ and when $V^{A}=100$ and $C=0$. In other words, the spillover effects from market $A$ to market $B$ are not more pronounced when there is a "crisis" (bad news) in market $A$.

\footnotetext{
${ }^{35}$ For additional results see Appendix D.2.
} 
Table 9. Distance of the final price of asset B from $V^{B}$, conditional on $V^{A}$ and C.

The table shows the mean, median, and standard deviation of the distance of the final price of asset B from $V^{B}$, conditional on the values of $V^{A}$ and $\mathrm{C}$. The final price is the average of the last five trade prices in a round (column 1), or of the last three trade prices in a round (column 2), or of the trades that occurred in the last 30 seconds of a round (column 3).

\begin{tabular}{lccc}
\hline & Last 5 trades & Last 3 trades & Last 30 seconds of trading \\
\hline & \multicolumn{3}{c}{$V^{A}=0, C=0$} \\
\cline { 2 - 4 } Mean & 20.12 & 19.67 & 18.05 \\
Median & 11.7 & 8.67 & 7.92 \\
Std. Dev. & 24.83 & 25.03 & 23.48 \\
$N$ & 12 & 12 & 12 \\
\hline & \multicolumn{3}{c}{$V^{A}=100, C=100$} \\
Mean & 25.43 & 25.58 & 24.82 \\
Median & 11.1 & 10 & 8.75 \\
Std. Dev. & 26.64 & 28.10 & 30.05 \\
$N$ & 24 & 24 & 22 \\
\hline & \multicolumn{3}{c}{$V^{A}=0, C=100$} \\
Mean & 38.96 & 38.9 & 37.90 \\
Median & 36.8 & 37.17 & 32.17 \\
Std. Dev. & 30.56 & 30.51 & 30.05 \\
$N$ & 10 & 10 & 10 \\
\hline & \multicolumn{3}{c}{$V^{A}=100, C=0$} \\
Mean & 39.6 & 38.10 & 38.62 \\
Median & 25.2 & 24.67 & 24.75 \\
Std. Dev. & 33.95 & 34.06 & 33.57 \\
$N$ & 14 & 14
\end{tabular}

\subsection{CONTAGION}

The previous section clearly documents the existence of an informational spillover from market $A$ to market $B$. In the literature, financial contagion is usually characterized as "excess correlation" among asset prices; in particular, there is contagion 
between two markets when the correlation between asset prices is greater than that between asset fundamentals: $\operatorname{Corr}\left(P^{A}, P^{B}\right)>\operatorname{Corr}\left(V^{A}, V^{B}\right)$. In our theoretical model, the informational spillover generates contagion: as we discussed above, the correlation between fundamentals is 0.5 , whereas that between prices is 0.71 . Contagion also occurs in the laboratory: across rounds, the correlation between final prices is 0.67 . This is an important result. It shows that the informational contagion predicted by our theoretical model is also the outcome of subjects' interactions in a market setting; in other words, the trading strategies subjects put in place in the laboratory lead to a contagion effect from market $A$ to market $B$.

Not only is the price correlation in the laboratory higher than that between fundamentals, it is also very close to the theoretical one (0.67 is not significantly different from 0.71). ${ }^{36}$ This is somehow surprising since we know from the previous analysis that the prices observed in the laboratory do not fully aggregate private information (whereas the REE prices do). To shed light on this result, recall two observations that we made in the previous section: i) in the two markets, signals are aggregated only partially, and the level of aggregation is (approximately) similar; ii) subjects attach (approximately) the theoretically correct weight to the information coming from market $A$. Intuitively, the first observation implies that, holding constant the informational spillover across markets, the variances of $P^{A}$ and $P^{B}$ and their covariance are lower than what is predicted by the theory. The second observation implies that the reduction in the covariance (with respect to the theoretical one) exactly

\footnotetext{
${ }^{36}$ We regressed the final price in market $B$ on the final price in market $A$ multiplied by the ratio of the standard deviations of the two prices (and on a constant). We cannot reject the null hypothesis that the estimated coefficient, which is equal to the correlation index, is equal to 0.71 using a cluster-robust t statistic- $\mathrm{p}$-value equal to 0.8 .
} 
offsets the reduction in the variances of $P^{A}$ and $P^{B}$, thus leading to a correlation very close to the theoretical one. A simple model in which these two observations hold (with no approximation) is: $P^{A}=\alpha+\beta V^{A}+\varepsilon$ and $P^{B}=\delta+\frac{1}{2} P^{A}+\frac{1}{2} \beta C+\eta$ (with $\alpha$ and $\delta$ being two constants, $0<\beta<1$ and $\varepsilon$ and $\eta$ two uncorrelated error terms). One can prove that, for $\varepsilon=\eta=0$, the correlation is identical to that of our theoretical model (in which $\beta=1$ ). In the experiment, of course, both error terms have a positive variance, but their net effect on the correlation turns out to be negligible. ${ }^{37}$

In other words, in our experiment, the same mechanism as in the theoretical model creates a wedge between price correlation and fundamental correlation. The only difference is that, in the experiment, learning is incomplete to a greater extent than in the model; as a result, variances and covariance between prices are lower than their theoretical counterparts. However, since subjects interpret information coming from the other market correctly (i.e., there is the right level of information spillover), the ratio between price covariance and variances (that is the correlation) is the same as in the theory. As a result, there is correlation among prices in excess of fundamental correlation. ${ }^{38}$

Finally, in the experiment, as in the theoretical model, the information coming from market $A$ increases the market's informational efficiency. Indeed, if subjects in market $B$ had attached zero weight to the information coming from market $A$

\footnotetext{
${ }^{37}$ In Appendix A.2, we show that the correlation is decreasing in the variance of $\eta$ but increasing in the variance of $\varepsilon$.

${ }^{38}$ As explained in Section 2.2, this result does not per se stem from learning being incomplete. One can write a model of incomplete learning where there is no uncertainty on the idiosyncratic or systematic nature of the shock, still the correlation between prices is equal to the correlation between fundamentals.
} 
(i.e., if the coefficient on $E\left(V^{A}\right)$ in the regression reported in Table 7 had been zero), the distance between the price and the fundamental would have been higher. Nevertheless, in the rounds in which the value of asset $B$ differs from that of asset $A$, the information coming from market $A$ is detrimental: the mean distance between price and fundamental in these rounds is 40-higher than 27, the average distance when the asset values are equal. ${ }^{39}$ This shows the negative impact of information contagion: although the information coming from other markets' prices is on average valuable, it becomes counterproductive when price changes reflect idiosyncratic shocks in those markets.

\subsection{INDEPENDENT FUNDAMENTALS AND ABSENCE OF CONTAGION: THE RESULTS OF TREATMENT II}

Until now, we have shown that allowing subjects to observe the history of trades in another market generates financial contagion in the laboratory. This empirical result agrees with the theoretical predictions: indeed, the correlation we obtain in the laboratory is remarkably close to the equilibrium one. One may wonder, however, whether in the laboratory contagion is really generated by informational spillovers, as in the theoretical model, or rather whether it is a mere artifact, caused by subjects in market $B$ being influenced by the trades and prices in market $A$, independently of their information content.

\footnotetext{
${ }^{39}$ The difference is statisitcally significant (Mann-Whitney one-sided test, $\mathrm{p}$-value $=0.09$ ). The average distance across all rounds is 29 .
} 
To tackle this issue, we ran Treatment $I I$, in which we set $p=0$; that is, $V^{A}$ and $V^{B}$ are independently distributed $\left(V^{B}\right.$ being equal to $C$ ). According to the theory, since the asset fundamentals are independent, there should be no information contagion.

In Table 10, we present the same regressions we had discussed in Table 7 for Treatment $I$. The differences between the two treatments are striking. First, both when we look at the behavior of the initial and of the final price, the coefficient on the value of asset $A$ and on its probit expectation are now much smaller than in Treatment $I$, in fact, not significantly different from zero. This is in accordance with theory: there is no evidence of information spillover between markets when asset fundamentals are independent. This result suggests that behavioral biases did not cause the informational contagion observed in Treatment $I$ (as would have been the case if, for instance, subjects in market $B$ were affected by the price in market $A$ independently of its information content); on the contrary, we find evidence that subjects use the information coming from market $A$ only in Treatment $I$, when such information is relevant. ${ }^{40}$

Additionally, when we look at the final prices, the coefficient on $C$ is now much higher than what was reported for Treatment $I$ (0.67 versus 0.28$)$. As a matter of fact, a statistical test reveals that this coefficient is not significantly different from the coefficient on the value of asset $A$ in market $A$ (in either treatment). ${ }^{41}$ This happens because the distribution of $V^{B}$ (equal to $C$ in this treatment) is the same as that of

\footnotetext{
${ }^{40}$ Subjects' behavior in market $A$ is similar to that of Treatment $I$. We report some descriptive statistics and regression results in Appendix $E$.

${ }^{41} \mathrm{In}$ both treatments, that coefficient is 0.55 (see Tables 3 and E2). The p-values for the test that the coefficients in columns 3 and 4 are not different from 0.55 are equal to 0.14 .
} 


\section{Table 10. Regression results for Treatment II}

The table shows the regression results of the initial (final) price of asset $\mathrm{B}$ on $\mathrm{C}$ and on $V^{A}$ in column 1 (4). Columns 2 and 5 show the regression results using the conditional expectation of $V^{A}$ (computed by the probit regression). Columns 3 and 6 show the regression results using the average elicited belief at the end of the round. Standard errors in parentheses are clustered at the session level. *,**,*** denote significance at the 10, 5, 1 percent level, respectively.

\begin{tabular}{|c|c|c|c|c|c|c|}
\hline \multirow{3}{*}{$C$} & \multicolumn{3}{|c|}{ Initial Price (first 5 trades) } & \multicolumn{3}{|c|}{ Final Price (last 5 trades) } \\
\hline & $0.291^{* * *}$ & $0.282^{* * *}$ & $0.281^{* * *}$ & $0.674^{* * *}$ & $0.670^{* * *}$ & $0.668^{* * *}$ \\
\hline & $(0.037)$ & $(0.036)$ & $(0.036)$ & $(0.071)$ & $(0.069)$ & $(0.069)$ \\
\hline$V^{A}$ & $\begin{array}{l}0.052^{*} \\
(0.025)\end{array}$ & & & $\begin{array}{l}0.013 \\
(0.065)\end{array}$ & & \\
\hline$E^{\text {probit }}\left(V^{A} \mid \bar{p}_{A}^{\text {Last5 }}\right)$ & & $\begin{array}{l}-0.025 \\
(0.087)\end{array}$ & & & $\begin{array}{l}-0.146^{*} \\
(0.060)\end{array}$ & \\
\hline Belief & & & $\begin{array}{l}-0.022 \\
(0.073)\end{array}$ & & & $\begin{array}{l}-0.116^{*} \\
(0.050)\end{array}$ \\
\hline Constant & $38.64^{* * *}$ & $42.65^{* *}$ & $42.60^{* * *}$ & $14.43^{*}$ & $21.99^{* *}$ & $20.83^{* *}$ \\
\hline Gollstallt & $(4.621)$ & $(6.435)$ & $(6.023)$ & $(6.900)$ & $(7.102)$ & $(6.700)$ \\
\hline R-squared & 0.427 & 0.414 & 0.414 & 0.627 & 0.640 & 0.637 \\
\hline
\end{tabular}

$V^{A}$, and subjects disregard the information coming from market $A$. Similarly to what we observed in market $A$, in both treatments, private signals are only imperfectly aggregated by the final price (the coefficient on $C$ is less than 1 ).

Given these results, it is not surprising that the correlation between final prices is -0.13 , not statistically different from that between fundamentals (i.e., zero). ${ }^{42}$ In other words, when asset values are independent, we do not observe financial contagion in the laboratory.

To gain more intuition on these aggregate results, we now look at how subjects

\footnotetext{
${ }^{42}$ We cannot reject the null hypothesis that the correlation is equal to 0 (by using the same test discussed in footnote 34$)-\mathrm{p}$-value $=0.13$.
} 
set prices in the two treatments. We regress, separately for the two treatments, the bid and ask prices that subjects posted in market $B$ on their private information and on their elicited belief that $V^{A}=100$; that is, for each treatment, we run the following two regressions:

$$
\begin{gathered}
\operatorname{ask}_{j, i, k}=\alpha+\beta_{1} \operatorname{Signal}_{j, i}+\beta_{2} \text { Belief }_{j, i}+\varepsilon_{j, i, k}, \\
\operatorname{bid}_{j, i, k}=\alpha+\beta_{1} \operatorname{Signal}_{j, i}+\beta_{2} \text { Belief }_{j, i}+\varepsilon_{j, i, k},
\end{gathered}
$$

where $a s k_{j, i, k}\left(b i d_{j, i, k}\right)$ is the $k^{t h}$ observed ask (bid) order posted by subject $j$ in round $i$; $\operatorname{Signal}_{i, j}$ is a dummy variable taking value 1 if subject $j^{\prime}$ s signal in round $i$ is green (i.e., good) and zero otherwise; and Belie $f_{j, i}$ is subject $j$ 's elicited belief in round $i$ (see footnote 27). The results are reported in Table 11. In Treatment I, the posted bid and ask prices are positively and significantly related not only to a subject's private information, but also to his belief about $V^{A}$ (see columns 1 and 2). Subjects' beliefs have a relatively large effect: a 10 unit increase in subjects' beliefs about $V^{A}$ results in, approximately, a 4 unit increase in the bid and in the ask price subjects post in market $B$. In contrast, in Treatment $I I$, while a subject's private information matters, there is no evicence that his assessment of the history of market $A$ does: indeed, the coefficients on subjects' beliefs are not significant both for the bid and the ask prices. We obtain analogous results if we look at the probability that a subject posts a bid rather than an ask as a function of his private information and his belief about $V^{A}$ through a probit regression: 


$$
d_{j, i, k}=\alpha+\beta_{1} \text { Signal }_{j, i}+\beta_{2} \text { Belief }_{j, i}+\varepsilon_{j, i, k},
$$

where $d_{j, i, k}$ is an indicator taking value 1 if the $k^{\text {th }}$ observed quote posted by subject $j$ in round $i$ is a bid. A subject with a high expectation on $V^{A}$ is significantly more likely to post a bid (that is, to try and buy the asset) in Treatment $I$; this effect disappears in Treatment $I I$ (see Table 12$).{ }^{43}$

Taken together, the results of Tables 11 and 12 show that, when posting bid and ask prices, subjects react to the history of trading activity in market $A$ when such history carries information on $V^{B}$ (as in Treatment $I$ ), but disregard it when it does not (as in Treatment $I I$ ). As a result of their behavior, we observe contagion in Treatment $I$ but not in Treatment $I I$.

\footnotetext{
${ }^{43}$ We obtain very similar results (available on request) if we run a logit regression or a linear probability model.
} 
Table 11. Bid and Ask prices conditional on subjects' private signal and belief

The table shows the results from a regression of ask and bid prices on a subject's belief about the value of good A and on a dummy equal to one if his private signal is green (i.e., good). Standard errors in parentheses are clustered at the session level. *, **, *** denote significance at the 10, 5, 1 percent level, respectively.

\begin{tabular}{lcccc}
\hline & \multicolumn{2}{c}{ Treatment $I$} & \multicolumn{2}{c}{ Treatment $I I$} \\
\hline \multirow{3}{*}{ Green Signal } & \multicolumn{1}{c}{ Bid } & Ask & Bid & Ask \\
\cline { 2 - 5 } & $13.82^{* *}$ & $10.75^{* *}$ & $32.60^{* *}$ & $22.73^{* *}$ \\
\multirow{3}{*}{ Belief } & $(4.835)$ & $(3.101)$ & $(5.167)$ & $(4.163)$ \\
& $0.425^{* *}$ & $0.376^{* *}$ & $-0.051^{*}$ & -0.076 \\
Constant & $(0.118)$ & $(0.080)$ & $(0.023)$ & $(0.043)$ \\
\multirow{2}{*}{ R-squared } & $13.91^{* *}$ & $29.56^{* * *}$ & $28.57^{* *}$ & $42.89^{* * *}$ \\
$N$ & $(3.16)$ & $(2.61)$ & $(5.65)$ & $(5.01)$ \\
& 0.333 & 0.284 & 0.192 & 0.098 \\
\hline
\end{tabular}

Table 12. Probability of posting a bid conditional on subjects' private signal and belief

The table shows the results from a probit regression of a dummy equal to one if the quote posted by a subject is a bid on a dummy equal to one if his private signal is green (i.e., good) and on his belief about the value of good A. Standard errors in parentheses are clustered at the session level. $*, * *, * * *$ denote significance at the 10, 5, 1 percent level, respectively.

\begin{tabular}{lcc}
\hline & Treatment $I$ & Treatment $I I$ \\
\hline \multirow{2}{*}{ Green Signal } & $0.345^{* * *}$ & $0.571^{* * *}$ \\
& $(0.024)$ & $(0.071)$ \\
Belief & $0.004^{* * *}$ & -0.001 \\
& $(0.001)$ & $(0.001)$ \\
Constant & $-0.494^{* * *}$ & $-0.380^{* * *}$ \\
$N$ & $(0.059)$ & $(0.048)$ \\
$N$ & 4,902 & 5,253 \\
\hline
\end{tabular}




\section{Conclusions}

In actual financial markets, traders often interpret price movements in one market as conveying information about asset fundamental values in other markets. In an influential paper, King and Wadhwani (1990) showed that, in a Rational Expectations Equilibrium, these informational spillovers across financial markets generate financial contagion, a well-established empirical regularity. We tested the predictions of King and Wadhwani (1990) in the laboratory. Our work supports the predictions of the theory. Although in the laboratory private information is not perfectly aggregated, subjects are able to use the information coming from the other market correctly. As a result, the correlation between asset prices is very close to the theoretical one. In principle, behavioral biases may lead subjects to under-react to the information coming from another market (and focus, instead, on the information about their own market) or, on the contrary, to overreact to it (for instance, a price decline in another market may cause subjects to be more prone to sell); this, however, does not happen in our experiment. Moreover, in the laboratory, we do not observe contagion when theory suggests we should not, that is, when the history of trades and prices in the other market conveys no relevant information. Overall, our experimental results show that the Rational Expectations Equilibrium performs remarkably well in describing financial contagion and the comovement among asset prices gener-

ated by informational spillovers. As a result, in future work with field data, one can study informational contagion with higher confidence that the Rational Expectations Equilibrium provides a good explanation of asset price comovements. 


\section{References}

[1] Allen, F. and Gale, D. (2000) Financial Contagion, Journal of Political Economy 108, 1-33.

[2] Allen, F. and D. Gale (2008) An introduction to financial crises, in: F. Allen and D. Gale, (eds.), Financial Crises, in The International Library of Critical Writings in Economics 218, (series editor: Mark Blaug), Edward Elgar, Cheltenham, pp 3-32.

[3] Bekaert, G., Harvey, C.R., and Ng, A. (2005) Market Integration and Contagion, The Journal of Business 78, 39-69.

[4] Bossaerts, P., Plott, C., and Zame, W. R. (2007) Prices and portfolio choices in financial markets: Theory, econometrics, experiments, Econometrica 75, 9931038.

[5] Boyer, B. H., Gibson, M. S., and Loretan, M. (1999) Pitfalls in tests for changes in correlations, International finance discussion paper 597, Board of Governors of the Federal Reserve System.

[6] Cason, T. and Friedman, D. (1999) Price formation and exchange in thin markets: A laboratory comparison of institutionsm, in: E. de Antoni, P. Howitt and A. Leijonhufvud (eds.), Money, Markets and Method: Essays in Honour of Robert W. Clower, Edward Elgar, Cheltenham, pp. 155-179. 
[7] Calvo, G. A. (2004) Contagion in emerging markets: When Wall Street is a carrier, in: E. Bour, D. Heymann and F. Navajas (eds), Latin American Economic Crises, Palgrave Macmillan, pp. 81-91.

[8] Cipriani, M., Gardenal, G., and Guarino, A. (2013) Financial contagion in the laboratory: The cross-market rebalancing channel, Journal of Banking $\&$ Finance 37, 4310-4326.

[9] Cipriani, M. and Guarino, A. (2005) Herd behavior in a laboratory financial market, American Economic Review 95, 1427-1443.

[10] Cipriani, M. and Guarino, A. (2008) Herd behavior and contagion in financial markets, B.E. Journal of Theoretical Economics (Contributions) 8, Article 24.

[11] Cipriani, M. and Guarino, A. (2009) Herd behavior in financial markets: An experiment with financial market professionals, Journal of the European Economic Association 7, 206-233.

[12] Copeland, T. E. and Friedman, D. (1991) Partial revelation of information in experimental asset markets, Journal of Finance 46, 265-295.

[13] De Bandt, O. and Hartmann, P. (2000) Systemic risk: A survey, ECB Working Paper 35.

[14] Drehmann, M., Oechssler, J., and Rider, A. (2005) Herding and contrarian behavior in financial markets: An internet experiment, American Economic Review 95, 1403-1426. 
[15] Edwards, S. and Rigobon, R. (2002) Currency crisis and contagion: An introduction, Journal of Development Economics 69, 307-313.

[16] Ehrmann, M., Fratzscher, M., and Rigobon, R. (2011) Stocks, bonds, money markets and exchange rates: Measuring international financial transmission, Journal of Applied Econometrics 26, 948-974.

[17] Eichengreen, B., Rose, A., and Wyplosz, C. (1996) Contagious currency crisis, The Scandinavian Journal of Economics 98, 463-484.

[18] Forbes, K. and Rigobon, R. (2001) Measuring contagion: conceptual and empirical issues, in: S. Claessens and K. J. Forbes (eds.), International financial contagion, Springer, Norwell, pp. 43-66.

[19] Forbes, K. J. and Rigobon, R. (2002) No contagion, only interdependence: measuring stock market comovements, The Journal of Finance 57, 2223-2261.

[20] Forsythe, R., and Lundholm, R. (1990) Information aggregation in an experimental market, Econometrica 58, 309-347.

[21] Fostel, A. and Geanakoplos, J. (2008) Leverage cycles and the anxious economy, American Economic Review 98, 1211-1244.

[22] Friedman, D. (1993) How trading institutions affect financial market performance: Some laboratory evidence, Economic Inquiry 31, 410-435.

[23] Friedman, D. and Sunder, S. (1994) Experimental methods: A primer for economists, Cambridge University Press, Cambridge, UK. 
[24] Glosten, L. and Milgrom, P. (1985) Bid, ask and transaction prices in a specialist market with heterogeneously informed traders, Journal of Financial Economics 14, $71-100$.

[25] Grossman, S. J. (1976) On the efficiency of competitive stock markets where trades have diverse information, Journal of Finance 31, 573-585.

[26] Grossman, S. J. (1978) Further results on the informational efficiency of competitive stock markets, Journal of Economic Theory 18, 81-101.

[27] King, M. and Wadhwani, S. (1990) Transmission of volatility between stock markets, Review of Financial Studies 3, 5-33.

[28] Knyazeva, A., Knyazeva, D., and Stiglitz, J. (2012) Crises and contagion: A survey, in: B. Lucey, C. Larkin and C. Gurdgiev (eds.), What if Ireland Defaults, Orpen Press, Dublin, Chapter 2.

[29] Kodres, L. and Pritsker, M. (2002) A rational expectations model of financial contagion, Journal of Finance 57, 769-799.

[30] Kyle, A. and Xiong, W. (2001) Contagion as a wealth effect, Journal of Finance 56, $1401-1440$.

[31] Longstaff, F. (2010) The subprime credit crisis and contagion in financial markets, Journal of Financial Economics 97, 436-450.

[32] Pavlova, A. and Rigobon, R. (2007) The role of portfolio constraints in the international propagation of shocks, Review of Economic Studies 75, 1215-1256. 
[33] Pericoli, M. and Sbracia, M. (2003) A primer on financial contagion, Journal of Economic Surveys 17, 571-608.

[34] Plott, C. R. and Sunder, S. (1982) Efficiency of experimental security markets with insider information: An application of rational-expectations models, Journal of Political Economy 56, 663-698.

[35] Plott, C. R. and Sunder, S. (1988) Rational expectations and the aggregation of diverse information in laboratory security markets, Econometrica 56, 1085-1118.

[36] Smith, V. (1962) An experimental study of competitive market behavior, Journal of Political Economy 70, 111-137.

[37] Smith, V. (1964) The effect of market organization on competitive equilibrium, Quarterly Journal of Economics 78, 181-201.

[38] Smith, V. L., Williams, A. W., Bratton, W. K., and Vannoni, M. G. (1982) Competitive market institutions: Double auctions vs. sealed bid-offer auctions, American Economic Review 72, 58-77.

[39] Trevino, I. (2016) Informational channels of financial contagion, Unpublished working paper, University of California, San Diego.

[40] Yuan, K. (2005) Asymmetric price movements and borrowing constraints: A REE model of crisis, contagion, and confusion, Journal of Finance 60, 379-411.

[41] Ziegelmeyer, A., March, C., and Krügel, S. (2013) Do we follow others when we should? A simple test of rational expectations: Comment, The American Economic Review 103, 2633-2642. 


\section{Appendix (for online publication)}

\section{Appendix A: Theoretical Results}

\section{Appendix A.1: REE derivation}

In this appendix, we derive the REE for the case of $p=0.5$ (as in Treatment $I$ of the experiment); the derivation of the REE equilibrium for $p=0$ (as in Treatment II of the experiment) is similar. The analysis follows the logic of Grossman (1976) and Grossman (1978), although applied to a much simpler setup. In order to find the REE, let us first define the Private Information Equilibrium (PIE), that is, the equilibrium in which each agent only uses his private information and neglects the information contained in the price. Figure $A 1$ shows the PIE in market $A$ when $V^{A}=0$. Since the precision of the private signal is 0.75 and 8 agents trade in market $A, 6$ agents evaluate the asset at 25 liras and 2 agents evaluate it at 75 liras. Bearing in mind that each agent is endowed with 4 units of the asset and 500 liras, supply and demand curves are easily derived. For instance, let us consider the supply curve. At a price lower than 25, no agent is willing to supply the asset. At a price of 25, 6 agents are just indifferent between holding and selling the asset (the maximum supply is, therefore, 24 units). At any price between 25 and 75 , these 6 agents supply all their endowment. At a price of 75, also the other 2 agents become weakly willing to supply the asset. For a price higher than 75 , all 32 units are supplied. The PIE price is 41.7, where demand and supply cross. A similar analysis shows that the PIE price when $V^{A}=100$ is 75 (as illustrated in Figure A2). Of course, these two prices cannot be a REE. Indeed from the first price, agents infer that the value is 0 and from the second, that it is 100 . Therefore in the first case demand and supply become those illustrated in Figure $A 3$; and 
in the second case they look like in Figure $A 4$. The REE prices are 0 and 100 respectively.

The analysis for market $B$ follows the same logic. In Figure $A 5$ we shows the REE (assuming $p=0.5$ ) when $V^{A} \neq C$. The equilibrium price becomes 50 .

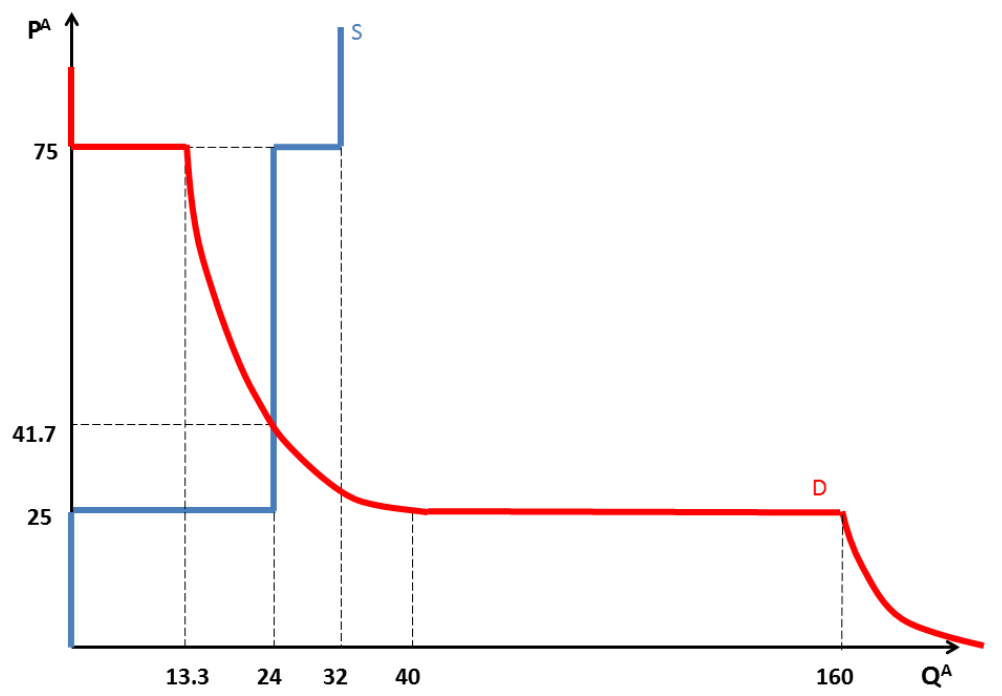

Figure A1. Private Information Equilibrium conditional on $V^{A}=0$ 


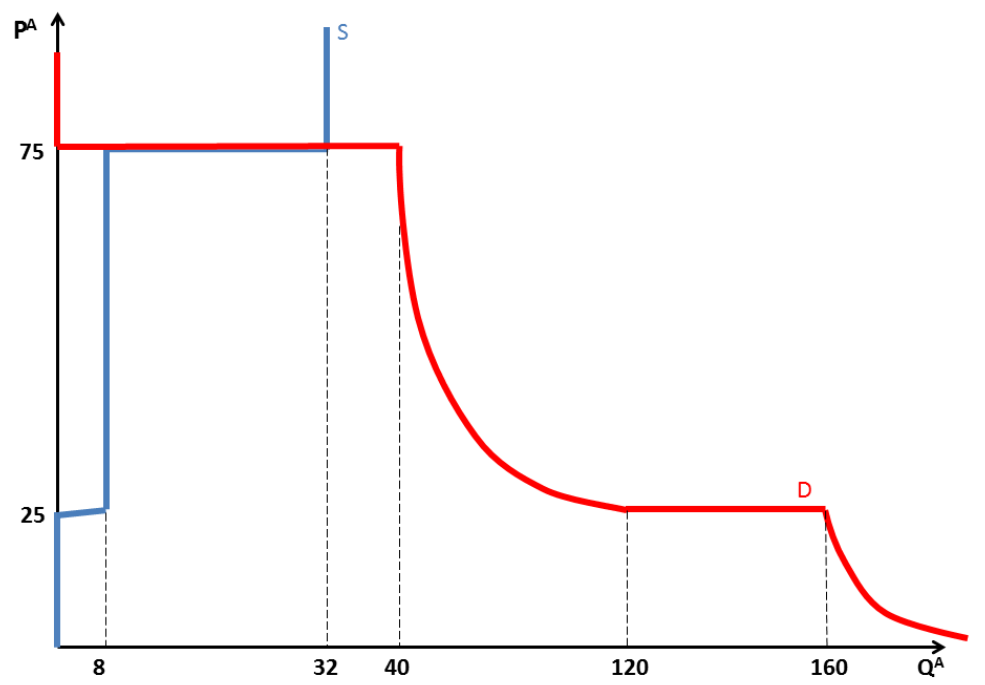

Figure A2. Private Information Equilibrium conditional on $V^{A}=100$

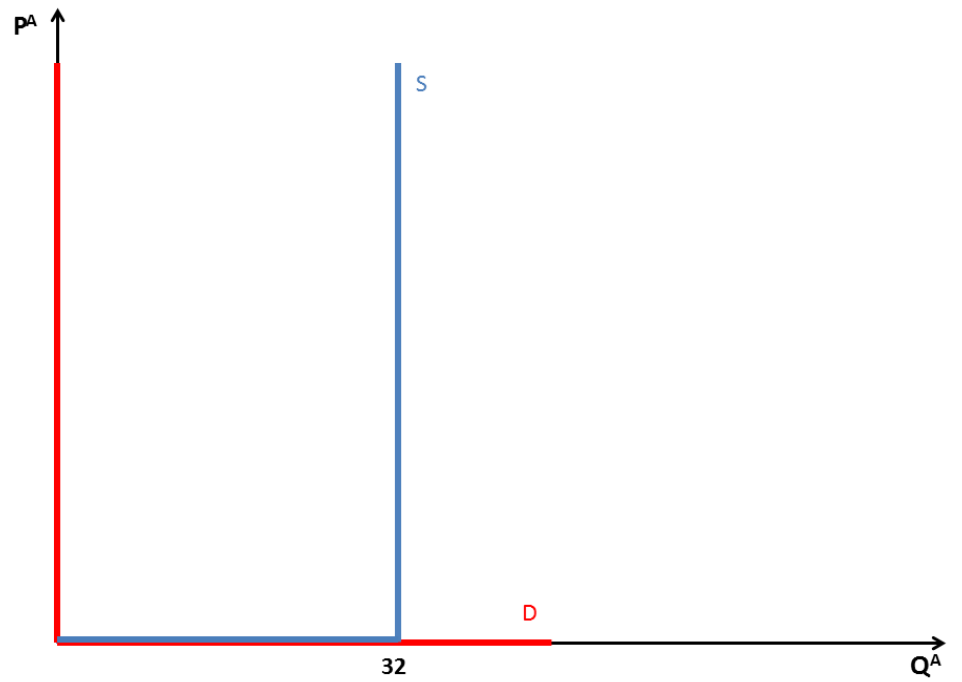

Figure A3. Rational Expectations Equilibrium conditional on $V^{A}=0$ 


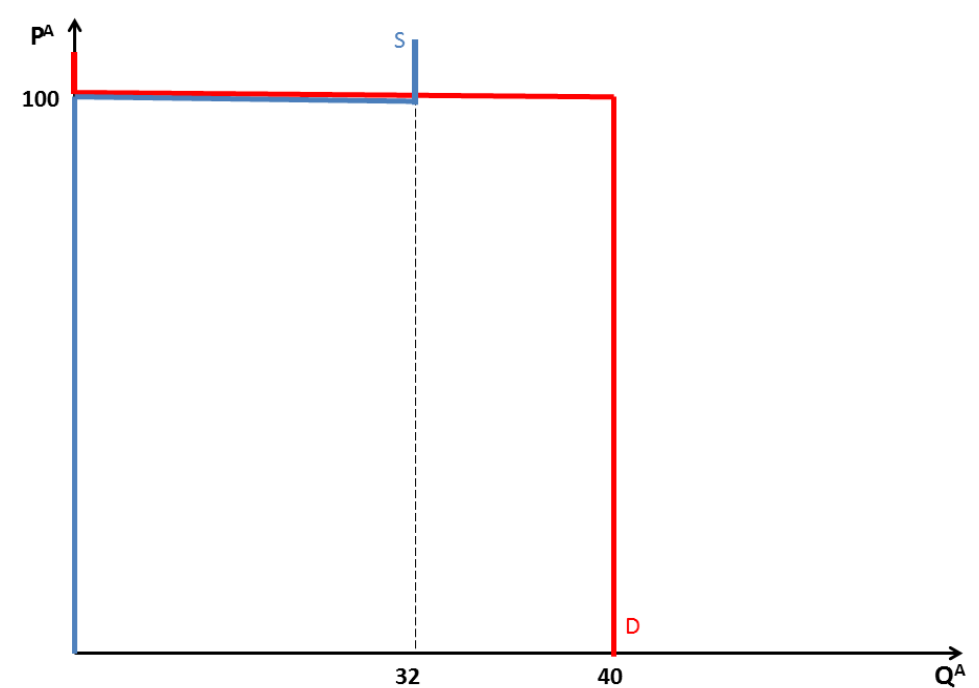

Figure A4. Rational Expectations Equilibrium conditional on $V^{A}=100$

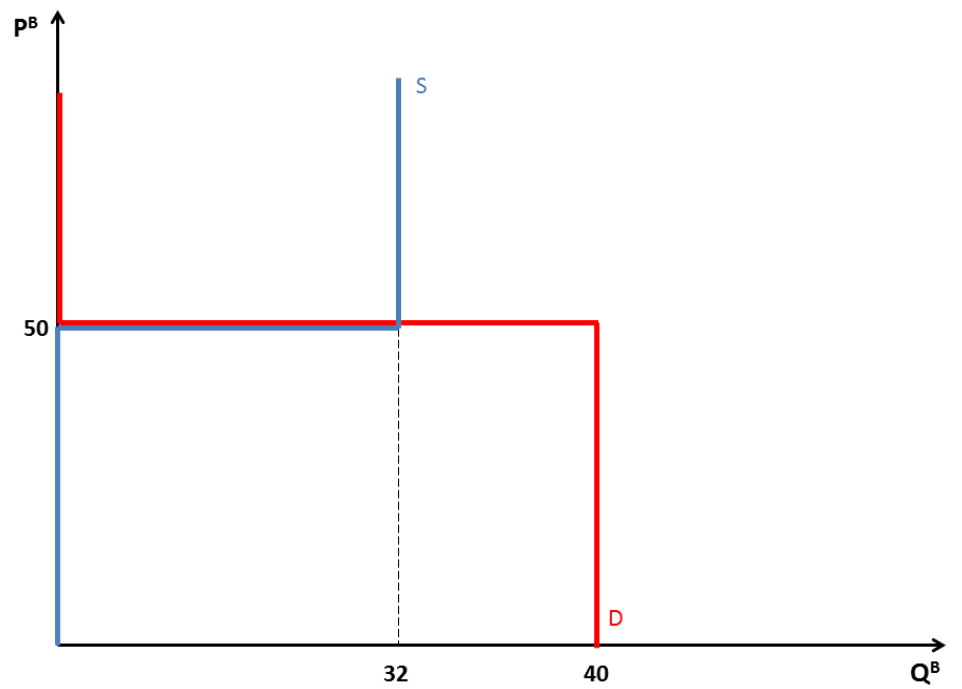

Figure A5. Rational Expectations Equilibrium conditional on $V^{A} \neq C$. 


\section{Appendix A.2: Correlations}

In this section, we compute the correlation coefficients presented in Section 2.2. First, let us derive the correlation between the fundamentals. To do so, we compute the variances and covariance of $V^{A}$ and $V^{B}$ :

$$
\begin{aligned}
& \operatorname{Var}\left(V^{A}\right)=E\left(V^{A^{2}}\right)-\left[E\left(V^{A}\right)\right]^{2}=\frac{1}{2} 100^{2}-50^{2}=2500 \\
& \operatorname{Var}\left(V^{B}\right)=E\left(V^{B^{2}}\right)-\left[E\left(V^{B}\right)\right]^{2}= \\
& E\left(V^{B^{2}} \mid V^{B}=V^{A}\right) \operatorname{Pr}\left(V^{B}=V^{A}\right)+E\left(V^{B^{2}} \mid V^{B}=C\right) \operatorname{Pr}\left(V^{B}=C\right)-\left[E\left(V^{B}\right)\right]^{2}= \\
& \frac{1}{2} 100^{2} p+\frac{1}{2} 100^{2}(1-p)-50^{2}=2500=\operatorname{Var}\left(V^{A}\right) \\
& \operatorname{Cov}\left(V^{A}, V^{B}\right)=\operatorname{Cov}\left(V^{A}, V^{B} \mid V^{B}=V^{A}\right) \operatorname{Pr}\left(V^{B}=V^{A}\right)+\operatorname{Cov}\left(V^{A}, V^{B} \mid V^{B}=C\right) \operatorname{Pr}\left(V^{B}=C\right)= \\
& \operatorname{Var}\left(V^{A}\right) p+0(1-p)=p \operatorname{Var}\left(V^{A}\right)
\end{aligned}
$$

Therefore, the correlation coefficient between fundamentals is:

$$
\operatorname{Corr}\left(V^{A}, V^{B}\right)=\frac{p \operatorname{Var}\left(V^{A}\right)}{\sqrt{\operatorname{Var}\left(V^{A}\right)} \sqrt{\operatorname{Var}\left(V^{A}\right)}}=p .
$$

We now turn to the computation of the correlation coefficient between prices. In the REE, $P^{A}=V^{A}$ and $P^{B}=p V^{A}+(1-p) C$. Therefore, variances and covariance are: 


$$
\operatorname{Var}\left(P^{A}\right)=\operatorname{Var}\left(V^{A}\right)=2500
$$

$$
\begin{gathered}
\operatorname{Var}\left(P^{B}\right)=\operatorname{Var}\left(p V^{A}+(1-p) C\right)= \\
p^{2} \operatorname{Var}\left(V^{A}\right)+(1-p)^{2} \operatorname{Var}(C)+2 \operatorname{Cov}\left(V^{A}, C\right)=\operatorname{Var}\left(V^{A}\right)\left(1-2 p+2 p^{2}\right)
\end{gathered}
$$

$$
\begin{aligned}
& \operatorname{Cov}\left(P^{A}, P^{B}\right)=\operatorname{Cov}\left(V^{A}, p V^{A}+(1-p) C\right)= \\
& p \operatorname{Var}\left(V^{A}\right)+(1-p) \operatorname{Cov}\left(V^{A}, C\right)=p \operatorname{Var}\left(V^{A}\right)
\end{aligned}
$$

The correlation coefficient between prices is therefore given by

$$
\operatorname{Corr}\left(P^{A}, P^{B}\right)=\frac{p \operatorname{Var}\left(V^{A}\right)}{\sqrt{\operatorname{Var}\left(V^{A}\right)} \sqrt{\operatorname{Var}\left(V^{A}\right)\left(1-2 p+2 p^{2}\right)}}=\frac{p}{\sqrt{\left(1-2 p+2 p^{2}\right)}} .
$$

It is easy to verify that $\frac{p}{\sqrt{\left(1-2 p+2 p^{2}\right)}}>p$ for all $0<p<1$.

For $p=0.5, \operatorname{Corr}\left(P^{A}, P^{B}\right)=0.71$.

Now we turn to the computation of the correlation coefficient for the model presented in Section 4.4 .

Consider the case in which the prices in both markets aggregates the information only partially. In particular, suppose that

$$
P^{A}=\alpha+\beta V^{A} \text { and }
$$




$$
P^{B}=\delta+p P^{A}+(1-p) \beta C .
$$

In this case, the variances of the prices and their covariance can be expressed as follows:

$$
\operatorname{Var}\left(P^{A}\right)=\beta^{2} \operatorname{Var}\left(V^{A}\right)
$$

$$
\operatorname{Var}\left(P^{B}\right)=\beta^{2} \operatorname{Var}\left(p V^{A}+(1-p) C\right)=\beta^{2}\left(1-2 p+2 p^{2}\right) \operatorname{Var}\left(V^{A}\right)
$$

$$
\begin{gathered}
\operatorname{Cov}\left(P^{A}, P^{B}\right)=\operatorname{Cov}\left(\beta V^{A}, \beta\left(p V^{A}+(1-p) C\right)\right)= \\
\beta^{2}\left[p \operatorname{Var}\left(V^{A}\right)+(1-p) \operatorname{Cov}\left(V^{A}, C\right)\right]=\beta^{2} p \operatorname{Var}\left(V^{A}\right) .
\end{gathered}
$$

Therefore, the correlation coefficient is

$$
\operatorname{Corr}\left(P^{A}, P^{B}\right)=\frac{\beta^{2} p \operatorname{Var}\left(V^{A}\right)}{\sqrt{\beta^{2} \operatorname{Var}\left(V^{A}\right)} \sqrt{\beta^{2}\left(1-2 p+2 p^{2}\right) \operatorname{Var}\left(V^{A}\right)}}=\frac{p}{\sqrt{\left(1-2 p+2 p^{2}\right)}}
$$

which is equal to the correlation obtained above for the REE. The partial information aggregation does not affect the correlation since it affects variances and covariance in the same way.

Finally, we compute the correlation coefficient when

$$
P^{A}=\alpha+\beta V^{A}+\varepsilon
$$

and 


$$
P^{B}=\delta+\frac{1}{2} P^{A}+\frac{1}{2} \beta C+\eta
$$

(note that, consistently with the text, we are considering the case in which $\left.p=\frac{1}{2}\right)$.

In this case, the variances of the prices and their covariance can be expressed as follows:

$$
\begin{gathered}
\operatorname{Var}\left(P^{A}\right)=\beta^{2} \operatorname{Var}\left(V^{A}\right)+\operatorname{Var}(\varepsilon) . \\
\operatorname{Var}\left(P^{B}\right)=\frac{1}{4} \beta^{2} \operatorname{Var}\left(V^{A}\right)+\frac{1}{4} \operatorname{Var}(\varepsilon)+\frac{1}{4} \beta^{2} \operatorname{Var}(C)+\operatorname{Var}(\eta) \\
\operatorname{Cov}\left(P^{A}, P^{B}\right)=\frac{1}{2} \beta^{2} \operatorname{Var}\left(V^{A}\right)+\frac{1}{2} \operatorname{Var}(\varepsilon) .
\end{gathered}
$$

Therefore, the correlation coefficient is

$$
\begin{gathered}
\operatorname{Corr}\left(P^{A}, P^{B}\right)= \\
\frac{\beta^{2} \operatorname{Var}\left(V^{A}\right)+\operatorname{Var}(\varepsilon)}{\sqrt{\left(\left(\beta^{2} \operatorname{Var}\left(V^{A}\right)+\operatorname{Var}(\varepsilon)\right)\left(2 \beta^{2} \operatorname{Var}\left(V^{A}\right)+\operatorname{Var}(\varepsilon)+4 \operatorname{Var}(\eta)\right)\right.}} .
\end{gathered}
$$

Finally note that this expression is decreasing in $\operatorname{Var}(\eta)$ but increasing in $\operatorname{Var}(\varepsilon)$. 


\section{Appendix B: Results for the training phase of the experiment}

Recall that in each session, and for both treatments, there was a training phase with the purpose of familiarizing subjects with the trading platform. The training phase consisted of 10 rounds of trading in one market; the trading protocol was identical to the one we used for market $A$ in the real experiment.

In this appendix, we show that the training phase was useful for subjects to familiarize themselves with the trading platform and to learn how to trade in a market. To this aim, we compare how the private information was aggregated in the first and in the last five rounds of the training phase. Since the training phase was identical in Treatment $I$ and $I I$, we pooled together all rounds from both treatments. Figures $B 1$ and $B 2$ show the distance of the final price from the asset fundamental value in the first and in the last five rounds, respectively. As can be easily observed, the price aggregates private information to a greater extent in the last five rounds. A Kolmogorov-Smirnov test confirms this result: the hypothesis that the two distributions in Figures $B 1$ and $B 2$ are the same is rejected (p-value equal to 0.001$)$. 


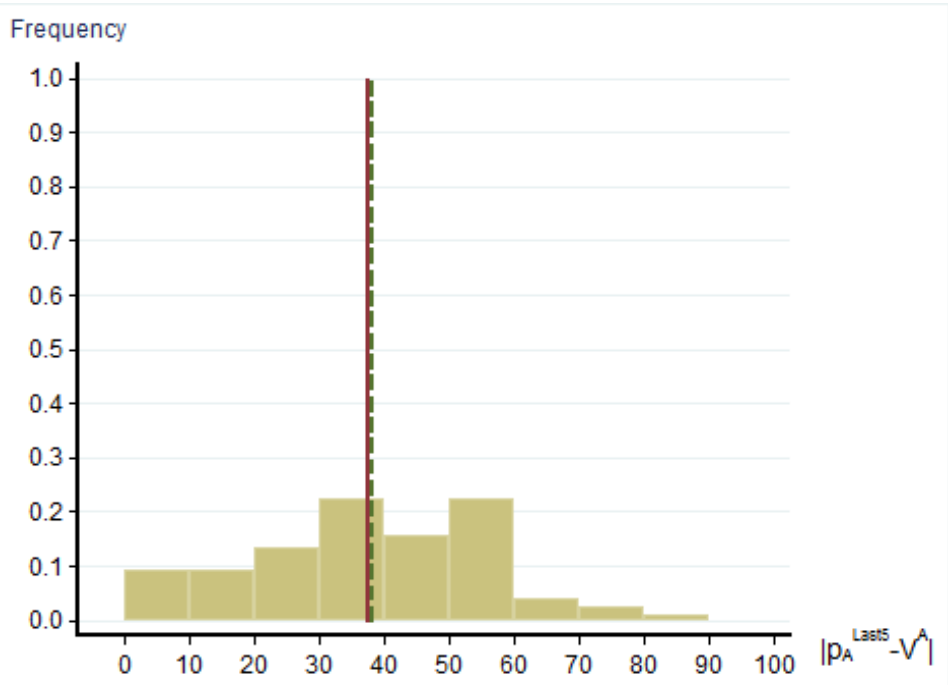

Figure B1. Distance between the final price and $V^{A}$ in the first five rounds of the training phase. The final price is defined as the average of the last five trade prices in a round. The mean is indicated by the solid line; the median by the dashed line.

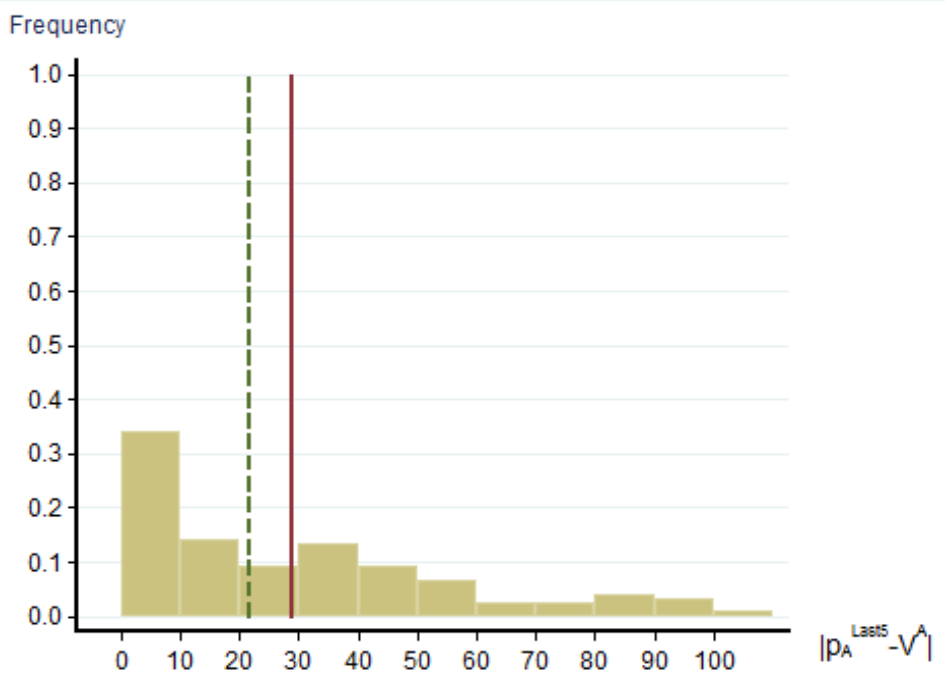

Figure B2. Distance between the final price and $V^{A}$ in the last five rounds of the training phase. The final price is defined as the average of the last five trade prices in a round. The mean is indicated by the solid line; the median by the dashed line. 


\section{Appendix C: Additional Results for Section 4.1}

\section{Appendix C.1: Probit regression of $V^{A}$ on the final price}

In this subsection, we describe the probit regression that we use to estimate the conditional expected value of $V^{A}$. In our main specification, we run the following regression:

$$
I\left(V_{i}^{A}=100\right)=\alpha+\beta \bar{p}_{A, i}^{L a s t 5}+\varepsilon_{i}
$$

where $I\left(V_{i}^{A}=100\right)$ is an indicator for $V^{A}$ being equal to 100 in round $i, \bar{p}_{A, i}^{L a s t 5}$ is the average final price of asset $A$ in round $i$ and $\varepsilon_{i} \sim N\left(0, \sigma^{2}\right)$ is a normally distributed error term. The results of this regression are reported in the first column of Table $C 1$. The results reported in columns 2 to 5 of the same Table are from probit regressions in which we replace $\bar{p}_{A, i}^{L a s t 5}$ with the trade imbalance "TI," defined as the difference between the total number of trades that occurred at the prevailing ask price (buys) and the total number of trades that occurred at the prevailing bid price (sells); the quote imbalance "QI," defined as the difference between the total number of buy offers (bids) and the total number of sell offers (asks) (column 3); the average final price and the trade imbalance (column 4); and the average final price and the quote imbalance (column 5). In order to compare across specifications, we also report measures of goodness of fit for each probit model that we have estimated. In particular, we computed:

- Mc Fadden's $R$-squared, $R_{M F}^{2}=1-\frac{\log L}{\log L_{0}}$, where $L$ is the likelihood function of the (unrestricted) probit and $L_{0}$ is the likelihood function of the restricted probit model in which $\beta=0$ 
- $R^{2}=\frac{1}{N} \sum_{i=1}^{N}\left[I\left(V_{i}^{A}=100\right) \Phi\left(\frac{\alpha-\beta \bar{p}_{A, i}^{L a s t 5}}{\sigma}\right)+\left(1-I\left(V_{i}^{A}=100\right)\right)\left(1-\Phi\left(\frac{\alpha-\beta \bar{p}_{A, i}^{L a s t 5}}{\sigma}\right)\right)\right]$ where $\Phi$ is the cdf of $\varepsilon$

$$
\begin{aligned}
& \text { - } D_{1}=\sqrt{\frac{1}{N} \sum_{i=1}^{N}\left[V_{i}^{A}-E\left(V_{i}^{A}\right)\right]^{2}}, \\
& \text { - } D_{2}=\frac{1}{N} \sum_{i=1}^{N}\left|V_{i}^{A}-E\left(V_{i}^{A}\right)\right| .
\end{aligned}
$$

Table C1. Probit regressions for market A

The table shows the results of a probit regression of asset A' $\mathrm{s}$ value on: the final price (column 1); the trade imbalance TI (column 2); the quote imbalance QI (column 3); the final price and the trade imbalance (column 4); the final price and the quote imbalance (column 5). $R_{M F}^{2}$ denotes Mc Fadden's R squared and $R^{2}, D_{1}, D_{2}$ are defined as above. Standard errors in parentheses are clustered at the session level. ${ }^{*},{ }^{* *},{ }^{* *}$ denote significance at the $10,5,1$ percent level, respectively.

\begin{tabular}{lccccc}
\hline & $(1)$ & $(2)$ & $(3)$ & $(4)$ & $(5)$ \\
\hline $\bar{p}_{A}^{\text {Last } 5}$ & $0.029^{* * *}$ & & & $0.031^{* * *}$ & $0.020^{*}$ \\
& $(0.007)$ & & & $(0.005)$ & $(0.011)$ \\
$T I$ & & $0.086^{* *}$ & & -0.018 & \\
& & $(0.041)$ & & $(0.038)$ & \\
$Q I$ & & & $0.058^{* * *}$ & & 0.026 \\
& & & $(0.013)$ & & $(0.017)$ \\
Constant & $-1.164^{* * *}$ & 0.160 & $0.661^{* * *}$ & $-1.237^{* * *}$ & -0.560 \\
& $(0.294)$ & $(0.128)$ & $(0.166)$ & $(0.214)$ & $(0.589)$ \\
\hline$R_{M F}^{2}$ & 0.406 & 0.125 & 0.361 & 0.409 & 0.436 \\
$R^{2}$ & 0.758 & 0.609 & 0.732 & 0.760 & 0.770 \\
$D_{1}$ & 34.842 & 44.205 & 36.374 & 34.768 & 34.096 \\
$D_{2}$ & 4.915 & 6.256 & 5.174 & 4.901 & 4.791 \\
\hline & & & & & \\
\hline
\end{tabular}

\section{Appendix C.2: Price convergence in market A}

In this subsection we replicate Figure 1, by showing the histograms of the distance between the final price of asset $A$ and the fundamental value using different definitions for the final price. In Figure $C 1$ the final price is computed as the 
average of the last three trade prices in a round. In Figure $C 2$ it is computed as the average of the trade prices in the last 30 seconds of trade in a round.

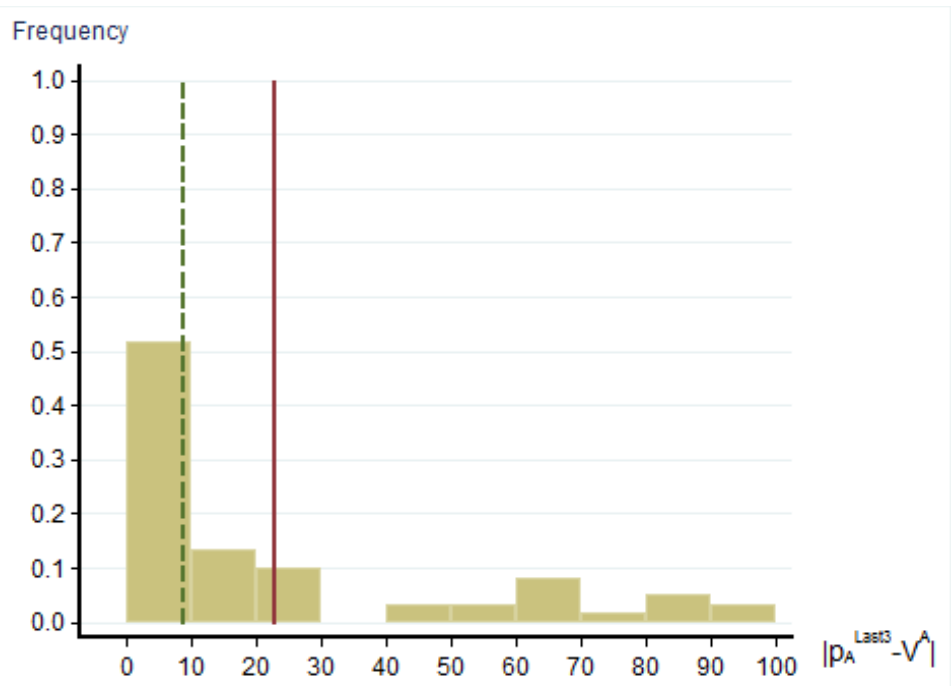

Figure C1. Per-round distance between the final price and $V^{A}$. The final price is defined as the average of the last three trade prices in a round. The mean is indicated by the solid line; the median by the dashed line. 


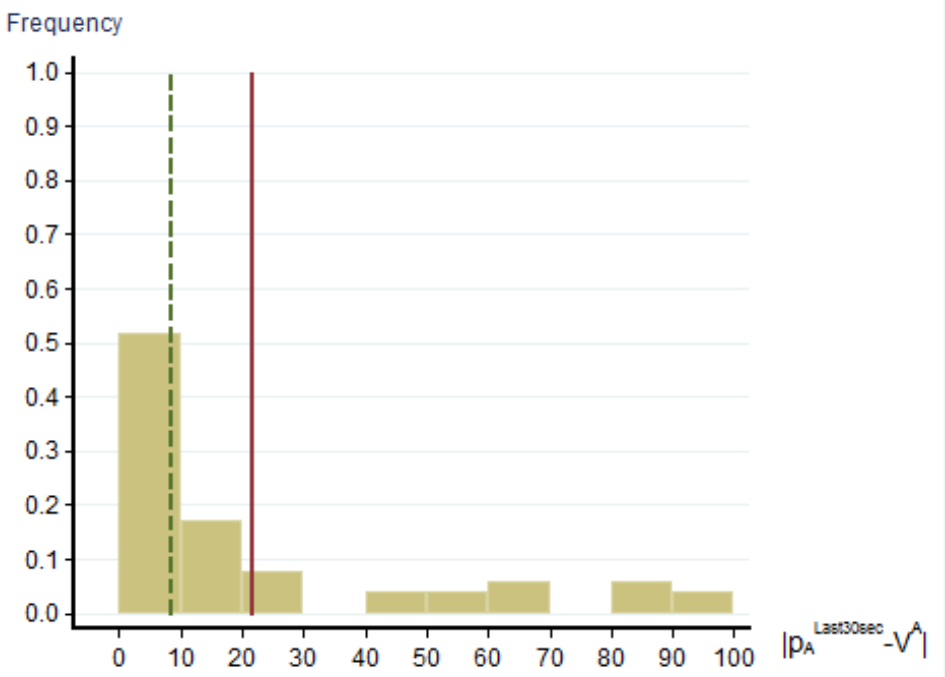

Figure C2. Per-round distance between the final price and $V^{A}$. The final price is defined as the average trade prices in the last 30 seconds of trade in a round. The mean is indicated by the solid line; the median by the dashed line.

\section{Appendix C.3: Price convergence in market A; trade and quote time}

This subsection replicates the convergence result of Figure 3 in trade time (Figure $C 3$ ) and quote time (Figure $C 4$ ).

Note that the right tail of Figure $C 4$ is based on a small number of observations: the number of quotes was higher than 90 in $3 \%$ of the rounds only. In $88 \%$ of the rounds, the number of quotes was not higher than 80 . 


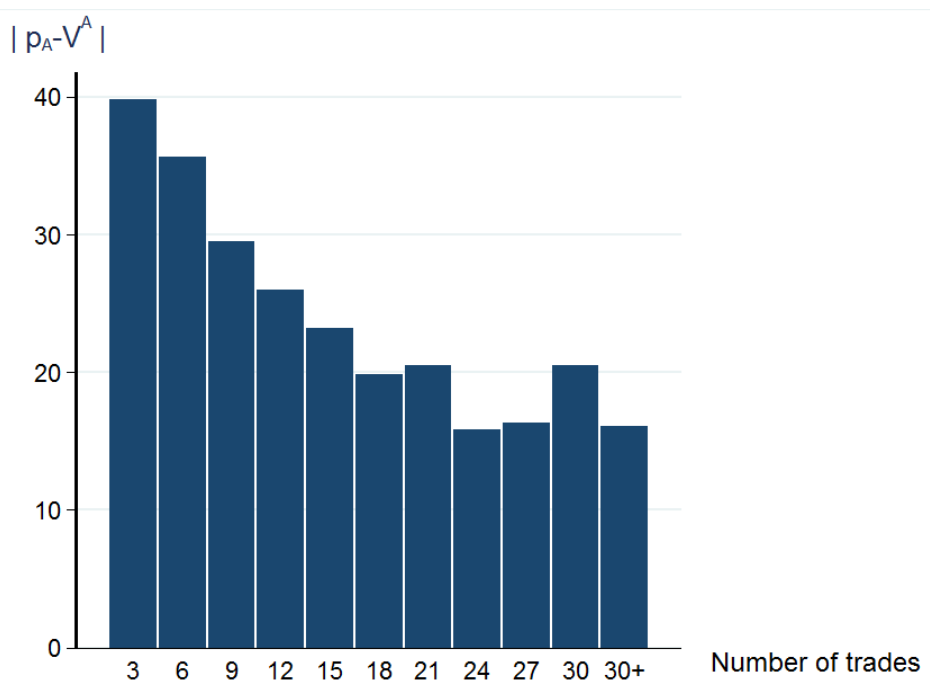

Figure C3. Distance of the price of asset $A$ from $V^{A}$ in trade times. The figure shows the average distance between the trading price and the asset fundamental value for transactions $1-3,4-6,7-9$, etc. 


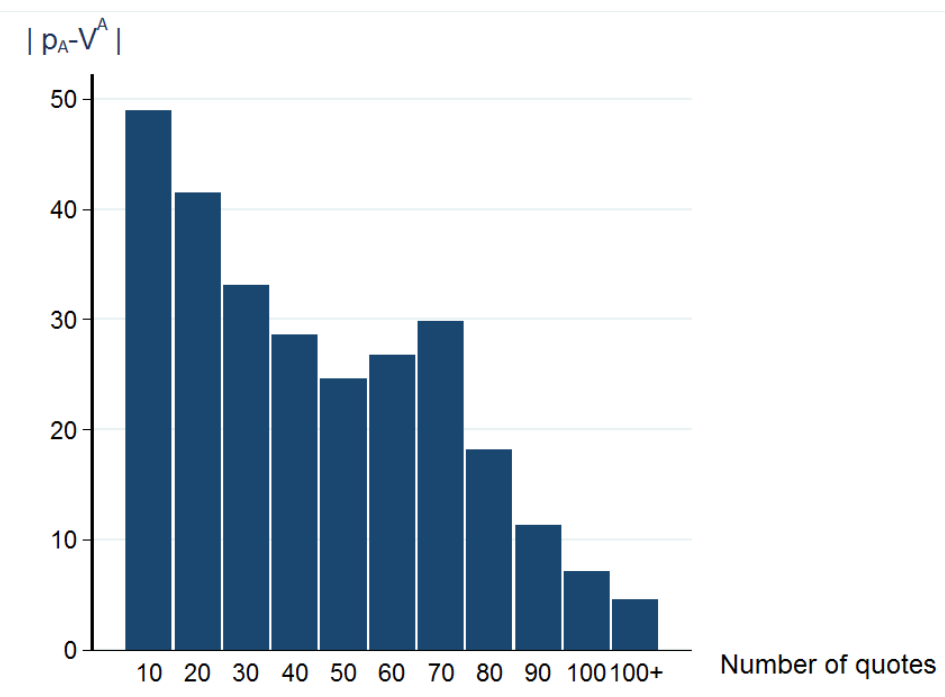

Figure C4. Distance of the price of asset $A$ from $V^{A}$ in quote times. The figure shows the average distance between the trading price and the asset fundamental value for quotes 1-10, 11-20, 21-30, etc.

Appendix C.4: Price convergence in market A conditional on high or low fundamental values

This subsection replicates Figure 1 and Table 2 separately for the case of $V^{A}=$ 0 and $V^{A}=100$. See Figure $C 5$ and Table $C 2$. 

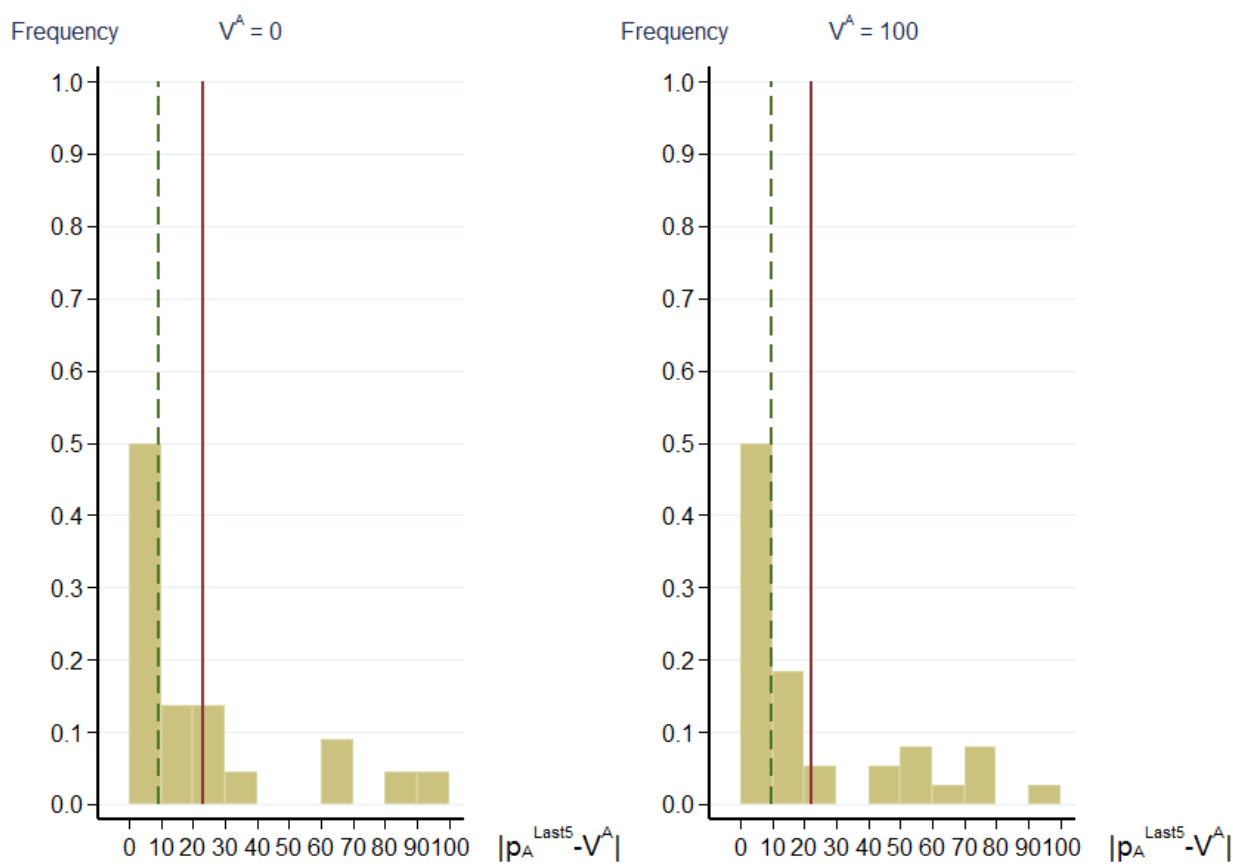

Figure C5. Per-round distance between the final price and $V^{A}$, conditional on $V^{A}=0$ and on $V^{A}=100$. 
Table C2. Distance of the final price of asset A from $V^{A}$, conditional on $V^{A}$.

The table shows the mean, median and standard deviation of the distance of the final price of asset A from $V^{A}$ for $V^{A}=0, V^{A}=100$ and for all rounds. The final price is the average of the last five trade prices in a round (column 1), or of the last three trade prices in a round (column 2 ), or of the trades occurred in the last 30 seconds of a round (column 3).

\begin{tabular}{lccc}
\hline & Last 5 trades & Last 3 trades & Last 30 seconds of trading \\
\hline & \multicolumn{3}{c}{$V^{A}=0$} \\
Mean & 23.10 & 22.70 & 22.56 \\
Median & 9.1 & 8.17 & 8.17 \\
Std. Dev. & 28.83 & 28.91 & 28.82 \\
$N$ & 22 & 22 & 22 \\
\hline & \multicolumn{3}{c}{$V^{A}=100$} \\
Mean & 22.38 & 22.66 & 21.01 \\
Median & 9.6 & 9.17 & 9.1 \\
Std. Dev. & 27.64 & 28.67 & 28.51 \\
$N$ & 38 & 38 & 30 \\
\hline & \multicolumn{3}{c}{ All } \\
Mean & 22.65 & 22.67 & 21.67 \\
Median & 9.3 & 8.67 & 8.6 \\
Std. Dev. & 27.85 & 28.51 & 28.37 \\
$N$ & 60 & 60 & 52 \\
\hline
\end{tabular}

\section{Appendix C.5: Session and round fixed effects}

This subsection replicates Table 3 adding fixed effects at the round and at the session level. See Table $C 3$. 


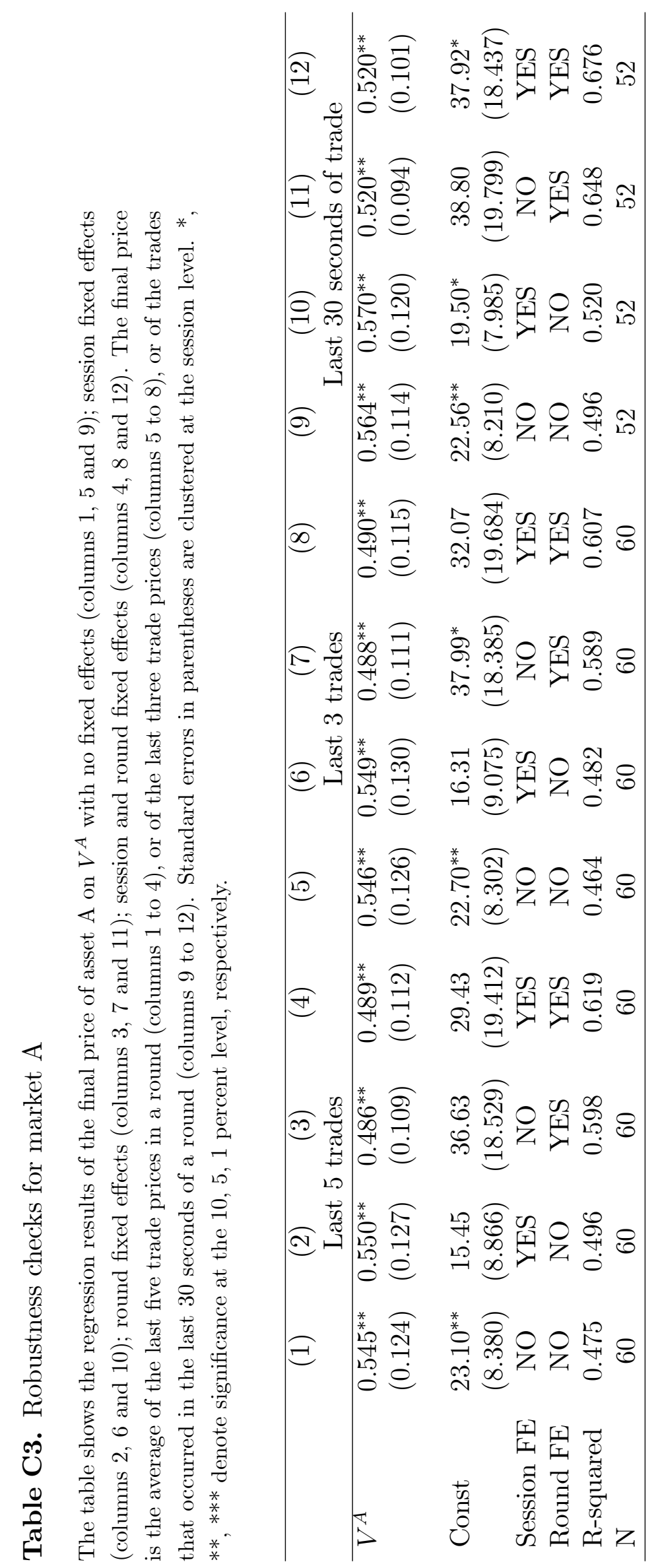




\section{Appendix C.6: Subjects' trading behavior}

In this subsection we present statistics on subjects trading behavior in all rounds, in rounds in which the price converges to the fundamental $\left(\left|p_{A}^{L a s t 5}-V^{A}\right|<\right.$ $30)$ and in rounds in which the price converges to the wrong value $\left(\left|p_{A}^{L a s t 5}-V^{A}\right|>\right.$ 70). All the variables reported in Table $C 4$ are self explanatory except the "Number of asks and bids against private information 1," defined as the number of asks (bids) posted by a subject with a green (i.e., good) signal at a price greater (lower) than 75 plus the number of asks (bids) posted by a subject with a red (i.e., bad) signal at a price greater (lower) than 25; and the "Number of asks and bids against private information 2," defined as the number of bids posted by a subject with a green signal at a price lower than 50 plus the number of asks posted by a subject with a red signal at a price higher than 50. As one can notice, for both these measures, the number of quotes against private information in the first 30 seconds of a round was higher when, eventually, the price converged to the wrong value. 


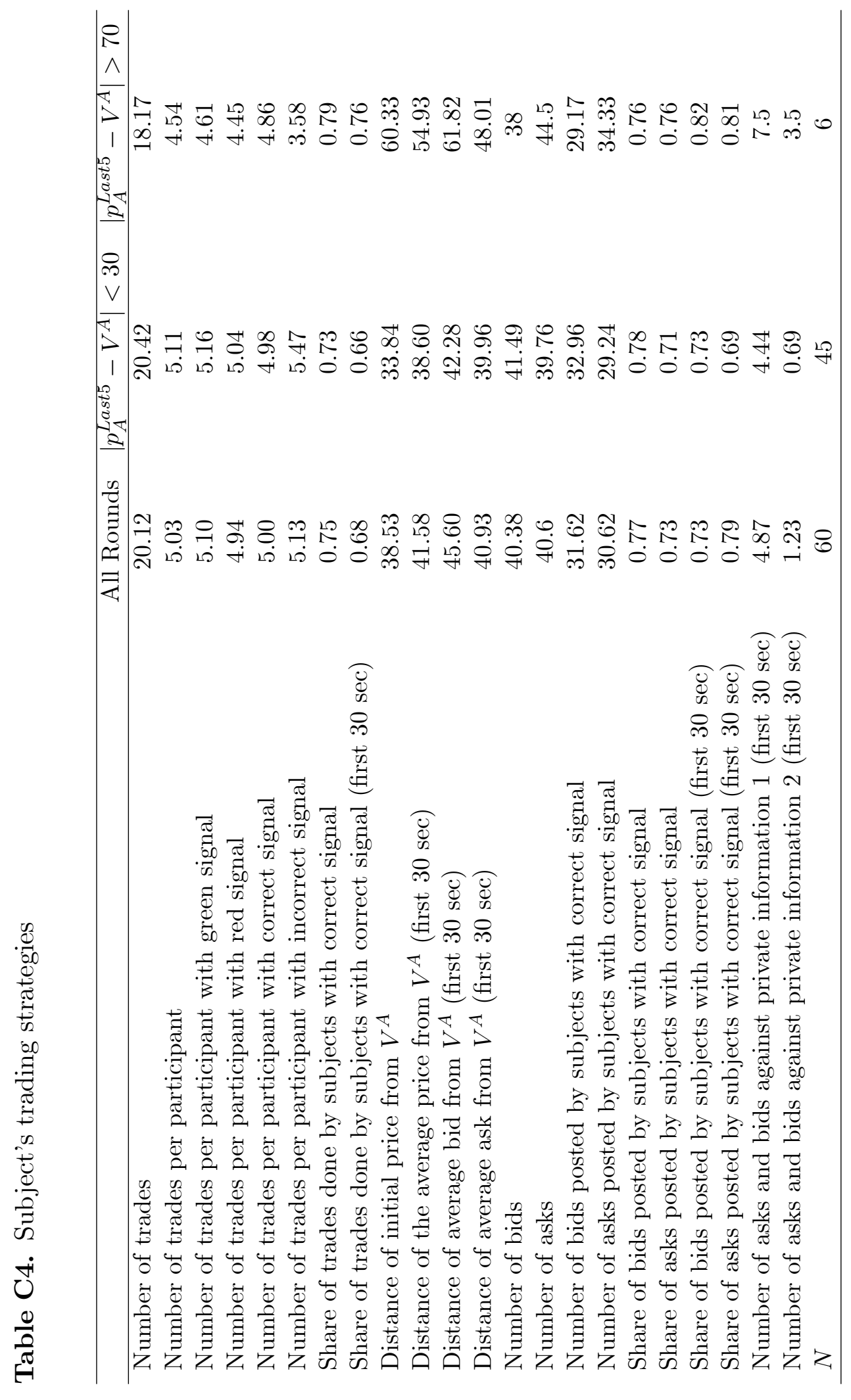




\section{Appendix D: Additional Results for Section 4.2}

\section{Appendix D.1: Price convergence in market B}

In this subsection, we replicate Figures 4 and 5 by showing the histograms for market $B$ of the distance between the final price and $V^{B}$ (Figures $D 1-D 2$ ) and of the distance between the final price and the REE price (Figures D3-D4), using different definitions for the final price. In Figures $D 1$ and $D 3$ the final price is defined as the average of the last three trade prices in a round, whereas in Figure $D 2$ and $D 4$ it is defined as the average of the trade prices in the last 30 seconds of trade in a round.

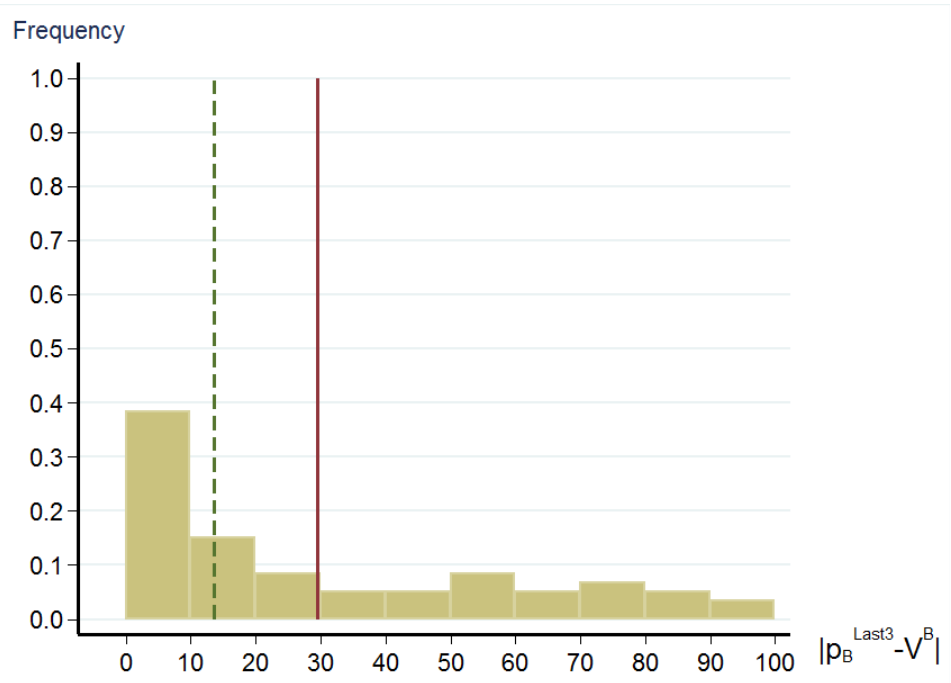

Figure D1. Per-round difference between the final price and $V^{B}$. The final price is defined as the average of the last three trade prices in a round. The mean is indicated by the solid line; the median by the dashed line. 


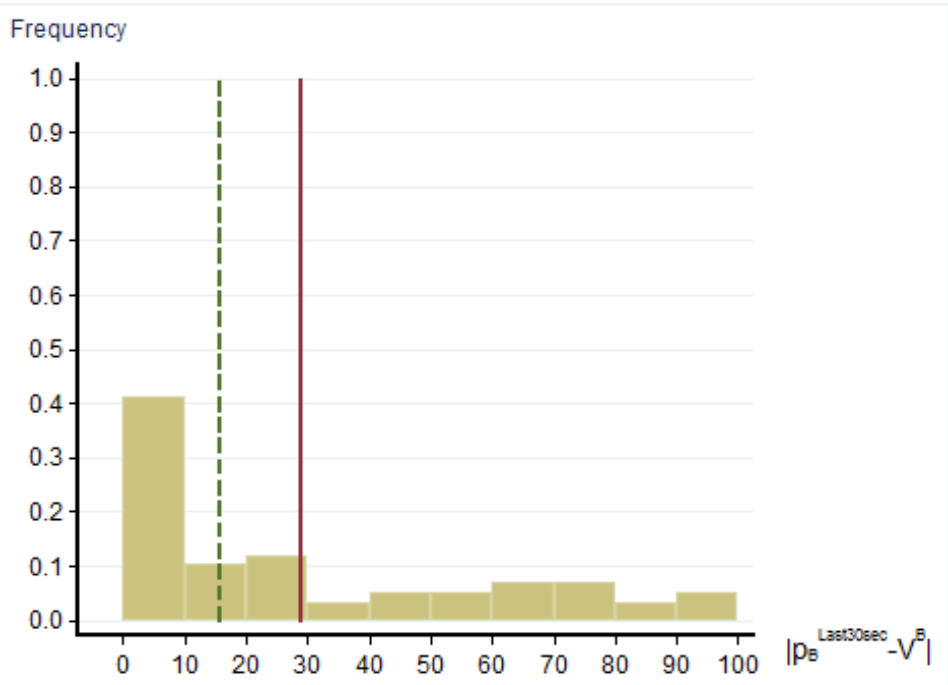

Figure D2. Per-round difference between the final price and $V^{B}$. The final price is defined as the average trade prices in the last 30 seconds of trade in a round. The mean is indicated by the solid line; the median by the dashed line.

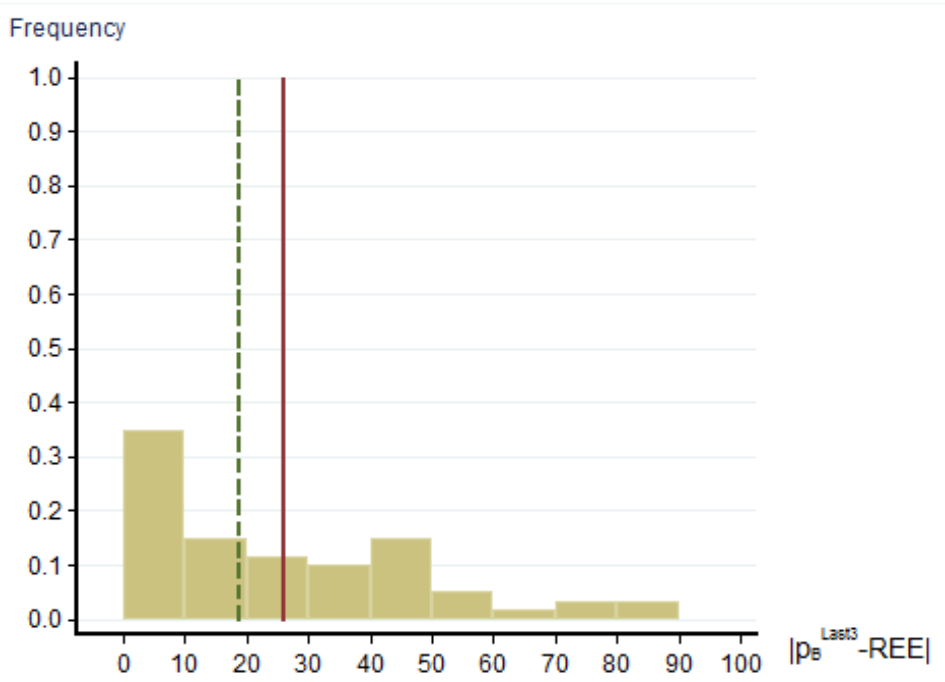

Figure D3. Per-round distance between the final price and the REE. The final price is defined as the average of the last three trade prices in a round. The mean is indicated by the solid line; the median by the dashed line. 


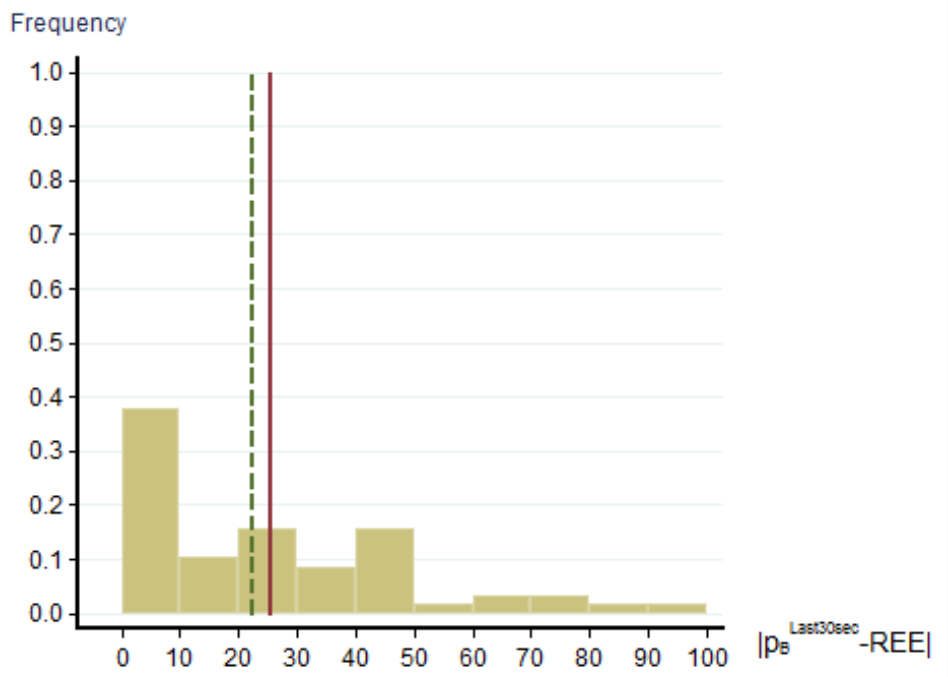

Figure D4. Per-round distance between the final price and the REE. The final price is defined as the average trade prices in the last 30 seconds of trade in a round. The mean is indicated by the solid line; the median by the dashed line.

\section{Appendix D.2: Price convergence in market B conditional on high} or low fundamental values

This subsection replicates Figures 4 and 5 and Table 6 separately for the following cases: $\left(V^{A}=0, C=0\right),\left(V^{A}=100, C=100\right),\left(V^{A}=0, C=100\right)$ and $\left(V^{A}=100, C=0\right)$. See Figures $D 5$ and $D 6$ and Table $D 1$. 


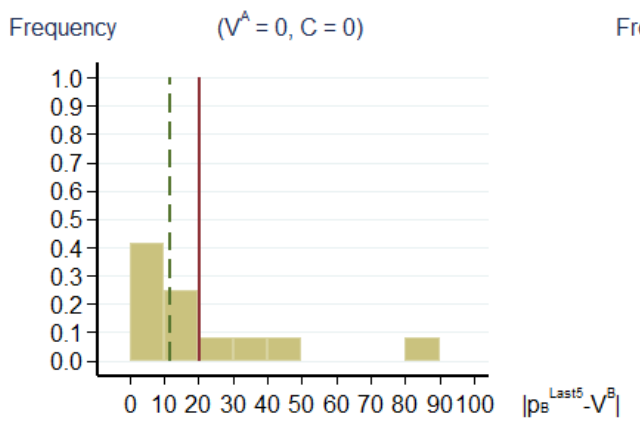

Frequency $\quad\left(V^{A}=100, C=100\right)$
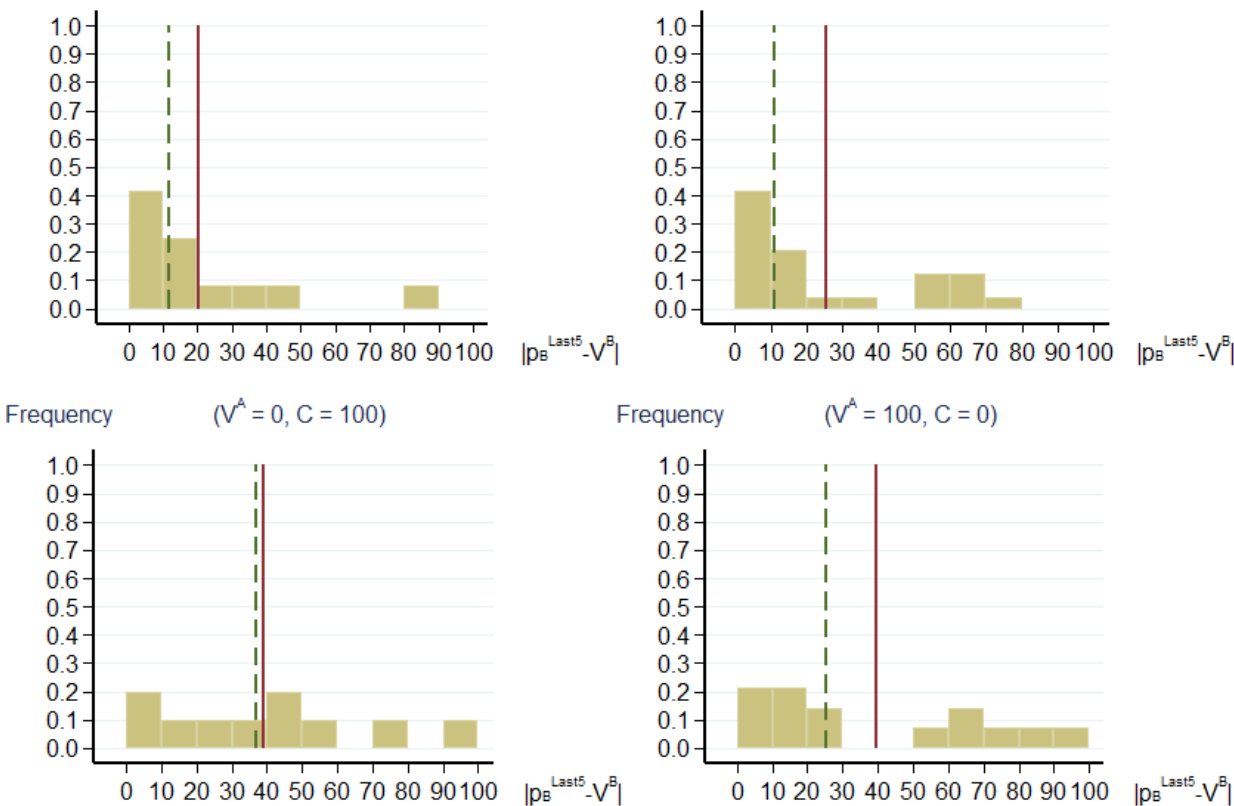

Frequency $\quad\left(\mathrm{V}^{\mathrm{A}}=100, \mathrm{C}=0\right)$

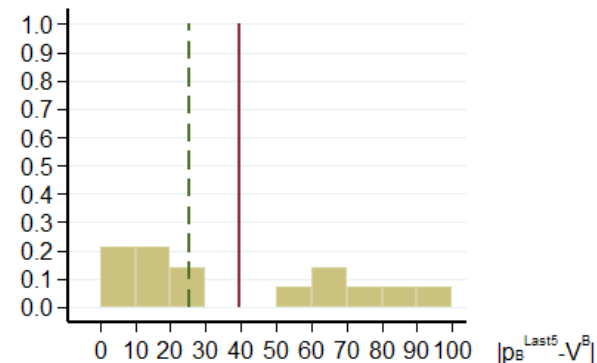

Figure D5. Per-round distance between the final price and $V^{B}$, conditional on $\left(V^{A}=0, C=0\right) ;\left(V^{A}=100, C=100\right) ;\left(V^{A}=0, C=100\right) ;\left(V^{A}=100, C=0\right)$. 

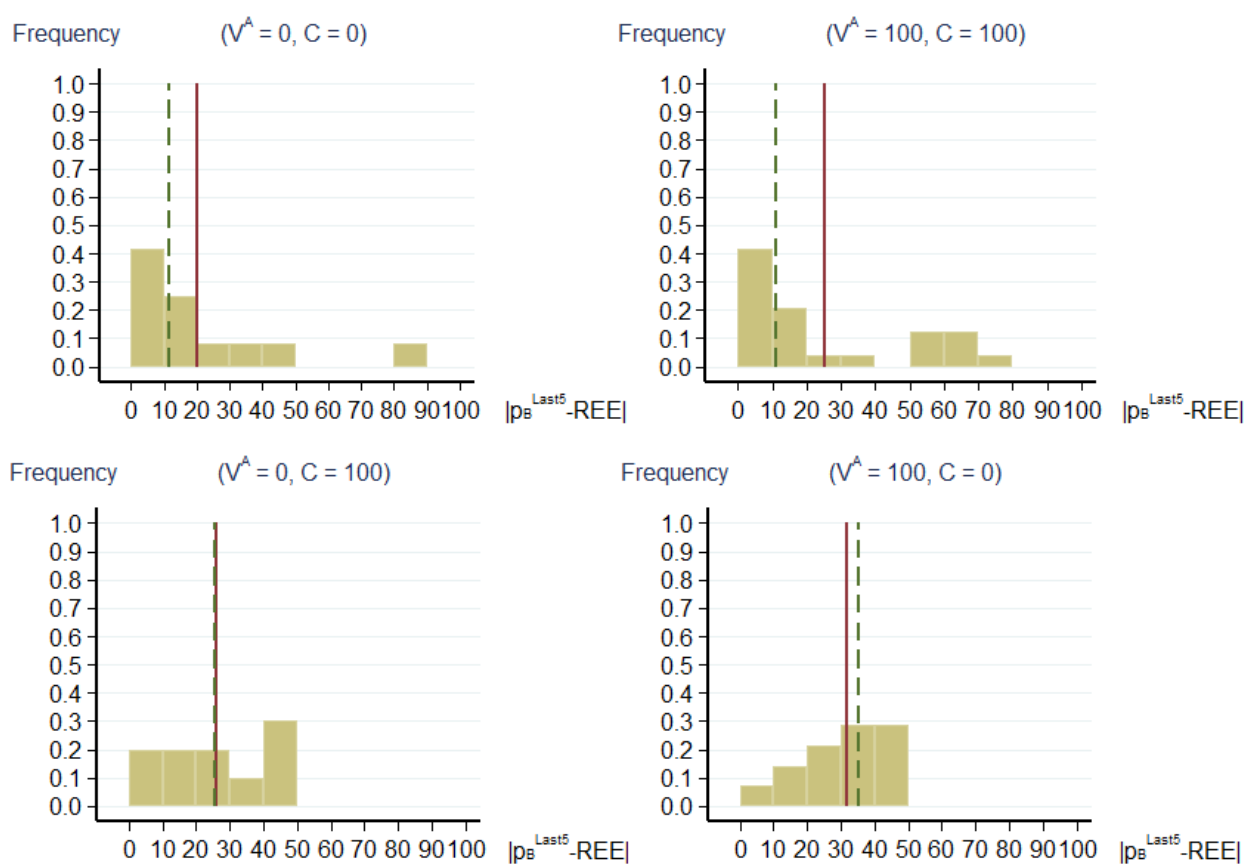

Figure D6. Per-round distance between the final price and the REE conditional on $\left(V^{A}=0, C=0\right) ;\left(V^{A}=100, C=100\right) ;\left(V^{A}=0, C=100\right) ;\left(V^{A}=100, C=0\right)$. 
Table D1. Distance of the final price of asset B from the REE, conditional on $V^{A}$ and $\mathrm{C}$.

The table shows the mean, median and standard deviation of the distance of the final price of asset $\mathrm{B}$ from the REE, conditional on the values of $V^{A}$ and $\mathrm{C}$ and for all rounds. The final price is the average of the last five trade prices in a round (column 1), or of the last three trade prices in a round (column 2), or of the trades occurred in the last 30 seconds of a round (column 3).

\begin{tabular}{|c|c|c|c|}
\hline & Last 5 trades & Last 3 trades & Last 30 seconds of trading \\
\hline & \multicolumn{3}{|c|}{$V^{A}=0, C=0$} \\
\hline Mean & 20.12 & 19.67 & 18.05 \\
\hline Median & 11.7 & 8.67 & 7.92 \\
\hline Std. Dev. & 24.83 & 25.03 & 23.48 \\
\hline \multirow[t]{2}{*}{$N$} & 12 & 12 & 12 \\
\hline & \multicolumn{3}{|c|}{$V^{A}=100, C=100$} \\
\hline Mean & 25.43 & 25.58 & 24.82 \\
\hline Median & 11.1 & 10 & 8.75 \\
\hline Std. Dev. & 26.64 & 28.10 & 30.05 \\
\hline \multirow[t]{2}{*}{$N$} & 24 & 24 & 22 \\
\hline & \multicolumn{3}{|c|}{$V^{A}=0, C=100$} \\
\hline Mean & 26.04 & 25.97 & 27.04 \\
\hline Median & 25.5 & 25.33 & 25.6 \\
\hline Std. Dev. & 17.77 & 17.85 & 17.46 \\
\hline \multirow[t]{2}{*}{$N$} & 10 & 10 & 10 \\
\hline & \multicolumn{3}{|c|}{$V^{A}=100, C=0$} \\
\hline Mean & 31.57 & 31.81 & 31.10 \\
\hline Median & 35.1 & 37 & 33.17 \\
\hline Std. Dev. & 13.98 & 14.94 & 14.99 \\
\hline$N$ & 14 & 14 & 14 \\
\hline & \multicolumn{3}{|c|}{ All } \\
\hline Mean & 25.90 & 25.92 & 25.32 \\
\hline Median & 19.5 & 19 & 22.33 \\
\hline Std. Dev. & 22.30 & 23.21 & 23.63 \\
\hline$N$ & 60 & 60 & 58 \\
\hline
\end{tabular}

\section{Appendix D.3: Price convergence in market B conditional on the} fundamental values $V^{A}$ and $V^{B}$

This subsection replicates Figure 4 and Table 5 separately for the following cases: $\left(V^{B}=V^{A}=C\right),\left(V^{B}=C \neq V^{A}\right)$ and $\left(V^{B}=V^{A} \neq C\right)$. See Figure $D 7$ 

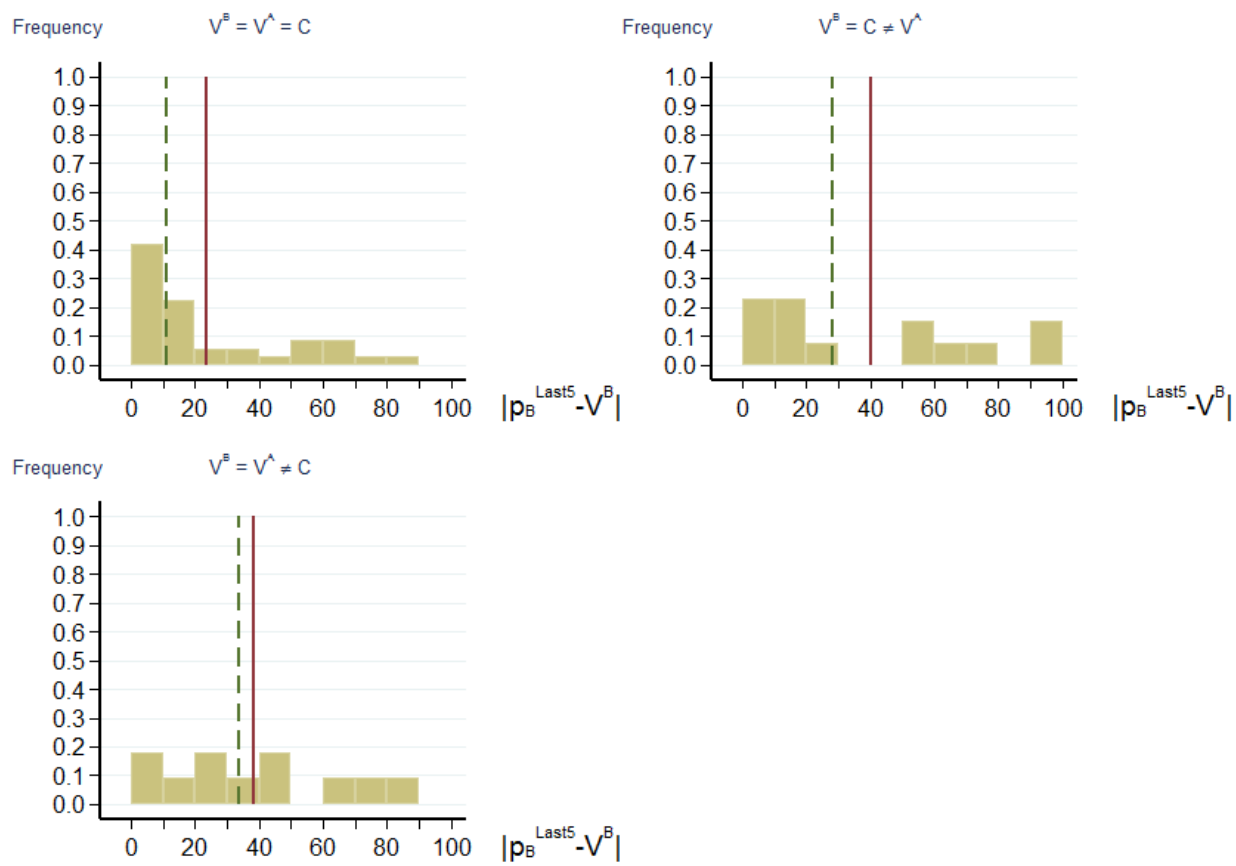

Figure D7. Per-round distance between the final price and $V^{B}$, conditional on $V^{B}=V^{A}=C ; V^{B}=C \neq V^{A} ; V^{B}=V^{A} \neq C$.

and Table $D 2$. 
Table D2. Distance of the final price of asset B from $V^{B}$, conditional on $V^{B}$ being equal to $V^{A}$ or $\mathrm{C}$.

The table shows the mean, median and standard deviation of the distance of the final price of asset B from $V^{B}$ for $V^{B}=V^{A}=C, V^{B}=C \neq V^{A}, V^{B}=V^{A} \neq C$ and for all rounds. The final price is the average of the last five trade prices in a round (column 1), or of the last three trade prices in a round (column 2), or of the trades occurred in the last 30 seconds of a round (column $3)$.

\begin{tabular}{|c|c|c|c|}
\hline & Last 5 trades & Last 3 trades & Last 30 seconds of trading \\
\hline & \multicolumn{3}{|c|}{$V^{B}=V^{A}=C$} \\
\hline Mean & 23.66 & 23.66 & 22.43 \\
\hline Median & 11.1 & 10 & 8.75 \\
\hline Std. Dev. & 25.82 & 26.90 & 27.73 \\
\hline \multirow[t]{2}{*}{$N$} & 36 & 36 & 34 \\
\hline & \multicolumn{3}{|c|}{$V^{B}=C \neq V^{A}$} \\
\hline Mean & 40.12 & 39.54 & 39.48 \\
\hline Median & 28.2 & 29 & 29 \\
\hline Std. Dev. & 35.39 & 35.62 & 35.80 \\
\hline$N$ & 13 & 13 & 13 \\
\hline & \multicolumn{3}{|c|}{$V^{B}=V^{A} \neq C$} \\
\hline Mean & 38.4 & 37.12 & 36.95 \\
\hline Median & 33.6 & 35 & 25 \\
\hline Std. Dev. & 28.88 & 28.65 & 27.97 \\
\hline$N$ & 11 & 11 & 11 \\
\hline & \multicolumn{3}{|c|}{ All } \\
\hline Mean & 29.93 & 29.54 & 29.01 \\
\hline Median & 16.7 & 13.5 & 15.75 \\
\hline Std. Dev. & 29.18 & 29.68 & 30.26 \\
\hline$N$ & 60 & 60 & 58 \\
\hline
\end{tabular}

\section{Appendix D.4: Session and round fixed effects}

This subsection replicates Table 7 adding fixed effects at the round and at the session level. See Table D3. 


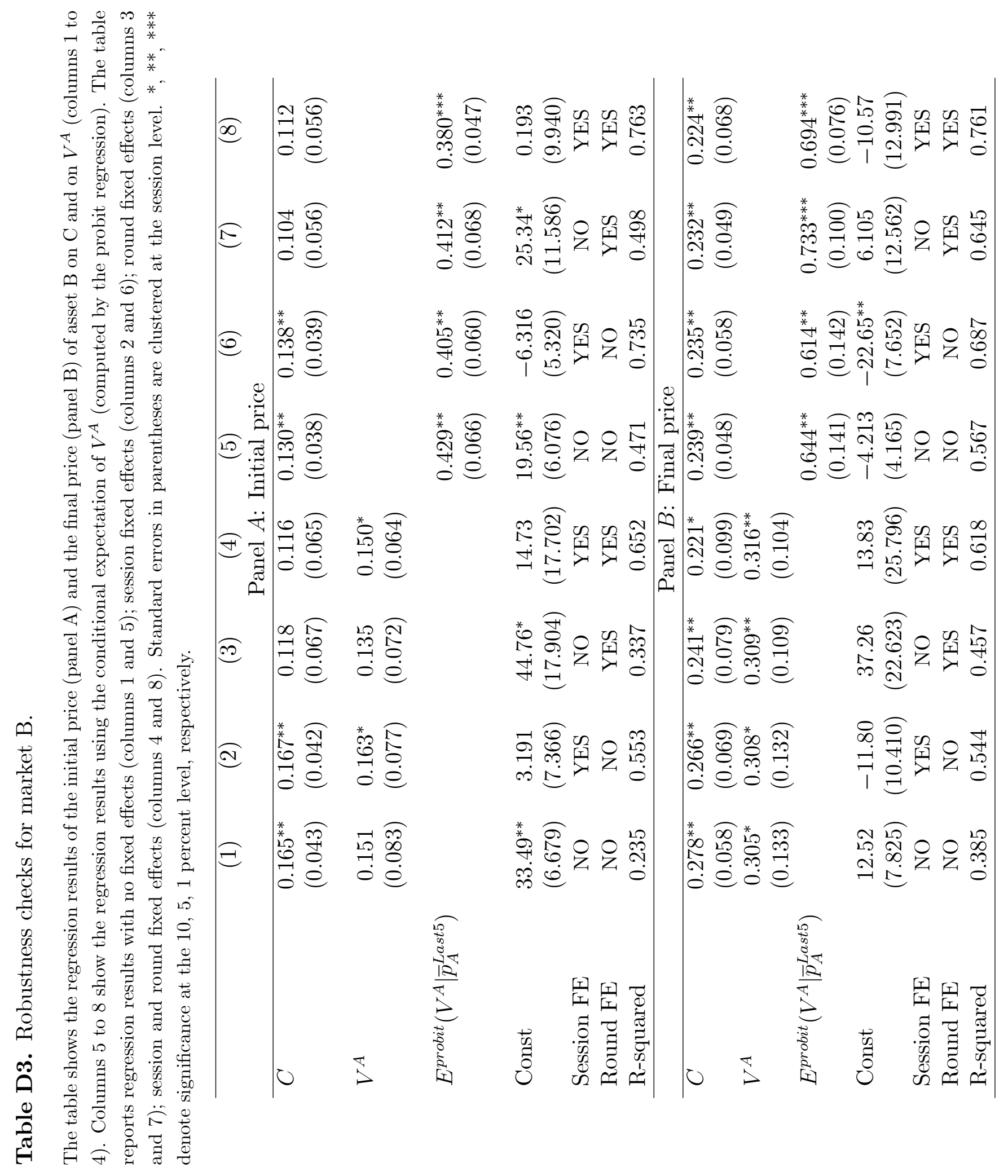




\section{Appendix E: Additional Treatment II}

In the text, when we described Treatment $I I$, we only reported some results for market $B$, which is the main object of our interest. In this appendix, we report the results for market $A$ and some additional results for market $B$.

\section{Appendix E.1: Distance between the final price and the asset value} in market $\mathbf{A}$

Table E1 reports the mean, median, and standard deviation for the distance between the asset value and the final price (defined in three different ways). Figure E1 reports the histogram of this distance (when the final price is computed as the average of the last five trade prices).

Table E1. Distance of the final price of asset A from $V^{A}$

The table shows the mean, median and standard deviation of the distance of the final price of asset A from $V^{A}$. The final price is the average of the last five trade prices in a round (column 1), or of the last three trade prices (column 2), or of the trades occurred in the last 30 seconds of a round (column 3).

\begin{tabular}{lccc}
\hline & Last 5 trades & Last 3 trades & Last 30 seconds of trading \\
\hline Mean & 22.16 & 21.34 & 22.18 \\
Median & 5.6 & 4.5 & 4.25 \\
Std. Dev. & 30.40 & 30.77 & 33.03 \\
$N$ & 60 & 60 & 56 \\
\hline
\end{tabular}




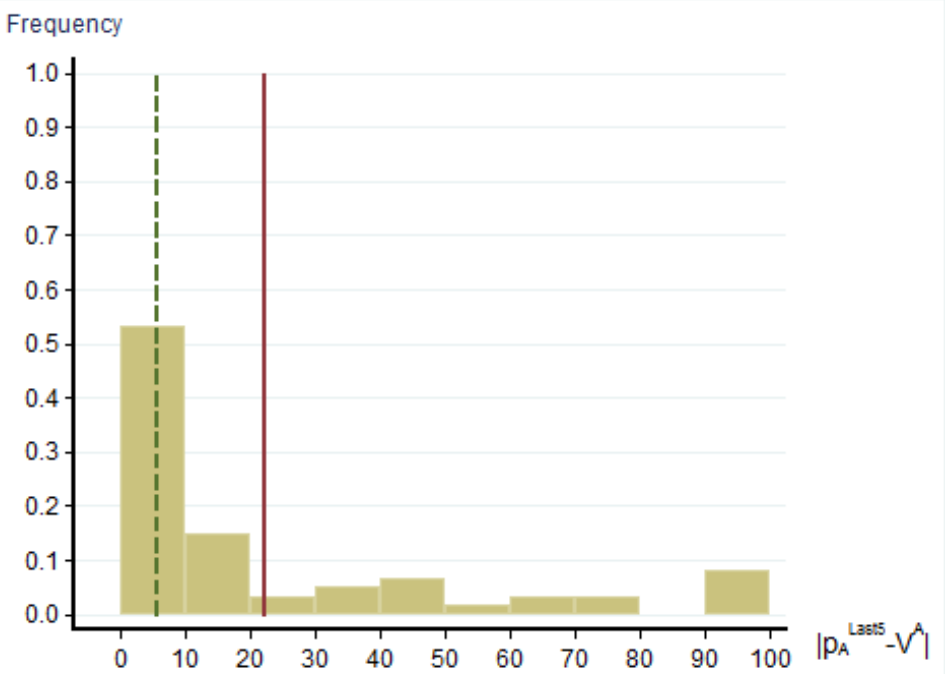

Figure E1. Per-round distance between the final price and $V^{A}$. The final price is defined as the average of the last five trade prices in a round. The mean is indicated by the solid line; the median by the dashed line.

\section{Appendix E.2: Regression results for market A}

This subsection replicates, for Treatment II, Table 3 adding fixed effects at the round and at the session level. See Table E2. 


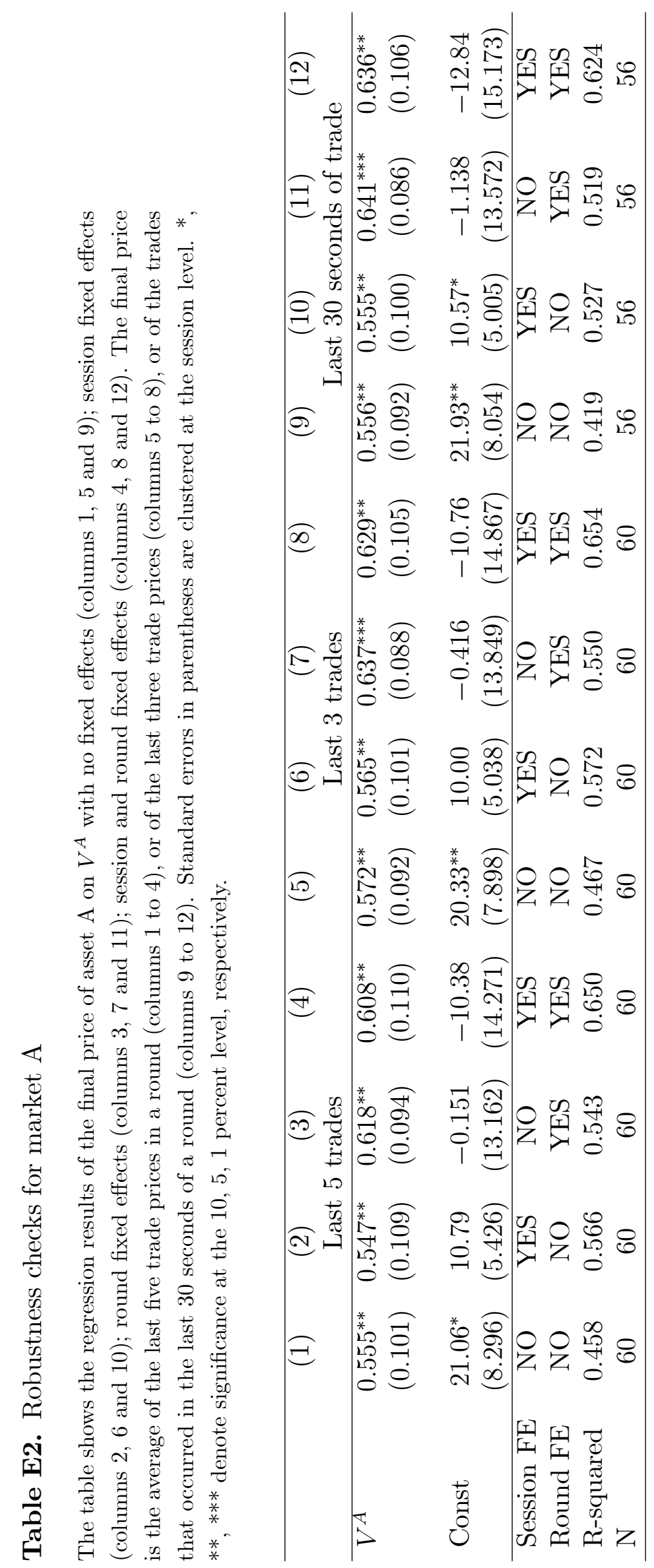




\section{Appendix E.3: Empirical Bayesian updates}

Table $E 3$ reports the frequencies of cases in which the last price was in a specific interval. It also reports the beliefs of a Bayesian agent relying on these frequencies and the average elicited beliefs at the end of the round. Figure E2 shows the conditional expected value of $V^{A}$ obtained from a probit regression of $V^{A}$ on the final price.

Table E3. Empirical Bayesian Updates

The table shows: 1) the frequencies with which the final price (defined as the average of the last five trade prices in a round) belonged to a particular range, conditional on $V^{A}$ (columns 1 and 2); 2) the Bayesian updates about $V^{A}$ computed using these frequencies (column 3); 3) average subjects' beliefs elicited 10 seconds before the end of the trading activity in market A (column $4)$.

\begin{tabular}{lcccc}
\hline & \multicolumn{2}{c}{ Frequencies } & Bayesian updates & Beliefs \\
\hline & $V^{A}=0$ & $V^{A}=100$ & $\operatorname{Pr}\left(V^{A}=100 \mid \bar{p}_{A}^{\text {Last }}\right)$ & \\
\hline $\bar{p}_{A}^{\text {Last }}>75$ & 0.09 & 0.68 & 0.88 & 89.0 \\
$50<\bar{p}_{A}^{\text {Last } 5} \leq 75$ & 0.09 & 0.18 & 0.66 & 63.2 \\
$25 \leq \bar{p}_{A}^{\text {Last }} \leq 50$ & 0.06 & 0.04 & 0.36 & 35.0 \\
$\bar{p}_{A}^{\text {Last }}<25$ & 0.75 & 0.10 & 0.12 & 13.9 \\
\hline
\end{tabular}




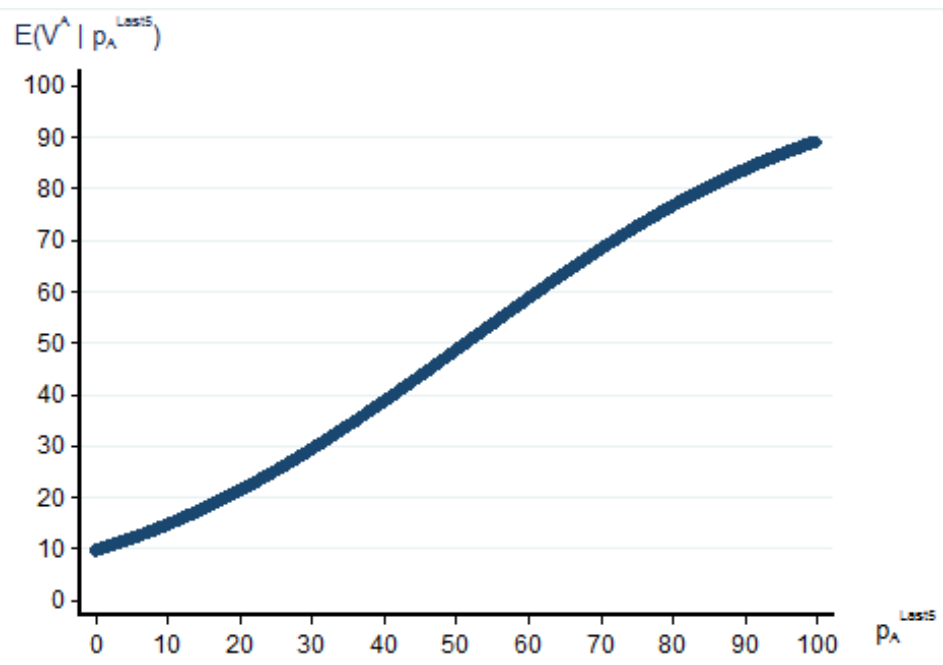

Figure E2. Expected value of $V^{A}$ as a function of the final price in market $A$.

\section{Appendix E.4: Price convergence in market A}

In this subsection, we replicate Figure 3 and Figures $C 3$ and $C 4$ (Appendix C.3) for Treatment II. Figure E3 shows price convergence over time; Figures E4 and $E 5$ show price convergence in trade-time and in quote-time, respectively. 


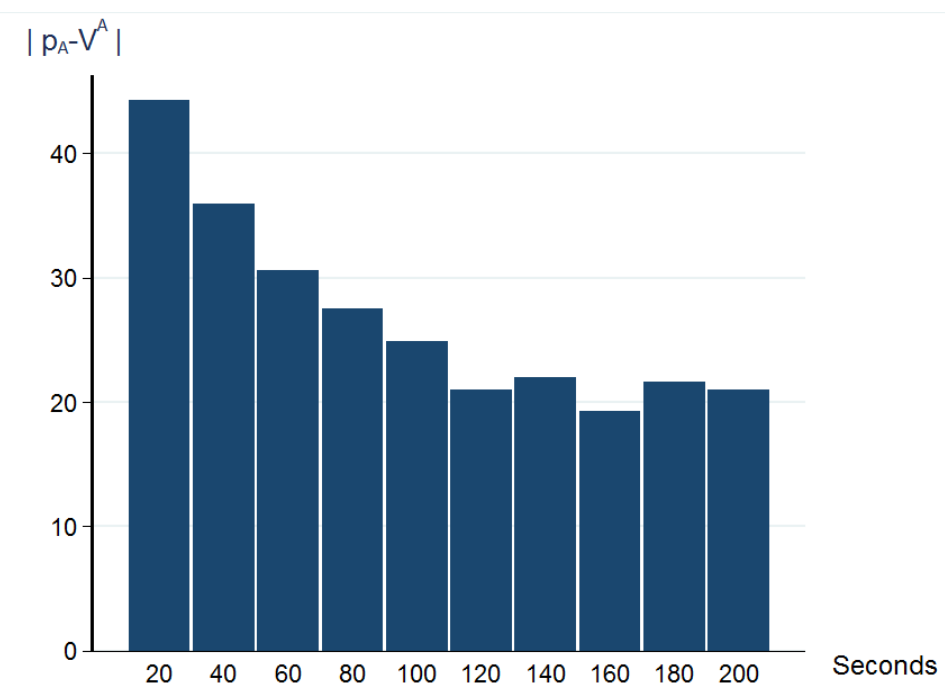

Figure E3. Distance of the price of asset $A$ from $V^{A}$ over time. The figure shows the distance between the average price and $V^{A}$ for each interval of 20 seconds.

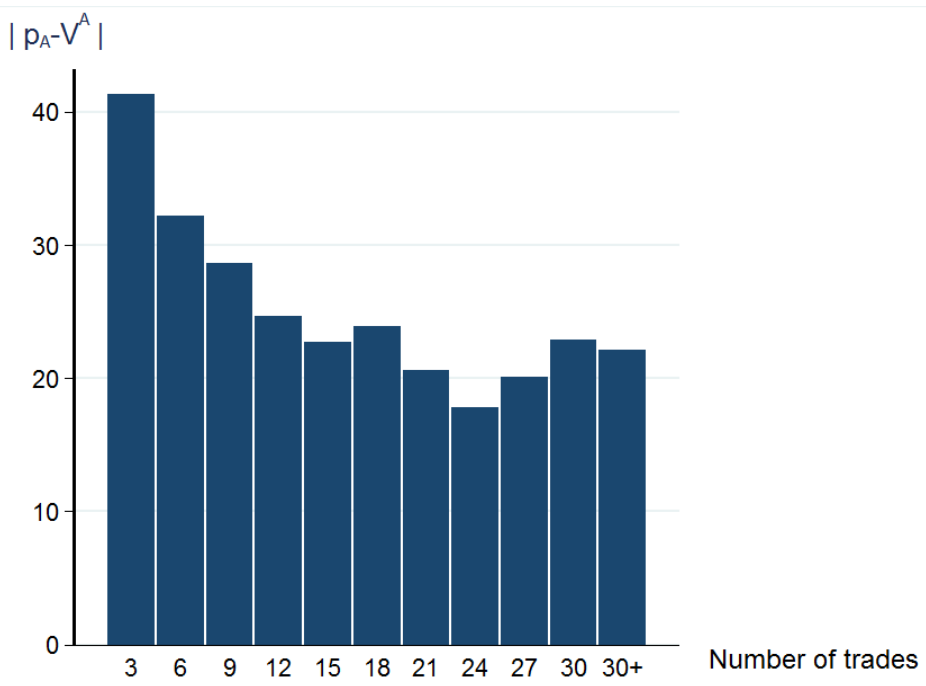

Figure E4. Distance of the price of asset $A$ from $V^{A}$ in trade times. The figure shows the average distance between the trading price and the asset fundamental value for transactions $1-3,4-6,7-9$, etc. 


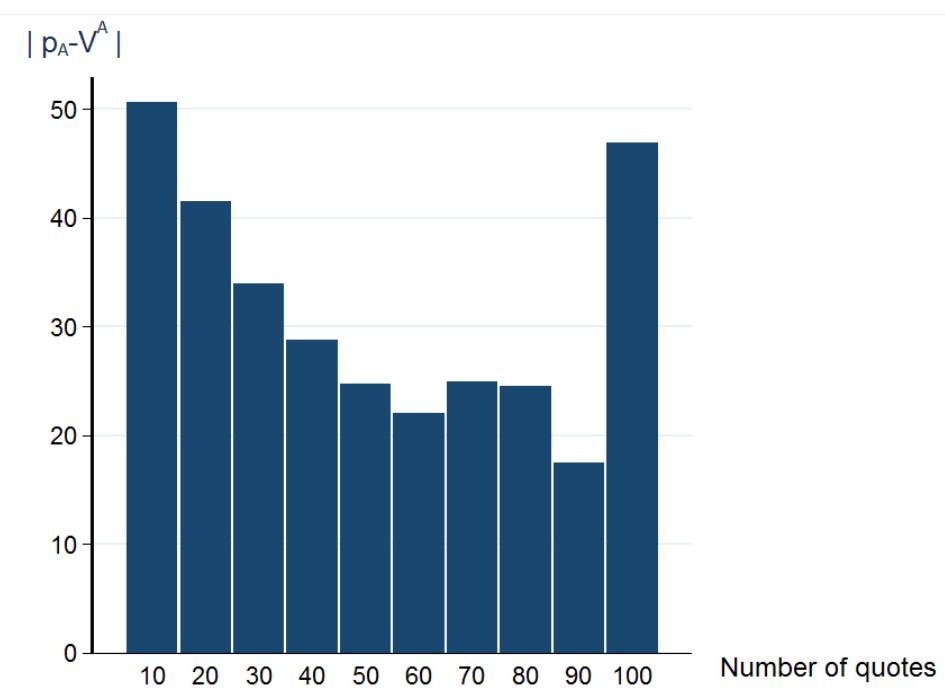

Figure E5. Distance of the price of asset $A$ from $V^{A}$ in quote times. The figure shows the average distance between the trading price and the asset fundamental value for quotes 1-10, 11-20, 21-30, etc.

Note that the right tail of Figure $E 5$ is based on a small number of observations: the number of quotes was higher than 90 in $7 \%$ of the rounds only. In $82 \%$ of the rounds, the number of quotes was not higher than 80 .

\section{Appendix E.5: Distance between the final price and the asset value} in market $B$

Table E4 reports the mean, median, and standard deviation for the distance between the asset value and the final price (defined in three different ways). Figure E6 reports the histogram of this distance (when the final price is computed as the average of the last five trade prices). 
Table E4. Distance of the final price of asset A from $V^{B}$

The table shows the mean, median and standard deviation of the distance of the final price of asset $\mathrm{B}$ from $V^{B}$. The final price is the average of the last five trade prices in a round (column 1 ); of the last three trade prices in a round (column 2); or of the trades occurred in the last 30 seconds of a round (column 3).

\begin{tabular}{lccc}
\hline & Last 5 trades & Last 3 trades & Last 30 seconds of trade \\
\hline Mean & 16.39 & 15.82 & 15.03 \\
Median & 4.1 & 3.7 & 3.7 \\
Std. Dev. & 25.97 & 26.02 & 24.95 \\
$N$ & 60 & 60 & 54 \\
\hline
\end{tabular}

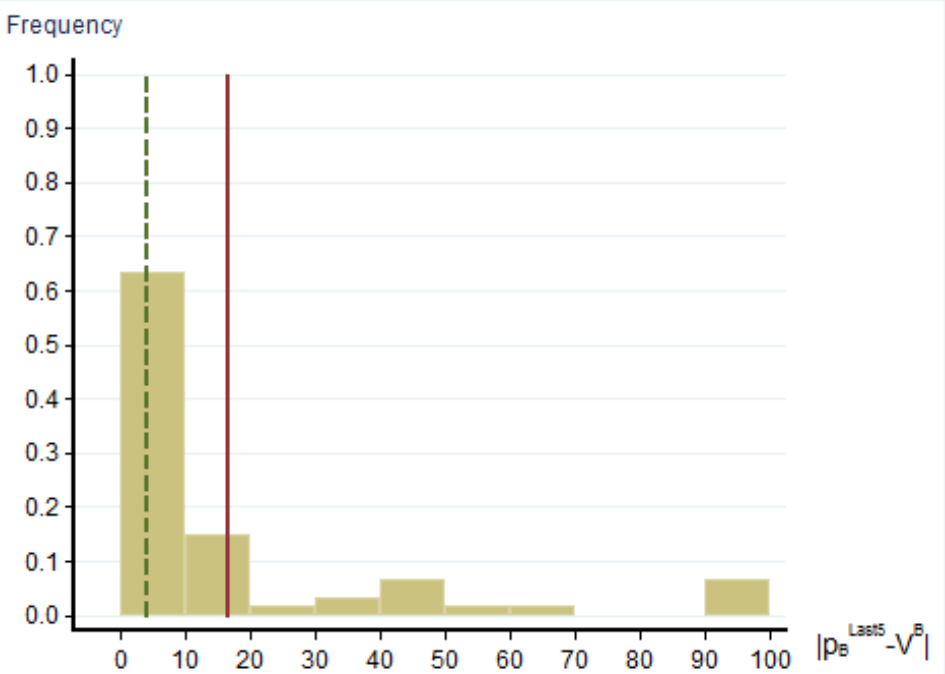

Figure E6. Per-round distance between the final price and $V^{B}$. The final price is defined as the average of the last five trade prices in a round. The mean is indicated by the solid line; the median by the dashed line.

\section{Appendix E.6: Regression results for market B}

This subsection replicates, for Treatment II, Table D3. See Table E5. 


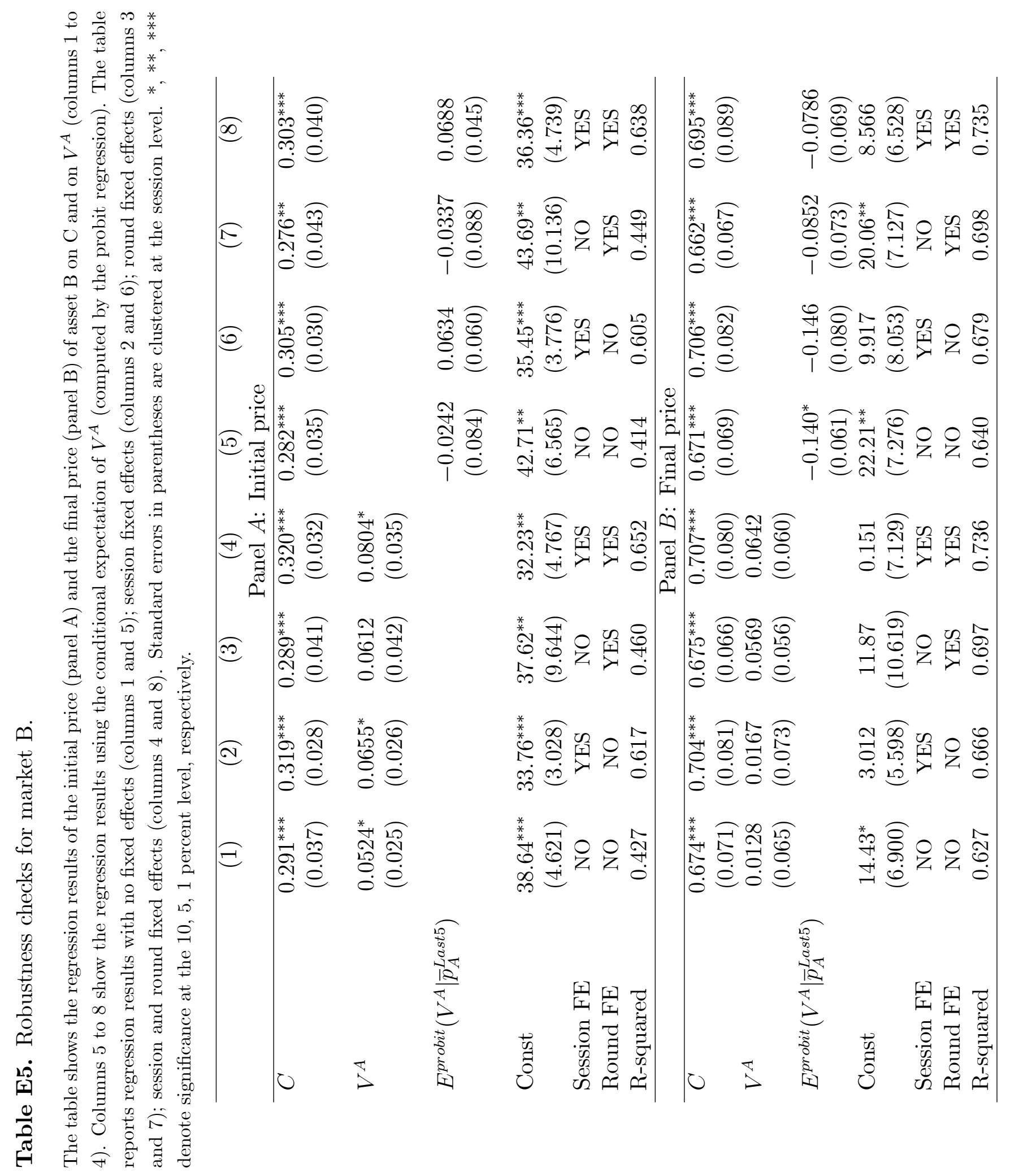




\section{Appendix F: Analysis of beliefs}

Recall that in our experiment, while a group of subjects traded in market $A$, the other group (who would later trade in market $B$ ) observed market $A$ prices and trading activity. While they were doing so, subjects in the latter group were asked to report their belief on the value of asset $A$ being 100 . They had to do so on three occasions: when the remaining trading time was 120, 60 and 10 seconds. In this appendix, we present a brief analysis of these data. For expositional convenience, we will sometimes refer to the beliefs when the remaining trading time was 120 , 60 and 10 seconds as the initial, intermediate and final beliefs.

First of all, it is instructive to look at the evolution of beliefs over time. Figures $F 1$ and $F 2$ show the average distance (defined as the absolute value of the difference) between asset $A$ 's value and the subjects' beliefs respectively for Treatment $I$ and $I I$. As one would expect, subjects' expectations tend to approach the value of the fundamental as time goes by. The distance of the value of asset $A$ from the initial belief is around 33, whereas that from the final belief is only 25 . As we know, the price in market $A$ converged over time to the value of the asset; as this happened, subjects in group $B$ also made better predictions on $V^{A}$. Nevertheless, since price aggregation was not perfect, subjects' beliefs at the end of the round are still 25 units away from $V^{A}$.

To understand better how subjects form their expectations, we computed the difference between the subjects' final beliefs and the average of all trade prices occurring between the intermediate and the final beliefs. The final belief follows the price observed in market $A$ : in $62 \%$ of the cases, the difference between the belief and the price was between -10 and 10 units. In Table F1, we report the results of a regression of subjects' beliefs on asset $A$ 's average price in the 50 


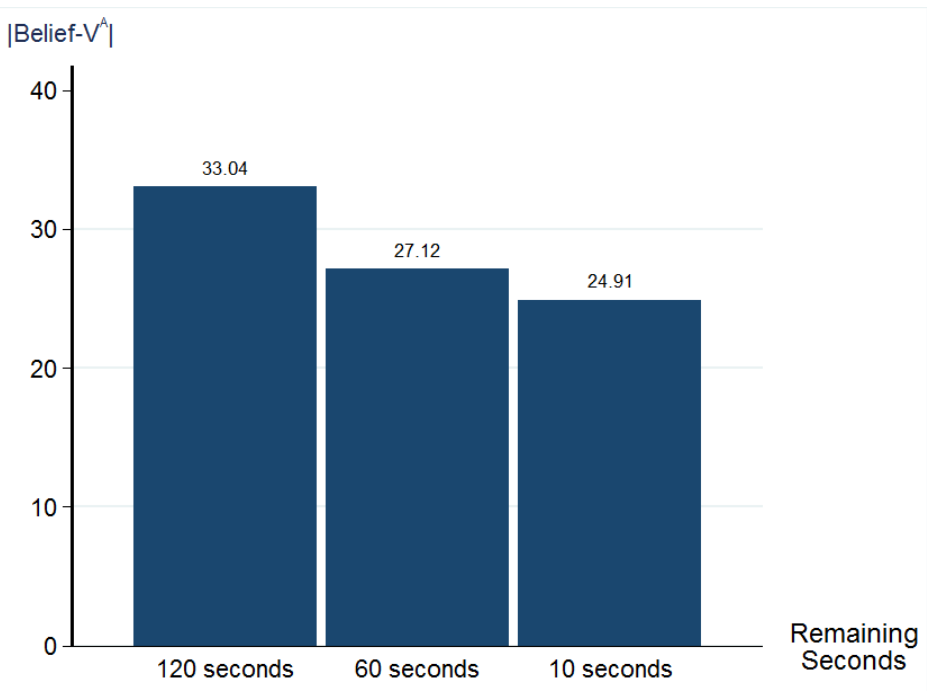

Figure F1. Distance between subjects' beliefs and $V^{A}$ in Treatment $I$.

seconds before the belief elicitation. The upper (lower) panel refers to Treatment $I$ (Treatment $I I$ ). The coefficients are all statistically significant and vary between 0.66 and 0.87 , indicating that beliefs followed the observed prices quite closely. 


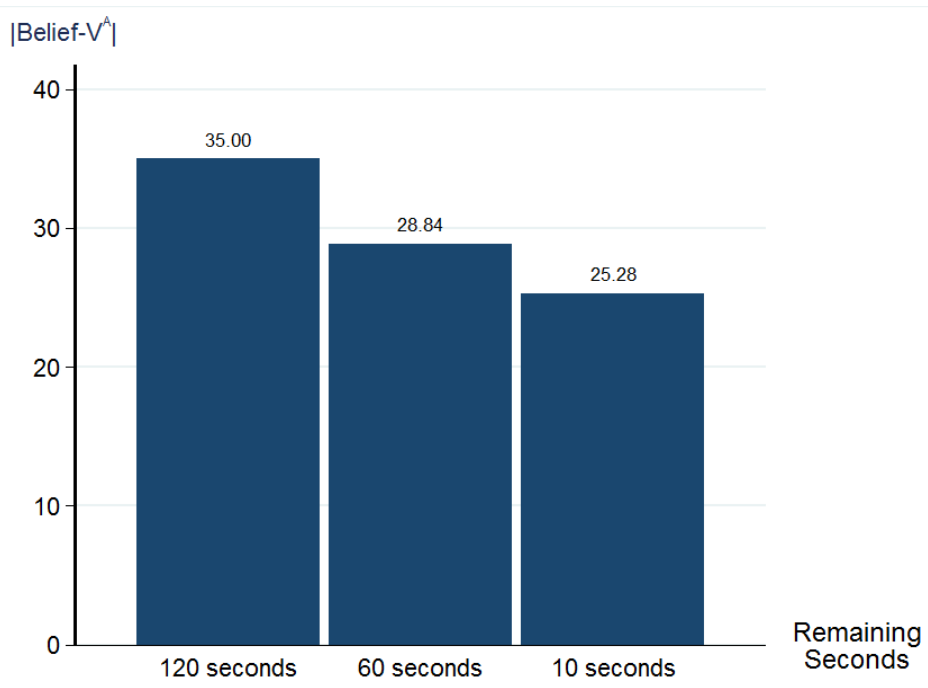

Figure F2. Distance between subjects' beliefs and $V^{A}$ in Treatment $I I$.

Table F1. Regression of subjects' beliefs on trade prices

The table shows the regression results of subjects' initial (column 1), intermediate (column 2) and final (column 3) beliefs on market A's prices. The upper (lower) panel shows the results for Treatment $I$ (Treatment $I I$ ).

\begin{tabular}{lccc}
\hline & Initial belief & Intermediate belief & Final belief \\
\hline Price & \multicolumn{3}{c}{ Treatment $I$} \\
& $0.748^{* * *}$ & $0.837^{* * *}$ & $0.869^{* * *}$ \\
Constant & $(0.101)$ & $(0.064)$ & $(0.044)$ \\
& 10.96 & 6.171 & 4.289 \\
R-squared & $(8.499)$ & $(4.626)$ & $(3.341)$ \\
$N$ & 0.57 & 0.73 & 0.74 \\
& 464 & 464 & 463 \\
\hline Price & $0.656^{* * *}$ & Treatment $I I$ \\
Constant & $(0.035)$ & $0.774^{* * *}$ & $0.831^{* * *}$ \\
& $16.71^{* * *}$ & $(0.025)$ & $(0.019)$ \\
R-squared & $(2.198)$ & $10.40^{* *}$ & $8.825^{* *}$ \\
$N$ & 0.49 & $(2.657)$ & $(1.672)$ \\
& 478 & 0.64 & 0.68 \\
& \multicolumn{3}{c}{472} \\
\end{tabular}




\section{Appendix G: (No) learning effects}

In this section, we check the robustness of the results across the full duration of the experiment. In other words, we test whether there are significant differences in subjects' behavior across rounds because of learning effects or because of a decrease in attention in the last rounds of the experiment.

We do so in two ways. First, we test that the degree of convergence of the final price to the true asset value (and to the REE) does not change between the first 3 rounds, the middle 4 rounds and the last 3 rounds of each session. Second, we check the robustness of our regression results by adding dummy variables for the middle 4 rounds and the last 3 rounds, and by interacting them with the regressors. Overall, we find that subjects' behavior did not change over the course of the experiment.

\section{Appendix G.1: Market A}

We start by considering the aggregation of information in market $A$, replicating the results of Figure 1. Figure $G 1$ plots the histogram of the distance between the final price (defined as the average of the last 5 transactions) and $V^{A}$ for the first 3 rounds (upper left panel), the middle 4 rounds (upper right panel) and the last 3 rounds (lower left panel). As one can see, there is little difference among the three distributions. This is confirmed by the Kolmogorov-Smirnov tests of the equality of the distribution in the first or in the last 3 rounds to the distribution in the middle 4 rounds (p-values reported in Table $G 1$ ). 

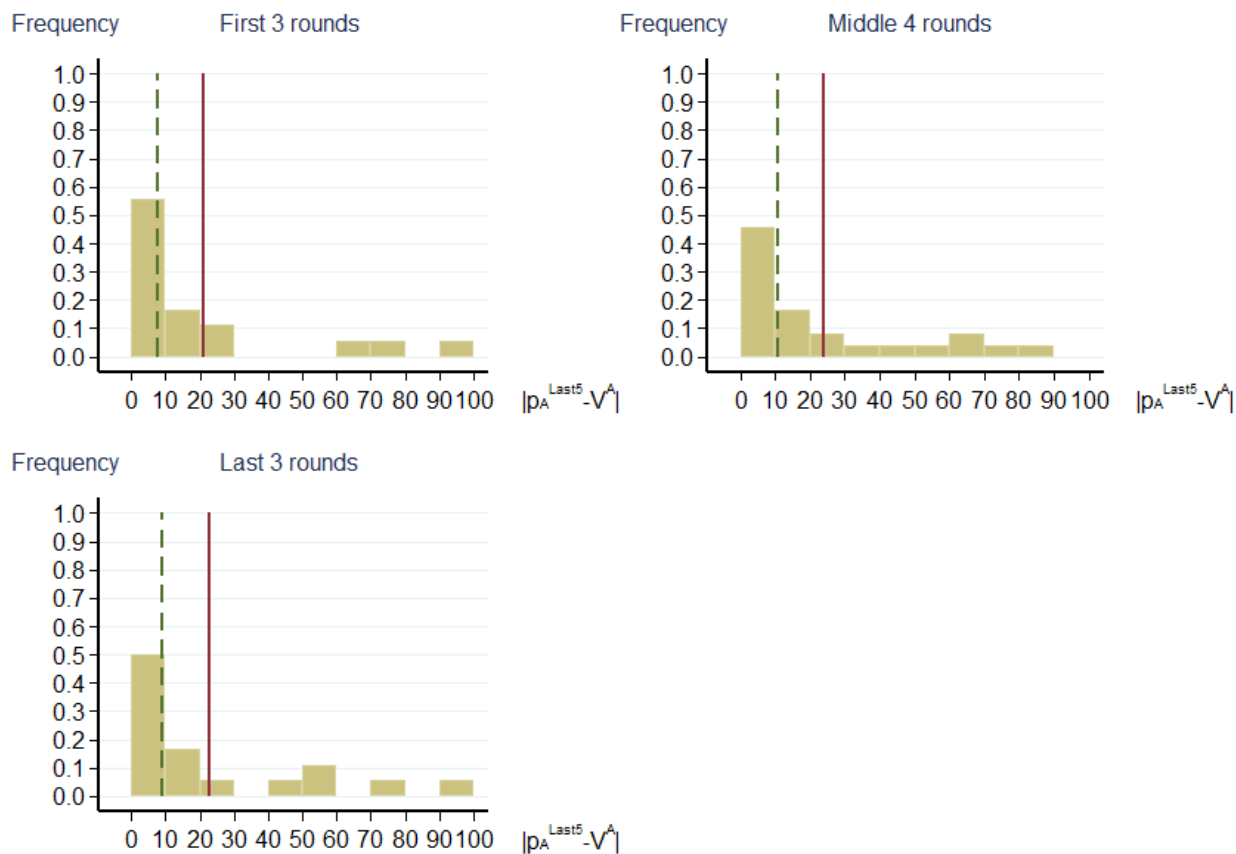

Figure G.1. Per-round distance between the final price and $V^{A}$ in the first 3, middle 4 and last 3 rounds 
Table G.1. KS test, distance between the final price of asset $\mathrm{A}$ and $V^{A}$

The table reports the p-values of Kolmogorov-Smirnov tests. The null hypothesis is that the distribution of the distance between the final price and the value of asset $\mathrm{A}$ in the middle 4 rounds is equal to the distribution of the same distance in the first 3 rounds (row 1 ) or in the last 3 rounds (row 2).

\begin{tabular}{lc}
\hline Kolmogorov-Smirnov test & p-value \\
\hline$H_{0}:$ Middle 4 rounds $=$ First 3 rounds & 0.978 \\
$H_{0}:$ Middle 4 rounds $=$ Last 3 rounds & 0.896 \\
\hline
\end{tabular}

Furthermore, we check that regression results of Table 3 are stable for the full length of the experiment. We estimate the following equation:

$$
p_{i}^{A}=\alpha_{0}+\alpha_{1} V_{i}^{A}+\alpha_{2} V_{i}^{A} \cdot M_{i}+\alpha_{3} V_{i}^{A} \cdot L_{i}+\alpha_{4} M_{i}+\alpha_{5} L_{i}+\varepsilon_{i}
$$

where $p_{i}^{A}$ is the final price of asset $A$ in round $i=1, \ldots, 60 ; V_{i}^{A}$ is the true value of asset $A ; M_{i}$ and $L_{i}$ are, respectively, indicators for the middle 4 rounds and the last 3 rounds. Our focus is on coefficients $\alpha_{2}$ and $\alpha_{3}$; values significantly different from zero imply that the impact of $V^{A}$ on $p^{A}$ is different throughout the rounds. Similarly to Table 3, we run three regressions, each for a different definition of the final price. Results are reported in Table G2. 
Table G.2. Robustness checks for market A

The tables shows the regression results of the final price of asset $\mathrm{A}$ on $V^{A}$, dummy variables for the middle 4 rounds (M) and the last 3 rounds (L) and their interactions with $V^{A}$. The final price is the average of the last five trade prices in a round (column 1), or of the last three trade prices (column 2), or of the trades that occurred in the last 30 seconds of a round (column 3). Standard errors in parentheses are clustered at the session level. $*, * *, * * *$ denote significance at the 10, 5, 1 percent level, respectively.

\begin{tabular}{lccc}
\hline & Last 5 trades & Last 3 trades & Last 30 seconds of trade \\
\hline$V^{A}$ & $0.487^{* *}$ & $0.502^{* *}$ & $0.565^{* *}$ \\
& $(0.108)$ & $(0.106)$ & $(0.131)$ \\
$V^{A} * M$ & & & \\
& 0.038 & 0.019 & -0.041 \\
$V^{A} * L$ & $(0.110)$ & $(0.115)$ & $(0.153)$ \\
& 0.142 & 0.125 & 0.050 \\
$M$ & $(0.085)$ & $(0.082)$ & $(0.135)$ \\
$L$ & -12.560 & -12.194 & -12.358 \\
& $(12.781)$ & $(12.733)$ & $(12.820)$ \\
Constant & $-27.320^{*}$ & $-27.800^{*}$ & $-28.300^{*}$ \\
& $(12.912)$ & $(12.266)$ & $(11.967)$ \\
$H_{0}: \alpha_{2}=\alpha_{3}, \mathrm{p}$-value & & & \\
$N$ & $36.160^{* *}$ & $35.667^{* *}$ & $35.733^{* *}$ \\
& $(13.327)$ & $(12.848)$ & $(12.820)$ \\
& 0.449 & 0.459 & 0.613 \\
\end{tabular}

None of the interaction terms are statistically significant, indicating that aggregation of information about $V^{A}$ does not differ in the middle four rounds or in the last three rounds as compared to the first three rounds. Moreover, we cannot reject the null hypothesis that the interaction coefficients on the middle and last three rounds are the same (second to last row of Table G2).

\section{Appendix G.2: Market B}

Figures $G 2$ and $G 3$ replicate Figures 4 and 5 by showing the distance between the final price and the true value of asset $B$ (Figure G2) and the REE (Figure G3) 


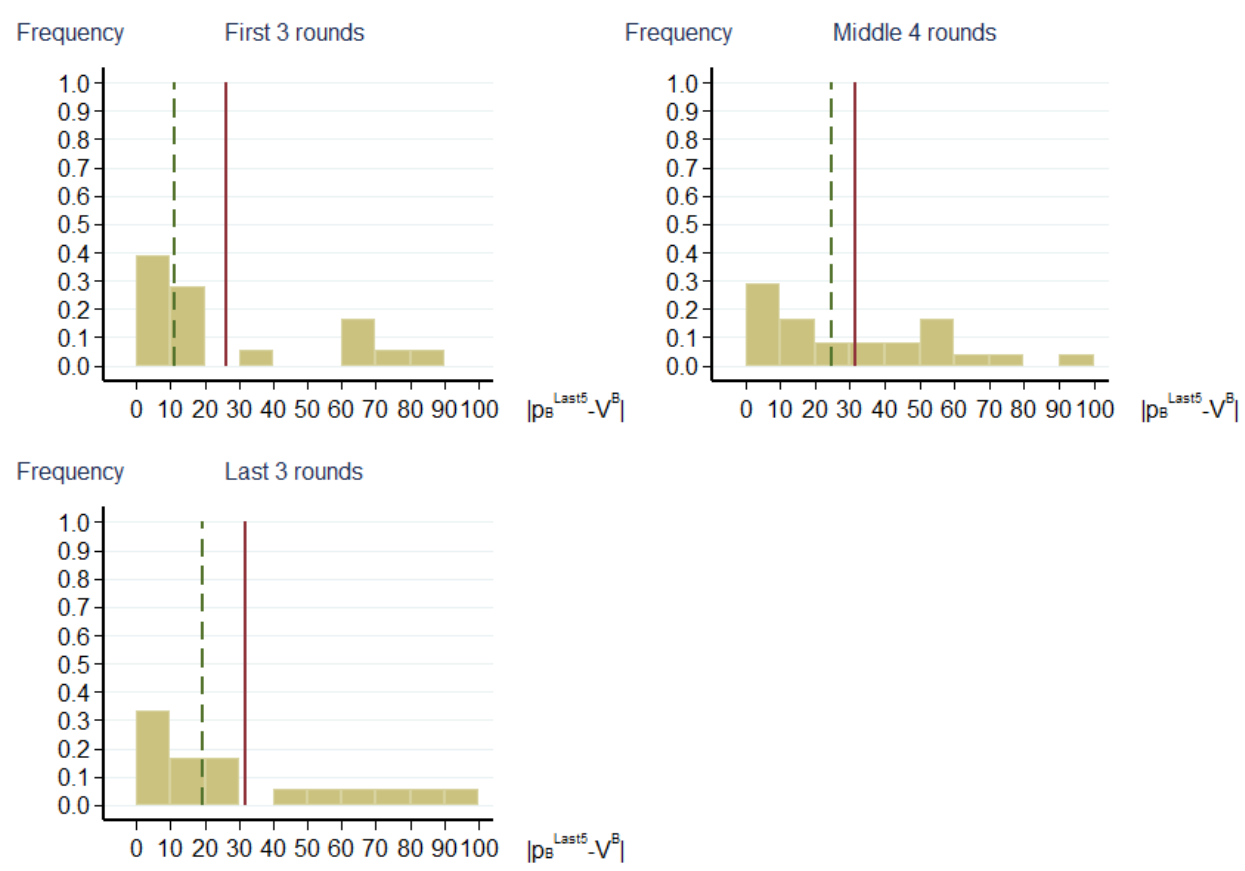

Figure G.2. Per-round distance between the final price and $V^{B}$

for the first 3 rounds (upper left panels), the middle 4 rounds (upper right panels) and the last 4 rounds (lower left panels). Moreover, in Tables $G 3$ and $G 4$ we report the p-values of Kolmogorov-Smirnov tests of equality of the distribution in the first or in the last 3 rounds to the distribution in the middle 4 rounds. Overall the Figures show that results are quite stable across rounds, suggesting that there are not substantial differences in the way subjects process the information in market $B$ across the experiment . 


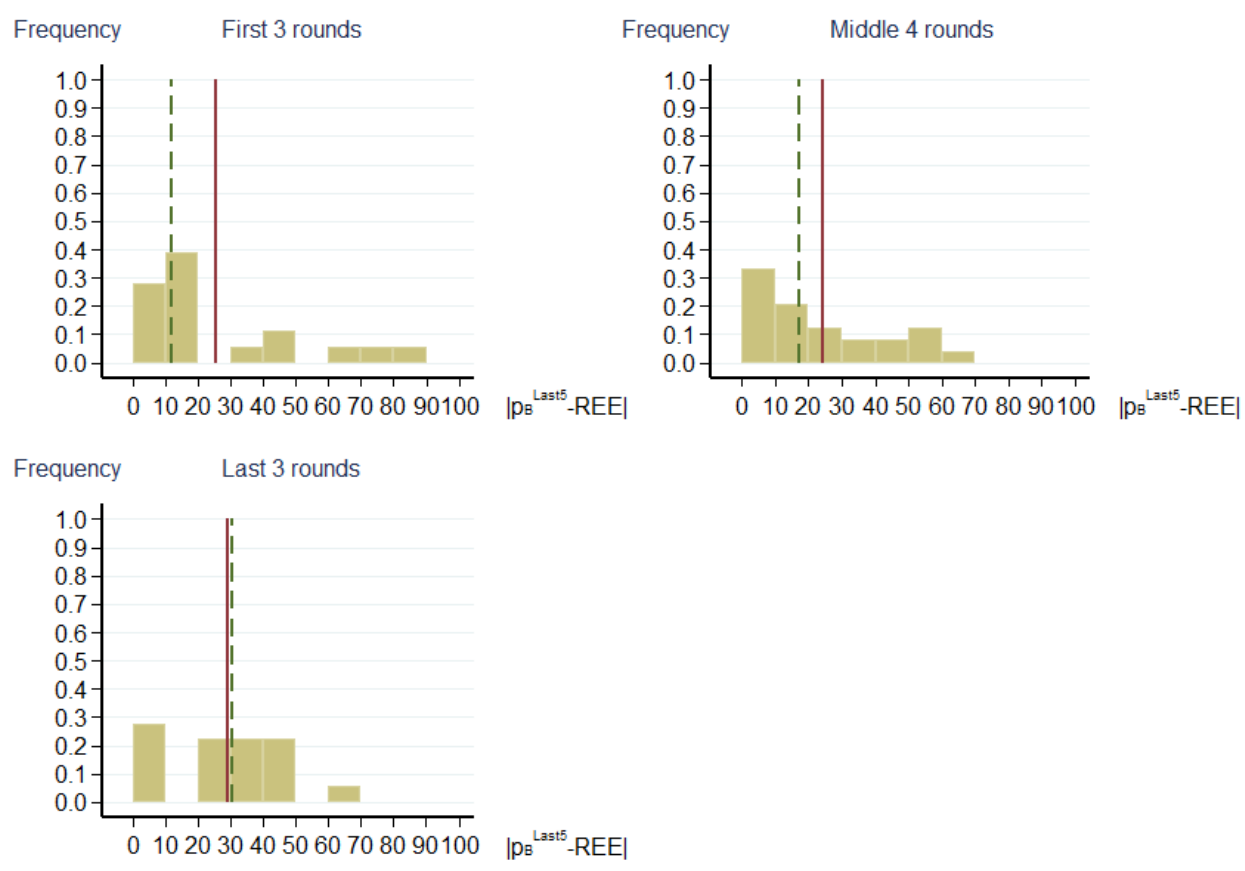

Figure G.3. Per-round distance between the final price and the REE

Table G.3. KS test, distance between the final price of asset $\mathrm{B}$ and $V^{B}$

The table reports the p-values of Kolmogorov-Smirnov tests. The null hypothesis is that the distribution of the distance between the final price and the value of asset $\mathrm{B}$ in the middle 4 rounds is equal to the distribution of the same distance in the first 3 rounds (row 1) or in the last 3 rounds (row 2).

\begin{tabular}{lc}
\hline Kolmogorov-Smirnov test & $\mathrm{p}$-value \\
\hline$H_{0}:$ Middle 4 rounds $=$ First 3 rounds & 0.250 \\
$H_{0}:$ Middle 4 rounds $=$ Last 3 rounds & 0.978 \\
\hline
\end{tabular}


Table G.4. KS test, distance between the final price of asset B and the REE

The table reports the p-values of Kolmogorov-Smirnov tests. The null hypothesis is that the distribution of the distance between the final price of asset B and the REE in the middle 4 rounds is equal to the distribution of the same distance in the first 3 rounds (row 1 ) or in the last 3 rounds (row 2).

\begin{tabular}{lc}
\hline Kolmogorov-Smirnov test & p-value \\
\hline$H_{0}:$ Middle 4 rounds $=$ First 3 rounds & 0.896 \\
$H_{0}:$ Middle 4 rounds $=$ Last 3 rounds & 0.250 \\
\hline
\end{tabular}

Finally, similarly to what we did for market $A$, we replicated Table 7 by adding dummy variables for the middle 4 and last 3 rounds and interacting them with the regressors. In other words, we estimate the following regressions:

$$
\begin{gathered}
p_{B, i}=\alpha_{0}+\alpha_{1} C_{i}+\alpha_{2} C_{i} \cdot M_{i}+\alpha_{3} C_{i} \cdot L_{i}+\alpha_{4} V_{i}^{A}+\alpha_{5} V_{i}^{A} \cdot M_{i}+\alpha_{6} V_{i}^{A} \cdot L_{i}+\alpha_{7} M_{i}+\alpha_{8} L_{i}+\varepsilon_{i}, \\
p_{B, i}=\beta_{0}+\beta_{1} C_{i}+\beta_{2} C_{i} \cdot M_{i}+\beta_{3} C_{i} \cdot L_{i}+\beta_{4} E^{\text {probit }}\left(V_{i}^{A} \mid \bar{p}_{A, i}^{\text {Last }}\right)+ \\
\beta_{5} E^{\text {probit }}\left(V_{i}^{A} \mid \bar{p}_{A, i}^{\text {Last } 5}\right) \cdot M_{i}+\beta_{6} E^{\text {probit }}\left(V_{i}^{A} \mid \bar{p}_{A, i}^{\text {Last } 5}\right) \cdot L_{i}+\beta_{7} M_{i}+\beta_{8} L_{i}+\varepsilon_{i},
\end{gathered}
$$

for $i=1, \ldots, 60$. Depending on the specification, $p_{B, i}$ is either the initial price of asset $B$ (defined as the average of the first 5 transactions) or the final price of asset $B$ (defined as the average of the last 5 transactions). As already discussed in the paper, we denote with $E^{\text {probit }}\left(V_{i}^{A} \mid \bar{p}_{A, i}^{L a s t 5}\right)$ the conditional expectation of $V^{A}$ given by a Probit regression of the value of asset $A$ on the final price of asset $A{ }^{1}$ Results are shown in Table G5. Estimated coefficients for interaction terms are

\footnotetext{
${ }^{1}$ We tested and could reject the hypothesis that the coefficients of the Probit regression are the same in the first 3, the middle 4 and the last 3 rounds. For this reason, we use the conditional expected value of $V^{A}$ over the total number of rounds in the above regression.
} 
not statistically significant. 
Table G.5. Robustness checks for market B

The table shows the regression results of the final price of asset $\mathrm{A}$ on $\mathrm{C}$ and $V^{A}$, dummy variables for the middle 4 rounds $(\mathrm{M})$ and the last 3 rounds $(\mathrm{L})$ and their interactions with $\mathrm{C}$ and $V^{A}$, in columns 1 and 3. Columns 2 and 4 show the regression results using the conditional expectation of $V^{A}$ (computed by the probit regression) and its interactions with $\mathrm{M}$ and L. Standard errors in parentheses are clustered at the session level. ${ }^{*},{ }^{* *},{ }^{* * *}$ denote significance at the $10,5,1$ percent level, respectively.

\begin{tabular}{|c|c|c|c|c|}
\hline & \multicolumn{2}{|c|}{ Initial price (first 5 trades) } & \multicolumn{2}{|c|}{ Final price (last 5 trades) } \\
\hline$C$ & $\begin{array}{l}0.104 \\
(0.117)\end{array}$ & $\begin{array}{c}0.042 \\
(0.136)\end{array}$ & $\begin{array}{c}0.288 \\
(0.149)\end{array}$ & $\begin{array}{c}0.219 \\
(0.178)\end{array}$ \\
\hline$C * M$ & $\begin{array}{l}-0.034 \\
(0.160)\end{array}$ & $\begin{array}{c}0.043 \\
(0.161)\end{array}$ & $\begin{array}{l}-0.130 \\
(0.216)\end{array}$ & $\begin{array}{c}0.013 \\
(0.224)\end{array}$ \\
\hline$C * L$ & $\begin{array}{c}0.162 \\
(0.090)\end{array}$ & $\begin{array}{c}0.186 \\
(0.180)\end{array}$ & $\begin{array}{c}0.011 \\
(0.144)\end{array}$ & $\begin{array}{c}0.023 \\
(0.236)\end{array}$ \\
\hline$V^{A}$ & $\begin{array}{c}0.122 \\
(0.127)\end{array}$ & & $\begin{array}{c}0.207 \\
(0.164)\end{array}$ & \\
\hline$V^{A} * M$ & $\begin{array}{c}0.047 \\
(0.165)\end{array}$ & & $\begin{array}{c}0.185 \\
(0.195)\end{array}$ & \\
\hline$V^{A} * L$ & $\begin{array}{c}0.094 \\
(0.147)\end{array}$ & & $\begin{array}{c}0.088 \\
(0.161)\end{array}$ & \\
\hline$E^{\text {probit }}\left(V^{A} \mid \bar{p}_{A}^{\text {Last } 5}\right)$ & & $\begin{array}{c}0.597^{* *} \\
(0.181)\end{array}$ & & $\begin{array}{c}0.747^{* *} \\
(0.120)\end{array}$ \\
\hline$E^{\text {probit }}\left(V^{A} \mid \bar{p}_{A}^{\text {Last5 }}\right) * M$ & & $\begin{array}{l}-0.283 \\
(0.229)\end{array}$ & & $\begin{array}{l}-0.232 \\
(0.239)\end{array}$ \\
\hline$E^{\text {probit }}\left(V^{A} \mid \bar{p}_{A}^{\text {Last5 }}\right) * L$ & & $\begin{array}{l}-0.194 \\
(0.223)\end{array}$ & & $\begin{array}{l}-0.120 \\
(0.187)\end{array}$ \\
\hline$M$ & $\begin{array}{c}-8.953 \\
(24.049)\end{array}$ & $\begin{array}{l}12.535 \\
(24.092)\end{array}$ & $\begin{array}{l}-14.986 \\
(20.683)\end{array}$ & $\begin{array}{c}7.303 \\
(10.536)\end{array}$ \\
\hline$L$ & $\begin{array}{l}-25.078 \\
(22.775)\end{array}$ & $\begin{array}{c}-0.661 \\
(16.889)\end{array}$ & $\begin{array}{l}-19.516 \\
(27.503)\end{array}$ & $\begin{array}{c}2.488 \\
(15.510)\end{array}$ \\
\hline Constant & $\begin{array}{l}46.111^{*} \\
(22.369)\end{array}$ & $\begin{array}{c}14.501 \\
(18.852)\end{array}$ & $\begin{array}{c}27.513 \\
(23.053)\end{array}$ & $\begin{array}{c}-8.808 \\
(11.687)\end{array}$ \\
\hline$H_{0}: \alpha_{2}=\alpha_{3}, \mathrm{p}$-value & 0.288 & & 0.462 & \\
\hline $\begin{array}{l}H_{0}: \beta_{2}=\beta_{3}, \mathrm{p} \text {-value } \\
H_{0}: \alpha_{5}=\alpha_{6}, \mathrm{p} \text {-value }\end{array}$ & 0.791 & $51^{0.465}$ & 0.708 & 0.954 \\
\hline$H_{0}: \beta_{5}=\beta_{6}, \mathrm{p}$-value & & 0.694 & & 0.701 \\
\hline$N$ & 60 & 60 & 60 & 60 \\
\hline
\end{tabular}




\section{Appendix H: Instructions Instructions for the Experiment: Phase I}

Welcome to our experiment! You are about to take part in a study on decision making with 15 other participants. The experiment consists of two phases. You will now read the instructions for Phase I and participate in it. For Phase II you will later receive additional instructions.

Everyone has the same instructions. Whenever you have questions, please, do not hesitate to ask one of the supervisors for clarification. Please, do not ask your questions loudly or try to communicate with other participants.

Before the experiment starts, we will randomly assign each of you to one of two groups: half of you (8 participants) will belong to group I, and the other half to group II. You belong to the same group throughout the entire experiment (your group will be shown on the computer screen).

\section{The Experiment}

The first phase of the experiment consists of 10 rounds. In every round, participants in each group have the opportunity to trade a good among themselves. Trading lasts for 200 seconds. Participants in each group only observe the decisions made in their group and can only trade among themselves.

The value of the good is expressed in a fictitious currency called "lira," which will be converted into British Pounds at the end of the experiment according to the following exchange rate:

$$
100 \text { liras }=£ 1 \text {. }
$$

\section{The value of the good}


At the beginning of every round, the value of the good will be determined by the computer with a mechanism simulating the tossing of a fair coin. The good can have value 0 or 100 liras depending on whether the coin lands heads or tails. Like in the toss of a fair coin, the chances of the good having value 0 or 100 are equal. Note that for each group the computer simulates the tossing of a fair coin at the beginning of every round. Thus, in each round the value of the good is the same for all participants in the same group. The value of the good can, however, change from round to round. And whether the value in a round is 0 or 100 does not depend on the value in previous rounds.

\section{The information you will receive}

All participants will receive some information about the value of the good.

\section{How is this information given?}

Suppose the value of the good in one group is 100 liras. In this case, we will use a random device similar to an urn with 8 coloured balls: 6 balls are green and 2 are red. Each of the 8 participants will receive one of these balls. Therefore, there is a chance of $3 / 4$ (equal to 6/8) that you will observe the message "The colour of the ball is GREEN" on your computer screen; and there is a chance of $1 / 4$ (equal to $2 / 8$ ) that you will observe the message "The colour of the ball is RED".

Suppose, instead, that the value of the good is 0 liras. In this case, we will use a random device similar to an urn with 8 coloured balls: 6 balls are red and 2 are green. Each of the 8 participants will receive one of these balls. Therefore, there is a chance of $3 / 4$ (equal to 6/8) that you will observe the message "The colour of the ball is RED" on your computer screen; and there is a chance of $1 / 4$ (equal to 2/8) that you will observe the message "The colour of the ball is GREEN". 
To recap:

- If the value is 100, then there are more GREEN balls in the box.

- If the value is 0 , then there are more RED balls in the box.

Therefore, the colour of the ball will give you some information about the value of the good.

When is the information given?

Every participant receives his/her information at the beginning of the 200 seconds.

\section{Procedure for each round}

The sequence of activities in each round will be the following:

1. Participants receive information on the value of the good in their group.

2. Participants trade the good for 200 seconds.

3. At the end of the 200 seconds, all participants receive information on the outcomes of their trading activity. In particular, everyone observes the true value of the good and will be able to compute his/her own payoff according to the rules indicated below.

After the first round is concluded, we start the second round of the experiment. The procedures are identical to those of the first round.

\section{Trading}

In Figure 1 you see a screen-shot of the trading platform on your computer. In the upper part of the screen, there are two boxes showing the existing Buy Offers and Sell Offers. In the lower part, there are buttons that you can use to buy or 
sell, and a box where you can insert the price at which you are willing to buy or sell.

On the top left-hand side you can see your holdings of cash and units of the asset (i.e., your Portfolio). On the bottom, you see a continuously updated history of the prices at which the good is traded.

\section{Initial Endowment}

At the beginning of each round, you receive an endowment of 4 units of the good and 500 liras. You can use your endowment to trade during the round. The box "Portfolio" is updated whenever you buy or sell a unit of the good. When you buy one unit of the good, the number of units of the good in your portfolio increases by one, and the amount of liras decreases by the price you have paid. When you sell one unit, the number of units of the good in your portfolio decreases by one, and the amount of liras increases by the price at which you have sold.

\section{How to sell or buy}

Buying and selling is very simple. If you want to sell one unit of the good, you simply click on the button SELL and enter the minimum amount of liras you want to obtain. Your offer appears immediately in the column Sell Offers where all open sell offers are collected. The open sell offers are ordered with the lowest price being on the top of the list. You can easily identify your own sell offers because they are marked with a button that gives you the opportunity to cancel them, if you so wish.

Similarly, if you want to buy one unit of the good, click on the button BUY and enter the maximum amount of liras you are willing to pay. Your offer appears immediately in the column Buy Offers, where all open buy offers are collected. 
The open buy offers are ordered with the highest price being on the top of the list. You can easily identify your open buy offers, because they are marked with a button that gives you the opportunity to cancel them, if you so wish.

You are always allowed to withdraw your buy or sell offer that have not been executed: just click on Cancel on the order you want to withdraw.

When and how does a trade take place? A trade is possible if the lowest Sell Price is lower than the highest Buy Price. In this situation, one participant is willing to pay more for the good than another participant asks for it. This situation is recognized by the system and trading takes place automatically.

A simple example will clarify this. Suppose that in a particular moment the lowest Sell Price is 55 liras and the highest Buy Price is 53 liras. Then, no trade is possible. If another participant is willing to buy at 55 liras, the only thing s/he needs to do is enter a Buy Price of 55 liras into the system. The system recognizes that a trade is possible and trade takes place: that is, the seller receives 55 liras from the buyer and the buyer receives one unit of the good from the seller. Note that the transaction always occurs at the pre-existing price. For instance, even if a participant enters a Buy Price of 61 in the system, since the pre-existing lowest Sell Price is 55, the transaction will occur at 55 liras. In other words, if you see a Sell Price at which you are willing to buy, it is enough that you enter a Buy Price equal or greater than that to buy the good.

Consider another example. Suppose that in a particular moment the highest Buy Price is 30 liras and the lowest Sell Price is 37 liras. Then, no trade is possible. If another participant is willing to sell at 30 liras, the only thing s/he needs to do is enter a Sell Price of 30 liras into the system. The system recognizes that a trade is possible and trade takes place: that is, the seller receives 30 liras from the 
buyer and the buyer receives one unit of the good from the seller. As we said, the transaction always occurs at the pre-existing price. Therefore, even if a participant enters a Sell Price of 23 in the system, since the pre-existing highest Buy Price is 30 , the transaction will occur at 30 liras.

As we said, the list of all prices at which a transaction took place appears on the bottom of the screen. The most recent transaction prices are on the top of the list. Your own transactions are identified so that you can keep track of your previous decisions.

\section{Payoff in each round}

At the end of every round, you will be told the true value of the good. Your total per-round payoff depends on: 1) the final value of your portfolio, which depends on the value of the good and the amount of liras and the number of units of the good that you hold at the end of the round, and 2) an extra payoff, which depends on the number of trades (sell or buy) you have made during the round.

\section{Value of your portfolio}

The value of your portfolio is computed in the following way:

$$
\text { Value of portfolio }=\text { liras }+(\text { units of the good }) \times(\text { value of the good })
$$

Example 1: Suppose you end a round having 200 liras of cash and 8 units of the good. Suppose the value of the good in that round is 100 . Then the value of your portfolio is $200+(8) *(100)=1000$.

Suppose, instead, that the value of the good is 0 . Then the value of your portfolio is $200+(8) *(0)=200$.

\section{Extra payoff}


You receive an extra payment of 5 liras for the first 5 buy or sell trades that you execute (i.e., up to a maximum of 25 liras in each round).

Example 1: If in one round you sell 2 goods and buy 2 goods (4 trades), you will earn an additional payment of $4 * 5=20$ liras.

Example 2: If in one round you sell 6 goods and buy 1 good (7 trades), you will earn $5 * 5=25$ liras, as your extra payment cannot exceed 25 liras.

Note that your extra payment will not immediately increase the amount of liras in your portfolio (which you can use to buy more assets), but will be only part of your final pay-off.

Your total per-round payoff will therefore be:

Total per-round payoff $=$ value of your portfolio + extra payoff

\section{Payment}

This first part of the experiment (Phase $I$ ) is meant as training for Phase $I I$. It gives you the opportunity to learn how to trade. Although we will compute the payoffs as described above, they will not affect your final payment. It is, however, important that you do your best to make profits also in this first part, since what you learn here will be useful for Phase $I I$, which will be paid. In Phase $I I$, the payoffs will be computed in the same way as described above. Those payoffs will be relevant for your final payment: the more money you make by trading, the higher your payment will be. We will convert your liras into pounds at the exchange rate of 100 liras $=£ 1$. That is, for every 100 liras you earn in Phase $I I$, you will get 1 pound. Moreover, you will receive a participation fee of $£ 5$ just for showing up on time. You will be paid in cash (in private) at the end of the experiment. 
You will now go through a short questionnaire to make sure that you have understood the instructions and then the experiment will start. 


\section{Instructions for Phase II - Treatment I}

Let us now move the Phase $I I$ of the experiment.

\section{Phase $I I$}

This phase consists of 10 rounds. The rules are identical for all rounds.

As we said, you belong to the same group as in Phase $I$. The main difference with respect to Phase $I$ is that there are now two goods, good $A$ and good $B$. Moreover, in each round, the two goods are traded one after the other: first, one group trades good $A$; then, after the group has finished, the other group trades good B. Each group trades for 200 seconds. Whenever a group is not trading, every participant in that group can observe the trading activity of the other group.

\section{The value of good $A$}

As in Phase $I$, at the beginning of every round, the value of good $A$ will be determined by the computer with a mechanism simulating the tossing of a coin. The coin can have value 0 liras or value 100 liras depending on whether it lands heads or tails. Like in the toss of a fair coin, the chances of the coin having value 0 or 100 are equal.

\section{The value of good $B$}

The value of good $B$ will be either 0 or 100 liras. In particular, it will be equal either to the value of good $A$ (with $50 \%$ chance), or to the value of a second coin, the "B-coin" (also with $50 \%$ chance). 


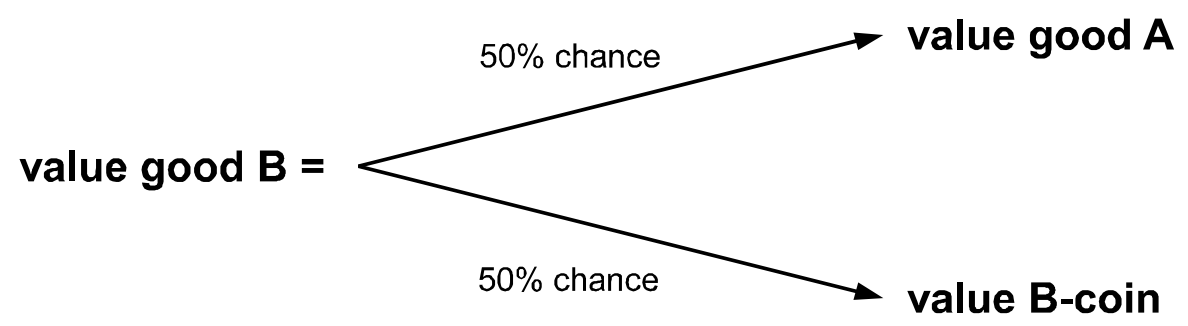

The value of the $B$-coin will also be determined by the computer at the beginning of every round, by simulating the tossing of a coin. The coin can have value 0 liras or value 100 liras depending on whether it lands heads or tails. Like in the toss of a fair coin, the chances of the coin having value 0 or 100 are equal.

In other words, suppose good $A$ is worth 100. Then,

\begin{tabular}{|l|l|}
\hline Value of $\operatorname{good} B=100$ & with $50 \%$ chance \\
\hline Value of $\operatorname{good} B=$ Value of $B$-coin & with $50 \%$ chance \\
\hline
\end{tabular}

Suppose, instead that good $A$ is worth 0 . Then,

\begin{tabular}{|l|l|}
\hline Value of $\operatorname{good} B=0$ & with $50 \%$ chance \\
\hline Value of $\operatorname{good} B=$ Value $B$-coin & with $50 \%$ chance \\
\hline
\end{tabular}

\section{Information you will receive}

When good $A$ is traded, all participants belonging to the group trading good $A$ will receive some information about the value of $\operatorname{good} A$. When $\operatorname{good} B$ is traded, all participants belonging to the group trading good $B$ will receive some information on the value of the $B$-coin. However, participants belonging to the group trading good $B$ will not know whether the value of good $B$ is equal to that of good $A$ or whether it is determined by the value of the $B$-coin. 


\section{How is this information given?}

When you trade good $A$, you will receive information on the value of the good exactly as described in Phase $I$. If the value is 100, you will receive a coloured ball; 6 participants will receive a green ball, whereas only 2 will receive a red ball. If, instead, the value is 0,6 participants will receive a red ball, whereas only 2 will receive a green ball.

When you trade good $B$, you will not receive information on the value of the good, but on the value of the $B$-coin. The procedure will be the same. If the value of the $B$-coin is 100 you will receive a coloured ball; 6 participants will receive a green ball, whereas only 2 will receive a red ball. If, instead, the value of the $B$-coin is 0, 6 participants will receive a red ball, whereas only 2 will receive a green ball.

When is the information given?

As in Phase $I$, every participant receives his/her information before his/her group starts trading (at the beginning of the 200 seconds).

\section{Procedures for each round}

As indicated above, the groups $I$ and $I I$ trade in sequence. In odd rounds (13-5-...), group $I$ trades good $A$ (for 200 seconds), and then group $I I$ trades good $B$ (for 200 seconds). In even rounds (2-4-6-...), group $I I$ trades good $A$ (for 200 seconds), and then group $I$ trades good $B$ (for 200 seconds).

The sequence of activities in round 1 will be the following:

1. Group $I$ participants receive information on the value of good $A$.

2. Group $I$ participants trade good $A$ for 200 seconds, while participants in the other group $(I I)$ only observe. While observing the behavior of Group $I$ 
participants, Group II participants will indicate, on a separate form, what they think the chance is that the true value of $\operatorname{good} A$ is 100 .

3. Group II participants receive information on the value of the $B$-coin.

4. Group $I I$ participants trade good $B$ for 200 seconds, while participants of the other group only observe.

5. All participants receive information on the outcomes of their trading activity. In particular, everyone will observe the true value of good $A$ and of good $B$ and will be able to compute his/her own payoff according to the rules indicated below.

After the first round is concluded, we start the second round of the experiment. The procedures are identical to those of the first round, with the exception that now group $I I$ starts and trades good $A$ and then group $I$ trades good $B$. The experiment continues until the $10 t h$ round is completed.

\section{Trading}

The trading platform on your computer, the initial endowment, and the way you sell or buy a good are all the same as in Phase $I$. The only difference is that now the two groups trade different goods (with possibly different values) one after the other, with one group observing the trading activity of the other.

\section{Payment at the end of the experiment}

The per-round payoffs will be determined in the same way as in Phase $I$. At the end of every round, you will be told the true value of both goods $A$ and $B$. Your total per-round payoff depends on: 
1) what you hold at the end of the round: the amount of liras plus the value of the units of the good $A$ or $B$ (according to the good that you traded);

2) an extra payment of 5 liras for the first 5 buy or sell trades that you execute (up to a maximum of 25 liras in each round).

We will randomly select 3 out of the 10 rounds of Phase $I I$ and we will sum your per-round payoffs in these three rounds to determine your final payoff in liras for Phase $I I$. We will then convert liras into pounds at the exchange rate of 100 liras $=£ 1$ and we will sum up this amount to the participation fee of $£ 5$. We will pay you in private, immediately at the end of the experiment.

You will now go through a short questionnaire to make sure that you have understood the instructions and then Phase $I I$ will start. 


\section{Instructions for Phase II - Treatment II}

Let us now move the Phase $I I$ of the experiment.

\section{Phase $I I$}

This phase consists of 10 rounds. The rules are identical for all rounds.

As we said, you belong to the same group as in Phase $I$. The main difference with respect to Phase $I$ is that there are now two goods, good $A$ and good $B$. Moreover, in each round, the two goods are traded one after the other: first, one group trades good $A$; then, after the group has finished, the other group trades good B. Each group trades for 200 seconds. Whenever a group is not trading, every participant in that group can observe the trading activity of the other group.

\section{The value of good $A$}

As in Phase $I$, at the beginning of every round, the value of good $A$ will be determined by the computer with a mechanism simulating the tossing of a coin. The coin can have value 0 liras or value 100 liras depending on whether it lands heads or tails. Like in the toss of a fair coin, the chances of the coin having value 0 or 100 are equal.

\section{The value of good $B$}

At the beginning of every round, the value of good $B$ will be determined by the computer with a mechanism simulating the tossing of a coin. The coin can have value 0 liras or value 100 liras depending on whether it lands heads or tails. Like in the toss of a fair coin, the chances of the coin having value 0 or 100 are equal. Note that the computer will use one coin (coin $A$ ) for good $A$ and one coin (coin $B$ ) for good $B$. These two coin tosses are independent, that is, the outcome of the one coin toss does not affect the other. 


\section{Information you will receive}

When good $A$ is traded, all participants belonging to the group trading good $A$ will receive some information about the value of $\operatorname{good} A$. When $\operatorname{good} B$ is traded, all participants belonging to the group trading good $B$ will receive some information on the value of good $B$.

\section{How is this information given?}

When you trade good $A$, you will receive information on the value of the good exactly as described in Phase $I$. If the value is 100, you will receive a coloured ball; 6 participants will receive a green ball, whereas only 2 will receive a red ball. If, instead, the value is 0,6 participants will receive a red ball, whereas only 2 will receive a green ball.

When you trade good $B$, you will receive information on the value of good $B$. The procedure will be the same. If the value of good $B$ is 100 you will receive a coloured ball; 6 participants will receive a green ball, whereas only 2 will receive a red ball. If, instead, the value of $\operatorname{good} B$ is 0,6 participants will receive a red ball, whereas only 2 will receive a green ball.

When is the information given?

As in Phase $I$, every participant receives his/her information before his/her group starts trading (at the beginning of the 200 seconds).

\section{Procedures for each round}

As indicated above, the groups $I$ and $I I$ trade in sequence. In odd rounds (13-5-...), group $I$ trades good $A$ (for 200 seconds), and then group $I I$ trades good $B$ (for 200 seconds). In even rounds (2-4-6-...), group $I I$ trades good $A$ (for 200 seconds), and then group $I$ trades good $B$ (for 200 seconds). 
The sequence of activities in round 1 will be the following:

1. Group $I$ participants receive information on the value of good $A$.

2. Group $I$ participants trade good $A$ for 200 seconds, while participants in the other group $(I I)$ only observe. While observing the behavior of Group $I$ participants, Group II participants will indicate, on a separate form, what they think the chance is that the true value of good $A$ is 100 .

3. Group $I I$ participants receive information on the value of good $B$.

4. Group $I I$ participants trade good $B$ for 200 seconds, while participants of the other group only observe.

5. All participants receive information on the outcomes of their trading activity. In particular, everyone will observe the true value of good $A$ and of good $B$ and will be able to compute his/her own payoff according to the rules indicated below.

After the first round is concluded, we start the second round of the experiment. The procedures are identical to those of the first round, with the exception that now group $I I$ starts and trades good $A$ and then group $I$ trades good $B$. The experiment continues until the 10 th round is completed.

\section{Trading}

The trading platform on your computer, the initial endowment, and the way you sell or buy a good are all the same as in Phase $I$. The only difference is that now the two groups trade different goods (with possibly different values) one after the other, with one group observing the trading activity of the other. 


\section{Payment at the end of the experiment}

The per-round payoffs will be determined in the same way as in Phase $I$. At the end of every round, you will be told the true value of both goods $A$ and $B$. Your total per-round payoff depends on:

1) what you hold at the end of the round: the amount of liras plus the value of the units of the good $A$ or $B$ (according to the good that you traded);

2) an extra payment of 5 liras for the first 5 buy or sell trades that you execute (up to a maximum of 25 liras in each round).

We will randomly select 3 out of the 10 rounds of Phase $I I$ and we will sum your per-round payoffs in these three rounds to determine your final payoff in liras for Phase $I I$. We will then convert liras into pounds at the exchange rate of 100 liras $=£ 1$ and we will sum up this amount to the participation fee of $£ 5$. We will pay you in private, immediately at the end of the experiment.

You will now go through a short questionnaire to make sure that you have understood the instructions and then Phase $I I$ will start. 


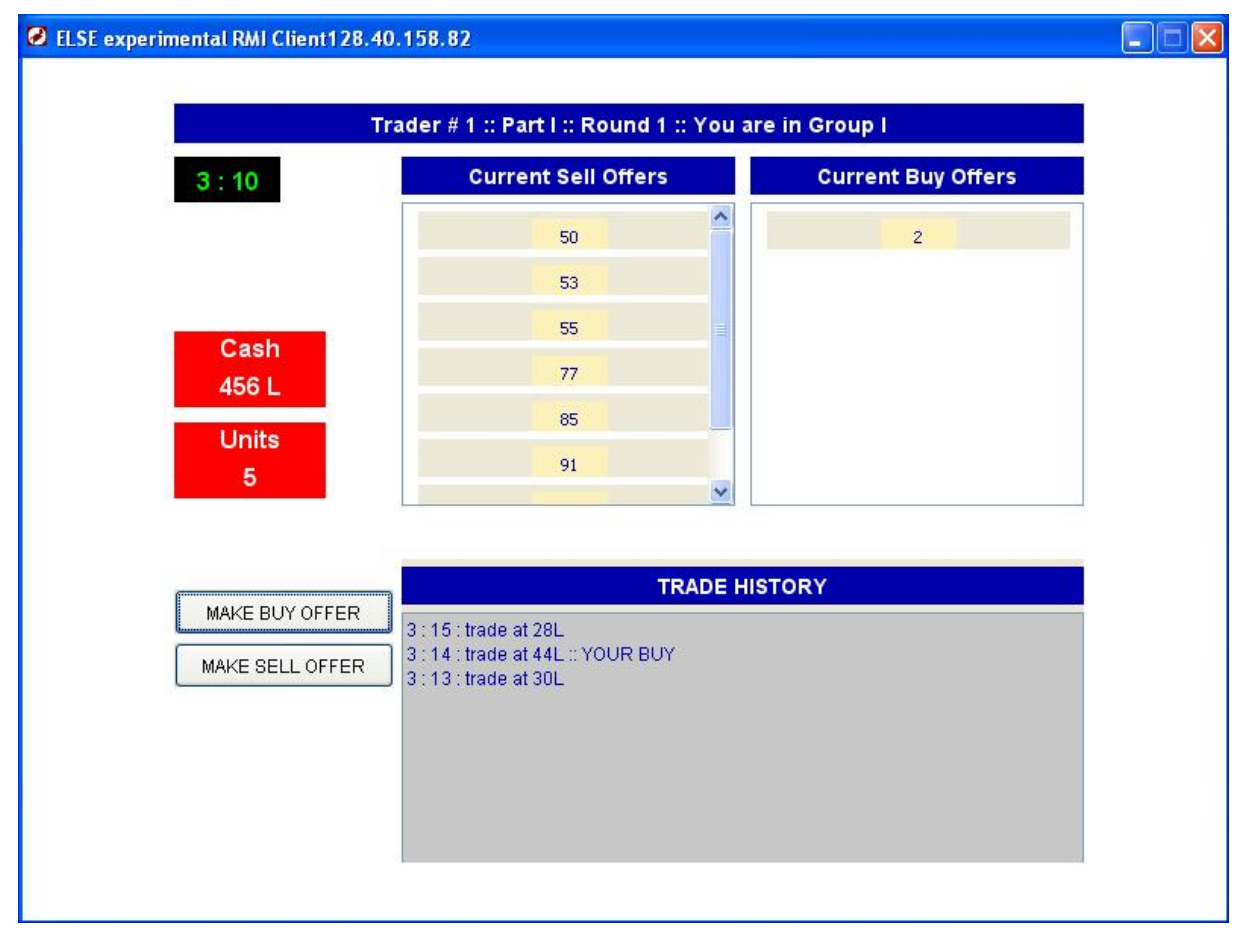

Figure H1. Trading Platform 